\title{
A Theory of Internal Conflict: Causes of Political Instability in Natural
}

Resource Rich Developing Economies

By

Joshua Gogo

A thesis submitted to

the Faculty of Graduate Studies and Research

in partial fulfilment of

the requirement for the degree of

Doctor of Philosophy

Department of Economics

Carleton University

Ottawa, Ontario

December 2007

(C) 2007, Joshua Gogo 


$\begin{array}{ll}\begin{array}{l}\text { Library and } \\ \text { Archives Canada }\end{array} & \begin{array}{l}\text { Bibliothèque et } \\ \text { Archives Canada }\end{array} \\ \begin{array}{l}\text { Published Heritage } \\ \text { Branch }\end{array} & \begin{array}{l}\text { Direction du } \\ \text { Patrimoine de l'édition }\end{array} \\ \begin{array}{l}\text { 395 Wellington Street } \\ \text { Ottawa ON K1A 0N4 } \\ \text { Canada }\end{array} & \begin{array}{l}\text { 395, rue Wellington } \\ \text { Ottawa ON K1A 0N4 } \\ \text { Canada }\end{array}\end{array}$

Your file Votre référence

ISBN: 978-0-494-40522-2

Ourfile Notre référence

ISBN: 978-0-494-40522-2

NOTICE:

The author has granted a nonexclusive license allowing Library and Archives Canada to reproduce, publish, archive, preserve, conserve, communicate to the public by telecommunication or on the Internet, loan, distribute and sell theses worldwide, for commercial or noncommercial purposes, in microform, paper, electronic and/or any other formats.

The author retains copyright ownership and moral rights in this thesis. Neither the thesis nor substantial extracts from it may be printed or otherwise reproduced without the author's permission.
AVIS:

L'auteur a accordé une licence non exclusive permettant à la Bibliothèque et Archives Canada de reproduire, publier, archiver, sauvegarder, conserver, transmettre au public par télécommunication ou par l'Internet, prêter, distribuer et vendre des thèses partout dans le monde, à des fins commerciales ou autres, sur support microforme, papier, électronique et/ou autres formats.

L'auteur conserve la propriété du droit d'auteur et des droits moraux qui protège cette thèse. $\mathrm{Ni}$ la thèse ni des extraits substantiels de celle-ci ne doivent être imprimés ou autrement reproduits sans son autorisation.
In compliance with the Canadian Privacy Act some supporting forms may have been removed from this thesis.

While these forms may be included in the document page count, their removal does not represent any loss of content from the thesis.
Conformément à la loi canadienne sur la protection de la vie privée, quelques formulaires secondaires ont été enlevés de cette thèse.

Bien que ces formulaires aient inclus dans la pagination, il n'y aura aucun contenu manquant.

\section{Canada}




\begin{abstract}
Conflict in natural resource rich emerging countries continues to be a challenge to poverty reduction efforts, especially in the countries of the global south dependent on natural resources. This thesis studies the role of individual mobility and the role played by form of democratic decision-making in these conflicts. It employs a public choice perspective to study the possibility of conflict, levels of social welfare and economic efficiency. At one political end, majority rule, when the median voter resides in the region that does not suffer the externality, can lead to a high potential for conflict and high levels of regional welfare disparity. At the other end, regionally decentralized decision-making may lead to inefficiently low levels of social welfare and public good production, again increasing the possibility of state failure.
\end{abstract}

A central focus of the thesis is on population mobility. Individual mobility in some circumstances will improve social welfare and reduce the potential for conflict. On the other hand, the pursuit of higher levels of welfare may become inconsistent with the pursuit of regional peace, especially when mobility is the primary mechanism for improving welfare. That is, mobility does not invariably reduce conflict, even when it is both individually and socially welfare improving. This thesis describes a strategic relationship that exists between cross regional mobility and stability at high mobility levels. Thus while there exists some level of mobility that is stability enhancing, this study can isolate those circumstances in which high levels of mobility exacerbate the likelihood of instability, poverty, and regional welfare disparity. One consequence of high mobility is to leave behind a population that is more uniform and rooted in the 
region adversely impacted. Hence the greater homogenization of the impacted region can be a source of policy reversal and instability. By substituting intensity for numbers and diminishing the unanimity of the majority, high mobility can lead to instances of minority control of policy, and provide an opportunity for resource cornering by an opportunistic opposition.

To highlight some of its other more striking results, this thesis finds that within types of democracies, a federal system is more likely to remain stable than a unitary system. Similarly resort to regional political rhetoric and ethnic bigotry may be a cause of greater stability in a political system as well as a potential cause of its instability. However, should conflict take root, such strategies inevitably increase the intensity of that conflict. Finally, while external factors such as changes in the price of resources and the emergence of natural disasters can affect the likelihood and/or intensity of conflict, they are not root causes. Hence this approach can absorb a number of partial hypotheses advanced to explain regional conflict. 


\section{ACKNOWLEDGEMENT}

The success of this thesis project has been due to the contribution of a number of persons. I sincerely acknowledge and appreciate their support, encouragement, guidance, and friendship. Here, I name and thank a few of them.

Professor Steve Ferris, my supervisor, deserves special thanks for his attention to this project and to me, and for providing a conducive and encouraging working environment despite his many other commitments. I consider myself very lucky and blessed to have the opportunity to work with Steve and to learn from him and his years of experience. I, specifically, thank him for his patience and understanding.

It was a special privilege to also work under the direction of Professors Arch Ritter, Dane Rowlands, and Jean-Francois Tremblay, the members of my supervising committee. They provided valuable reviews and directions that led to the most important contributions this work has made to conflict and poverty research.

The ideas that formed the foundational hypotheses of this thesis came to me while taking a course (Public Choice) with Professor Stan Winer. In the years that followed, I had several interactions with him, and he made critical contribution to this thesis. He also gave me the opportunity to present and test these ideas, while they were being put together, at a seminar he organised for the SEPPP (Seminar on Economics, Politics and Public Policy). I also thank him for making his time and knowledge available to me as the basic ideas went through several refinements that resulted in this thesis.

I also take this opportunity to thank the staff and faculty members in the Departments of Economics at Carleton University and University of Ottawa, who have iv 
made my study period full of new and exciting experiences. They have all contributed to the success of this thesis. I thank them for their support and the friendly working environment they provided. I must specifically mention Ms Marge Brooks, Dawn Bjornson, Amy Fraser, and Amanda Wright. Others are Professors Vicky Barham, Frances Woolley, Fanny Demers, Zhou Yu, and Stefan Dodds.

By the same measure, I thank Professor Chris Worswick for his guidance, support and understanding, as the supervisor of the $\mathrm{PhD}$ program, throughout the years I spent in the program.

Now, to my parents, siblings, and especially my wife Dango Gogo and my daughter Oraibi Nengi Gogo, I owe this work. Their support, encouragement and longsuffering, while I dedicated the best part of my time to this research, made a critical difference in ensuring its successful completion.

Above all, I thank God, to whom I owe all, who granted me this unique opportunity and privilege, and the discipline to contribute to the human experience and knowledge pool. 


\section{DEDICATION}

This work is dedicated to efforts at making poverty and conflict history, the world over. 


\section{Table of Contents}

Abstract .ii

Acknowledgement iv

Dedication vi

Table of Contents. .vii

List of Figures xi

List of Tables xii

List of Appendices xiii

Chapter 1. General Introduction and Literature Review. 1

Chapter 2. The Basic Model: Democratic Decision-making, Governance, and Externalities

2.1 Stylized Facts. 13

2.2 The model 17 
2.3 Case A: The Externality Falls Uniformly on All Individuals in the Country..

2.3.1 Individual Problem for Case A

2.4 Case B: A Unitary Political System with a Localized Externality 28

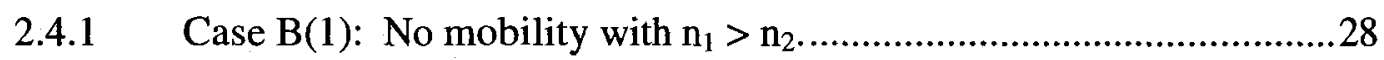

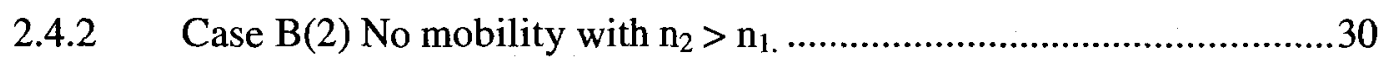

2.5 Case C: A Federal (Decentralized) System with a Localized Externality ... 35

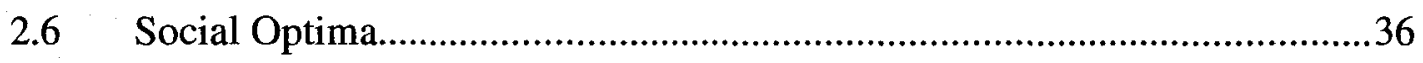

2.7 Summary of Results under Non-Uniform Externality ............................39

Chapter 3. Mobility and Welfare in Resource Developing Democracies with Externality 61

3.1 The Role of Mobility and Welfare in the Resolution of Resource-Related Conflict .61

3. 2 The Choice of Level of Resource Exploitation, and the Choice of Relocation... 66

3.3 Mobility, Welfare, and Political Stability .77

3.3.1 Political Stability and Welfare under Federalism and Unitarism when migration across regions does not change the level of resource exploitation 79

viii 
3.3.2 Political Stability and Welfare under Federalism and Unitarism when migration across regions results in a change in the political equilibrium and the level of resource exploitation

Chapter 4. Mobility, Political Change, and Stability in Resource Developing

Democracies.

4.1 A Theory of Political Change in Natural Resource Developing Economies...89

4.2 Regional Options, Strategies, and Stability Under Federalism 94

4.3 Regional Options, Strategies, and Stability Under Unitarism 102

4.3.1 When $n_{2}>n_{1}$, so that the political equilibrium does not change .......102

4.3.2 When $n_{1}>n_{2}$, and $n_{2}+\left(n_{1}-k^{*}\right)>k^{*}$, so that the political equilibrium changes under unitarism 107

4.4 Probability of Conflict: The Role of Information and Politicians 110

4.4.1 The Probability of Unilateral Success.................................................111

4.4.2 Regional Expected Gains and Options ... 113

Chapter 5. Measuring Stability and Predicting Conflict. 144

5.1.1 Stability Index without Externality or when Externality Affects All Regions 146

5.1.2 The Stability Index when the Externality Affects only Region 1 .......151

5.2 Stability, Mobility, the Democratic Process, and Natural Resources 172 ix 
5.2.1 Stability and Political Institutions From Colonialism to Independence .. 173

5.2.2 Stability and Political Institutions from Independence to the Discovery of Natural Resources

Chapter 6. Evidence from Nigeria and Sudan 188

6.1 The Conflict in Sudan . 191

6.1.1 Sudan: Mobility, Stability and Political Institutions from Colonialism to Independence 192

6.1.2 Sudan: Mobility, Stability and Political Institutions from Independence to the Discovery of Natural resources. 195

6.2 Conflicts in Nigeria .204

6.2.1 Nigeria: Mobility, Stability and Political Institutions From Colonialism to Independence .206

6.2.2 Nigeria: Mobility, Stability and Political Institutions from Independence to the Discovery of Natural resources. 209

Chapter 7. Policy Implications, and Policy Prescription .229

Chapter 8. Concluding Remarks 237

Nomenclature.

Literature Cited .245 


\section{List of Figures}

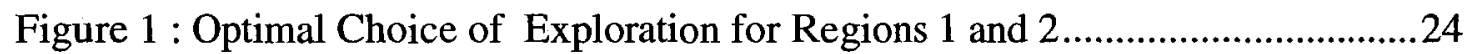

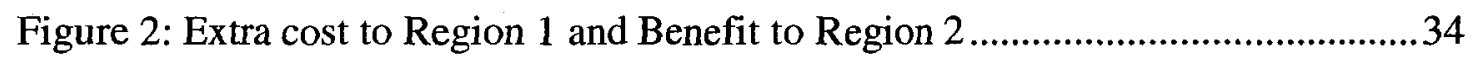

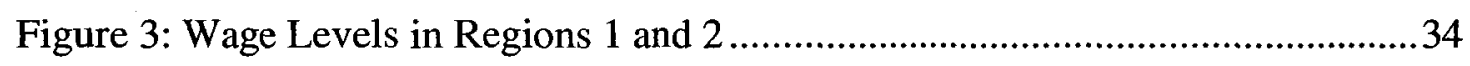

Figure 4: Social Optimum with Utilitarian Welfare Function ................................40

Figure 5: Wage Levels under the Social Optimum...............................................40

Figure 6: Optimal Exploration Level and Welfare of Migrants .............................75

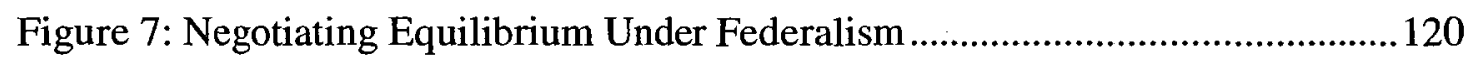

Figure 7b: Limit of Negotiations Under Federalism........................ 124

Figure 8: Negotiation Equilibrium and Limit of Negotiation Under a Unitary System139

Figure 9: Stability Index and Mobility Augmented Stability Index ........................171 


\section{List of Tables}

Table 1: Taxonomy of African States in Conflict and Political System.....................189

Table 2: Federal - State Percentage Share In Petroleum Proceeds 1960 - 1999........217 


\section{List of Appendices}

Appendix 2.1: Comparative Statics: The response of resource exploitation to changes in the price of the natural resource.

46

Appendix 2.2: Altruism and Resource Related Conflict..........................53

Appendix 6.1 Regional Map of Sudan.............................................................226

Appendix 6.2 Linguistic and Vegetation Map of Nigeria....................................227 


\section{CHAPTER 1}

\section{General Introduction and Literature Review}

Natural resource exploitation and environmental policy design have been thorny issues for southern democracies, more so, because of the complex interaction of local livelihood, cultural perceptions, geographical immobility and institutional dynamics. The primacy of natural resources as a revenue source for government, combined with illdefined property rights, pervasive externalities, market failure and incomplete markets, and low levels of education have complicated the design and implementation of environmental policies. Tran, Euan, and Isla (2002); Assetto, Hajba, and Mumme (2003); Puppim De Oliveira (2002); Hero and Tolbert (2004).

In recent times there has also been a proliferation of armed and violent conflict in the natural resource abundant regions of the world. More than any thing else the issues of natural resource exploitation and environmental management have come to threaten the very existence of a number of countries-seemingly amid plenty. Here poverty alleviation and other social assistance programs have failed largely as a consequence of armed conflict hindering access to the poor. The convocation of democratic processes to resolve these conflicts often seem to make things worse, as political representation often leads minorities to demand more than the majority feels it is able to give up.

In the study of conflict, scholars such as Elbadawi and Sambanis (2000), Baker (2003), Collier and Hoeffler (2000) amongst others have often blamed the political 
context of natural resource exploitation. Although each of these scholars have pointed to a different way in which political violence is positively associated with ethnic heterogeneity, and with the nexus connecting conflict, natural resources and certain types of political institutions, they have failed to investigate the relationship between forms of democratic organization and conflict. Collier and Hoeffler (2000) began a new focus in the debate on the link between natural resources and conflict when they posited that countries that are largely dependent on exportation of primary commodities (natural resources) are prone to violent conflict. In their greed or grievance hypothesis, they conclude that the important determinants of conflict in resource-rich countries are neither cultural nor political but the greed of rebels and the trading opportunities in looted resources. The empirical work by Collier and Hoeffler (hereafter $\mathrm{CH}$ ), likening rebels to criminals, was founded simply on self-interest. $\mathrm{CH}$ posited that rebellions stem from the utility-maximizing decisions by individuals in poor countries who weigh the economic gains from violent conflict against the perceived risks.

Suffice to say that by abstracting away from the cultural and political setting for such conflicts, $\mathrm{CH}$ will have missed some of the critical root causes for resource related conflict. This is the position of Humphrey (2005) who argues that the simple combination of primary commodities and poverty is insufficient to generate conflict. Humphrey proceeded to outline a series of channels through which natural resources would cause conflict. Together with Fearon (2005), Ross (2004), Humphrey (2005) focused on the role of the state. These authors dispute the greed-grievance position of $\mathrm{CH}$ and hold that it is a weak state (state strength) rather than the resource itself that lies at the root of 
conflict in resource-rich countries. In investigating the robustness of the study by CH, Humphrey (2005), Fearon (2005), and Ross (2004) find no robust causal link running from natural resources to conflict even using the data of $\mathrm{CH}$. In my opinion, however, they also ignore certain fundamental characteristics of the resource-rich countries of the global South that seem to make them prone to conflict, namely the link between economic livelihood and state resource exploitation within and without the resource-rich area of the country and the cultural interconnection with mobility and conflict. Admittedly, however, such authors reinvigorated the debate with their emphasis on the role of the state.

In yet another shift in the debate, Weinstein (2005) focused on the rebels rather than the state or the market for the looted resources. He posited that in the resourcerelated conflicts, the effort of well-intended rebels who may be driven by ideological, political and cultural consideration could be, and are sometimes, crowded out by opportunistic and criminal minded rebels. He concluded that conflicts centered around resources that can be looted and those with readily available markets for looted resources are more likely to attract such opportunistic criminals posing as freedom fighters or liberators than conflicts with paucity of resources. Hence he attempted to explain why greed and grievance could be found at the same time in any given resource-related conflict.

My study contributes to this growing literature by providing a unifying theoretical approach to the study of conflict in resource rich democracies of the global South. It combines methodological individualism and instrumental rationality centered on 
economic considerations with the state centered approach that emphasizes the role of collective decision-making. In addition, it incorporates other considerations ignored thus far in the debate, namely the link between local livelihood and resource exploitation in the global south, and the cultural/ethnicity dimension (as manifested in the lack of cross regional mobility) in these conflicts. Such a unified approach will provide a stronger theoretical foundation for the next generation of empirical studies in establishing the nexus between resources and conflict.

In the present literature on rational conflict the role of information and cash transfers have been seen as critical to the generation of rational conflict. Fearon (1995) in his analysis of the rationalist's explanation of war concluded that there is no rational explanation to war, that the literature as a whole has failed to explain why parties to a conflict cannot reach a negotiated solution ex ante. Here, we study general and specific cases within a theoretical framework that generate circumstances in which rational conflict can occur. In general, a democratic political system can transfer (share) some of the benefits of a regional resource surplus by cash transfers, good production or by encouraging inter-regional migration. Then by subjecting a democratic system to an unequal regional distribution of cost and benefits from the production of resource surplus and by adding constraints to the ways that such benefits and costs can be redistributed, we can generate cases of rational conflict between regions, even in the presence of perfect information. In our specific case of the unequal distribution of the cost of producing a public good across regions, a limitation on migration across regions and the removal of more traditional means of transfer across regions restricts the margins for 
interregional negotiation and results in all or nothing choices that may result in rational conflict.

Although the details of our study focus on the specific case of natural resources, natural resource externalities and a common produced public good, the model developed is applicable more generally. That is, our research looks at the specific case where the revenue from resources is used to produce a public good with a local externality and where other sources of government revenue are strictly limited. However, the same general analysis would produce a model of rational conflict if the externality were public (affecting all regions) whereas the resources producing regional benefits were strictly local. Hence, the sufficient condition for general application are limited migration, differences in regional preferences and a common incident of either a benefit or cost of public policy, but not both. What is critical to this result of rational conflict is the separation of cost and benefit, and the non-substitutability of the two goods - public and private.

Collier et al (2005) admit that conflict is the outcome of a complex system of factors and that no one paradigm or school of thought may be able to explain it. In their case, they argue that the "greed and grievance" debate should be abandoned for a richer, complex model because conflicts are complex in substance and process. However while today we are able to say when a conflict has occurred, none of the studies thus far carried out has been able to predict accurately when a given society will plunge into conflict as a function of what prevailing conditions. In response to this challenge, I attempt in this study to integrate elements of existing paradigms to explain in the context of a theoretical 
model why conflict can arise. Moreover, it responds to the question of when conflict may arise by developing an index incorporating the elements found to underlie such conflicts. The stability index (and the Mobility Augmented Stability Index) developed later in the thesis is then predictive in nature, using the various underlying factors to forecast the likelihood of conflict. At this stage the index is purely theoretical, what remains to be done to make this index operational is to develop the data set that translates conceptual measures into their empirical counterpart.

An associated feature of our analysis is that it counters the presumption that conflict can be resolved through democracy. That is, the present literature on conflict resolution predicts that in democracies with majority rule, the majority dictates final policy. And, where some form of minority political power is allowed, the expectation is that the probability of conflict and violence will fall rather than rise. In contradistinction, it seems that non-pecuniary differences amongst the majority are often instrumental in explaining why the concerns of minorities can sometimes dominate and this division, in turn, leads to violent conflict. Even in countries where natural resources play less of a triggering role, low intensity conflict exists over minority-majority views on such divisive issues as the role of public goods (such as education) and externalities (such as pollution). Here the resolution of conflicts has often led to a strengthening of the minority position rather than the dominance of the majority. This appears counterintuitive to the predictions of majority rule and is, as yet, unexplained in the literature designed to explain the forces that have led to such outcomes in democratic bargaining. 
In the African region, countries such as Nigeria, Sudan, Liberia, Congo, and Sierra Leone have all experienced armed conflicts seemingly caused and fuelled by environmental and natural resources issues that in turn have resulted in state failure, aggravated poverty, and ongoing refugee crises. Most, if not all, of the conflicts from Africa to Asia can be traced back to disagreements on how natural resources should be exploited and environmental concerns handled. In the study of institutions that can help mediate such environmental concerns, the literature has largely assumed circumstances relevant to the advanced democracies of the north rather than the south. In these analyses property rights are assumed to be well established and enforced, economic activity is fully privatized, and government revenues can be derived from broadly based taxes and duties rather than resource revenues [see Goulder (1998), Schneider and Volkert (1999), Kirkchgassner and Schneider (2003), Kraft (1998), Geldermann and Rentz (2003), Gersbach (2000), and Steele and Weber (2001)]. As such these studies largely ignore southern realities. My motivation is to broaden and make more relevant the analysis by including southern realities in the design of environmental models and policy prescriptions.

From a global perspective, conflict in the least developed regions of the world poses the greatest challenge to the attainment of the United Nations millennium development goals. For the most part they make access to the global poor almost impossible and hence further aggravate poverty levels. Understanding the underlying forces driving these conflicts is therefore of the utmost importance. This study attempts to uncover more of the interrelated root causes of natural resource conflict. For instance 
while the literature is concerned with the general relationship between natural resources and conflict, few have analysed theoretically exactly how natural resource conflict arises in the global south. In this study, I suggest that the regional specificity of natural resources combined with non-overlapping areas of resource externality and ethnic immobility interact with jurisdictional democratic decision making to form a root cause of natural resource related conflict. In the literature there is no consensus on the relationship between ethnic diversity and conflict. While some studies maintain that ethnic fractionalisation makes countries more vulnerable to conflict, others posit that a high level of ethnic heterogeneity is a stabilizing force in multi-ethnic societies. In this study I show that it is non-ethnic differences--for instance ideological differences-that produce the absence of consensus on the relationship between ethnic heterogeneity and conflict. Specifically, when there exists sufficient non-ethnic differences within the majority ethnic group on important ideological issues (such as the importance of education and/or environmental degradation), then ethnic heterogeneity can serve as a stabilizing force to reduce or prevent the likelihood of violent conflict in resource producing countries. This can be fortified by greater non-ethnic homogeneity in the minority ethnic group itself-for instance a common view on environmental issues.

Many investigators have also suggested that strong democratic institutions can reduce the likelihood of conflict; see, for example Hegre et al (2001), Wickham-Cowley (1993), Omeje (2005), Fearon (2005), Ross (2004), Goodwin (2000), Grugel (2002), Douglas (2001), Obi (1999), Ibeanu (2000), and others. From my perspective, these studies have not paid sufficient attention to the specific type of institution. In this study, I 
assume a strong functioning democratic state and examine the differential impact of federalism and unitarism in a resource producing economy. I posit that democracy (majority rule) in itself does not reduce conflict. This is because the inefficiency inherent in the resource exploitation is not eliminated by the adoption of either unitarism or federalism in ethnically diverse countries in which natural resources occur in some regions but not in others. In such cases, democracy must be combined with other nonethnic differences within the majority to prevent or reduce the likelihood of conflict.

In this these positions are formalized to show:

(i) that when environmental policy and conflict arising from environmental issues are mediated within a democracy, ethnic and non-ethnic differencesfor instance religion and individual values- together with self-interest and livelihood issues play a significant role in relation to the potential for violence;

(ii) that in a democracy with ethnic and non-ethnic diversity and where natural resources and their externalities occur in some regions but not others, unitarism and federalism often lead to sub-optimal, inefficient levels of resource exploitation because different political jurisdictions will choose different levels of resource exploitation;

(iii) that the asymmetric distribution of natural resources and the externalities that result from their exploitation lead to consumption and production inefficiencies across different jurisdictions; 
(iv) that under unitary majority rule ethnic differences in minority and majority regions can lead to political instability, and the existence of nonethnic differences adds an extra layer of ambiguity into this relationship;

(v) that in ethnically diverse democracies with secondary differences in the majority, a minority that is cohesive, that is politically vocal can set policy. Should the majority feel sufficiently disenfranchised, the political conciliatory process may then lead to violent expressions of disenchantment. Mobility may then lead to a strengthening of the cohesiveness of the minority region.

(vi) that when mediating potential conflict arising from environmental issues in a democracy, geographical (im)mobility plays a significant role.

(vii) that mobility has the effect of reducing externalities when negative externalities are localized in a multi-jurisdictional democracy. However, while mobility may initially increase welfare and reduce the likelihood of conflict, this is not invariably so.

(viii) that an index can be defined, what I call the Mobility Augmented Stability Index (MASI) that will indicate what level of geographical mobility enhances social welfare and political stability.

(ix) that a strategic relationship exists between resource exploitation, public good production and mobility across regions. I also show why opportunistic and ideological rebels may exist. 
(x) that for certain levels of externality (resource exploitation) and mobility only external institutions may be able to prevent conflict. This is because internal institutions may fail to motivate cross-regional negotiation. In such cases conflict may seem rational to all regions.

The goal of this thesis is to show theoretically how these hypotheses arise in the context of a formal public choice model. Difference - diversity - together with mobility is central to the analysis and arises not only in economic outcomes but also in the ethnic and value mix arising in individuals across different political jurisdictions. Mobility in the sense I have used it refers to the ability of individuals to permanently relocate from one geographical region to another within a country. Hence perfect mobility would be to be culturally and occupationally accepted and integrated without the loss of identity as defined and practiced in the culturally active regions of the world, such as Africa, and Latin America. The key questions addressed are: why are environmental policies usually inefficient; and, why do natural resources often lead to instability and violent conflicts in southern democracies?

The conclusions of this analysis and the proposition that rational conflict is possible derive from the following critical assumptions. First, the public good produced from resource revenues is not a substitute for a private good. Second, resource revenues must be used to produce a public good. Third, other forms of transfer are blocked. Thus while all regions enjoy the benefits from any increase in the public good, the externality from resource production is strictly local. Furthermore, the fact that revenues from the resource do not go to providing a private good for any region makes it infeasible for the unaffected 
region to use some of the revenue to pay for the externality. It follows that paying the impacted region with part of the proceeds of resource exploitation does not make any one better off. This is because it reduces the public good to all with no benefit to the region not impacted by the externality. Also, because of the convexity of the cost function both sides are necessarily worse off than they would be were the extra unit of the resources that generated the revenue not produced. Furthermore, by limiting mobility across regions, a traditional means of equalizing welfare across regions is blocked. That is, mobility has the effect of enabling those affected by the externality to escape by emigrating to the other region, since the marginal productivity of land in this region is unaffected by the resource externality.

The remainder of this thesis is thus organized: Chapter 2 lays out the stylized facts and develops the basic model. In Chapter 3 the basic model is extended to analyze the impact of mobility. A theory of stability is developed in Chapter 4, while an index for measuring and predicting (in)stability is built in Chapter 5. Chapter 6 examines the evidence, while the policy implications and prescriptions are discussed in Chapter 7. Chapter 8 concludes, and a section in which all the symbols used in this thesis are defined is provided at the end of the conclusion. Appendix 2.2 also extends the basic model to examine the role of altruism and voters education in conflicts. 


\section{CHAPTER 2}

\section{The Basic Model: Democratic Decision-making, Governance, and Externalities}

\subsection{Stylized Facts}

The environmental policy milieu in southern democracies is enormously different from that in the north. It is characterized by very low geographical mobility of population. Very high diversity in cultural and ethnic practices and beliefs, and land tenure systems that are largely communal and feudal, result in very poorly defined property rights. Educational and information flow levels are also very low, and technical and human capital capacities are abysmally low compared to northern democracies. Cultural practices and belief systems inseparably tie local livelihood to the natural environment, especially the land, and inhibit occupational and geographical mobility, which also prohibits in most cases the commoditization of land and the natural environment.

The level of privatization of the economy is still very low in the south compared to the north. Public participation in the private sector is a key characteristic. The size of the public sector and the market activities of the government are of very high significance in the design of market oriented policies. Government parastatals enjoy in certain cases monopoly in the areas considered to be the domain of the private sector. Although deregulation of economic systems is underway, it is far from being complete in most southern democracies. 
Governments of most democracies of the south face enormous challenges in generating revenue through taxes; this is due largely to informational difficulties and the size of their informal sectors (WDR 2003) ${ }^{1}$. In countries where natural resources abound, like the petroleum producing countries, the governments are actively involved, and in certain cases enjoy monopoly, in the production of oil and gas. This serves as the major source of revenue for the government. In such circumstances government's determination to design and implement effective environmental policy runs contrary to the desire to maximize government revenue for the provision of public good. In almost all these countries, fiscal centralism is also practiced: where the central government distributes national revenue from resources to the lower tiers of government, as local tiers of government are usually not financially viable. Capacity at the local levels is usually inadequate for highly technical issues such as efficiency in environmental policy design and implementation, hence, the gravitation towards a centralized policy milieu. These conditions describe a polluting government.

Furthermore, geographical mobility of population is generally limited as individuals are, for cultural and traditional considerations, occupationally associated with given geographical regions. Natural resources occur in such manner that in most of these countries only a few of the communities are located where these resources are found. The implication of this is that while the revenue accruing from the resources from this communities are distributed by the federal government to all federating units, these communities bear a disproportionate level of the real cost of producing the natural

\footnotetext{
${ }^{1}$ World Bank, World Development Report 2003. http://econ.worldbank.org/wdr/wdr2003/. Last visited November 20,
} 
resources in terms of pollution and disruption of community occupational way of life. So to these communities, the costs may far outweigh the benefits accruing to them from the public good produced from the resources, while the rest of the federation reaps benefit in excess of cost.

Most of the southern countries practice geographical representation in their legislatures $^{2}$. A national majority elects the federal government on a platform that promises increasing the public good (through increasing revenue from natural resources). This platform de-emphasizes pollution abatement (a local good) that is costly, and can only come at the expense of the public good (increased revenue) favoured by the majority. Local communities affected by pollution desire an excessively low level of natural resources exploration consistent with the benefit they enjoy from the public good. Representatives from these geographical regions can only win elections on such platforms. Representatives from every other region of the federation are elected on the platform of maximizing the benefit accruing to their regions from the federation account, which means minimizing environmental remediation and pollution abatement. Local governments in these countries are also elected in such conflicting circumstances. Unanimity in the legislature is, therefore, nearly not feasible on environmental policy. Centralization of the environmental policy, where the impacted region is in minority, will lead to inefficiently low abatement policies as predicted by Schneider and Volkert (1999), and as our model shows. We also show that decentralization may lead to level of 
resource exploitation that is sub-optimally too low, and therefore inefficient- a result not captured by Schneider and Volkert.

In view of these stylized facts, these studies are not sophisticated enough (or too sophisticated) to describe environmental policy making, and/or explain the nexus connecting natural resources and conflict in southern democracies. Theories and models that seek to describe environmental policy and/or conflict in the south must be cast in the context of a cultural milieu governed by such conflicting interests described above. This study takes into account some of the stylized facts stated above in order to broaden the understanding of conflict in natural resources producing democracies in which the externalities occur in some regions but not in others.

Although the model developed here is focused on a specific case of natural resources externalities, public goods and migration, it is more general in its applicability. Our research looks at the case where the revenue from resources produces a public good with localized externality and limited government revenue, and how this may lead to a rational conflict. The model could equally be used to produce a rational conflict when the externalities are public and affects all regions whereas the good produced from the resources are local. Hence, what suffices for this general applicability is limited migration, differences in regional preferences and a common incident of either benefit or cost of public policy. In this regard, a specific form of this model may be used to study the incidence of global cost of producing local or private goods in a milieu of global governance and limited global migration and transfers. 


\subsection{The model}

Suppose there exists a single country with two distinct regions, called for convenience regions 1 and 2 . Prior to the discovery of an important natural resource, $R$, the two regions are assumed to be identical in that both are agricultural and each labourer working on the common type of land receives the same constant marginal product. Let that common productivity level, $\mathrm{z}$, be $\mathrm{z}=\mathrm{z}_{0}$. However, while labour productivity is assumed to be the same across the two regions, population size differs, i.e., there are $n_{1}$ and $\mathrm{n}_{2}$ individuals in the two regions. Lastly, we assume that simply living together in distinct geographic regions will lead to family intermarriage and the development of common regional habits and customs. In this sense, individuals become ethnically different across regions in ways that may hamper mobility.

Suppose now that the two regions could be organized politically in two distinct ways: either through a common central government—a unitary political system-or through separate local governments linked together as a federal political system. In what follows we consider what difference these two forms of democratic, majority voting organizations will make for the provision of a common public good and the associated potential for conflict. To begin our analysis we assume, for convenience, that neither form of government has the ability to tax (i.e., it is prohibitively costly to raise taxes from farmers on the land). Hence prior to the discovery of the natural resource, the size of a central or federal government will be small with no independent ability to provide a public good, G. 
It follows that if individuals receive utility from units of private consumption, $x$, and a public good, $\mathrm{G}$, then the utility of a representative person with access to a common technology, equally productive land and who supplies, inelastically, one unit of labour in either region 1 and 2 can be described (using a separable utility function) as:

$$
U_{1}\left(x_{1}\right)+U_{1}(G=0)=U_{1}\left(x_{1}\right)=U_{2}\left(x_{2}\right)=U_{2}\left(x_{2}\right)+U_{2}(G=0),
$$

where all income is consumed so that $\mathrm{x}=\mathrm{z}$ and $\mathrm{x}_{1}=\mathrm{x}_{2}=\mathrm{z}_{0}$. In the country before the discovery of the resource, then, all individuals perform the same economic task, receive the same income and consume the same quantities of the private consumption goods. No public good is provided and there is no incentive for individuals to wish to migrate across regions. Finally, with no economic differences, there is no potential for economic conflict across individuals or regions.

Into this world we now introduce the discovery of a natural resource in region 1. Ownership of the resource we assume lies with the government who also decides to operate the resource in order to fund the provision of the valued public good, G. Unfortunately, resource exploitation involves an externality that increases (at an increasing rate) in the intensity of resource use, $e=e(R), e_{R} \equiv \partial e / \partial R>0$ and $e_{R R}>0$. Here the externality will be modelled as decreasing the productivity of agricultural land through the direct destruction of the productivity of farmland through pollution. Hence the productivity of each worker now becomes $\mathrm{z}(\mathrm{e})$, where $\mathrm{z}(\mathrm{e}=0)=\mathrm{z}_{0}$ and $\mathrm{z}_{\mathrm{e}} \equiv \partial \mathrm{z} / \partial \mathrm{e}<0$. 
Assume that the output coming from the natural resource, $R(n)$, is a concave function of the labour, $\mathrm{n}_{\mathrm{i}}{ }^{\mathrm{r}}$, used to exploit the resource. ${ }^{3}$ With state ownership and government operation of the resource, the resource residual $=p R\left(n_{i}^{r}\right)-n_{i}^{r} d$ can be used to fund the production of a public good that will be enjoyed equally by all the citizens of the country. ${ }^{4}$ Here $\mathrm{p}$ is the relative price of the resource in terms of agricultural output and $\mathrm{d}$ is the opportunity cost of hiring labour off the farm (measured in units of agricultural output). To keep things simple, we suppose that the public good, $G$, can be provided from resource revenue at a constant (unitary) cost so that in the absence of the ability to tax, $\mathrm{G}$ $=p R\left(n_{i}^{r}\right)-n_{i}^{r} d$, where $n^{r}$ is again the level of employment in the resource industry. Finally we must add to the story the harm produced by exploiting the natural resource that is not fully internalized by the market. Incorporating this into d,

$$
\mathrm{G}=\mathrm{pR}\left(\mathrm{n}_{\mathrm{i}}^{\mathrm{r}}\right)-\mathrm{n}_{\mathrm{i}}^{\mathrm{r}} \mathrm{z}(\mathrm{e}(\mathrm{R}))
$$

What is then left to specify is how the externality is distributed across the two regions and how the individuals affected can influence the size of the externality through their vote. To begin we also assume that cultural or ethnic differences across individuals in each region generate enough of a difference to keep migration across regions from arising.

Summarizing the equations of our model thus far,

\footnotetext{
3 To ensure a unique internal solution, we assume that the production function satisfies the Inada Conditions.
} 


$$
\mathrm{U}_{\mathrm{i}}(\mathrm{x}, \mathrm{G})=\mathrm{U}(\mathrm{x})+\mathrm{U}(\mathrm{G}) \quad \text { where } \mathrm{U}_{\mathrm{x}}, \mathrm{U}_{\mathrm{G}}>0, \mathrm{U}_{\mathrm{xx}}, \mathrm{U}_{\mathrm{GG}}<0
$$

$$
\mathrm{R}=\mathrm{R}\left(\mathrm{n}^{\mathrm{r}}\right)
$$

where $R(n)$ satisfies the Inada conditions

$$
G=p R\left(n^{r}\right)-n^{r} d
$$

$$
\mathrm{e}=\mathrm{e}(\mathrm{R})
$$

$$
\text { with } \mathrm{e}(0)=0, \mathrm{e}_{\mathrm{R}}>0, \mathrm{e}_{\mathrm{RR}}>0
$$

and $\quad \mathrm{x}=\mathrm{d}=\mathrm{z}(\mathrm{e})$

$$
\mathrm{z}_{\mathrm{e}}<0, \mathrm{z}_{\mathrm{ee}}<0.5
$$

In what follows, I solve the model for the political equilibrium under the following conditions:

a) A unitary system where the externality impact is uniform across both regions

b) A unitary system with a localized externality

c) A federal (decentralized) system with a localized externality

\footnotetext{
${ }^{4}$ To begin we assume that $\mathrm{R}$ employs only a relatively small number of workers from the region where the resource is located, here region 1 , so that we can treat the opportunity cost of its workers as $d=z(e)$. 5 Note that (2.4) and (2.5) together imply $\partial \mathrm{d} / \partial \mathrm{R}=\partial \mathrm{z} / \partial \mathrm{R}=\mathrm{z}_{\mathrm{e}} \mathrm{e}_{\mathrm{R}}<0$ and $\partial \mathrm{z}^{2} / \partial \mathrm{R}^{2}<0$. That is, the cost to each individual of increasing the rate of resource exploitation is increasing at an increasing rate. This is experienced as a faster rate at which productivity (income) is falling.
} 


\subsection{Case A: The Externality Falls Uniformly on All Individuals in the Country}

If the harm produced by resource exploitation, $\mathrm{e}_{\mathrm{A}}$, affects individuals equally, all workers in agriculture will have their productivity reduced proportionally. Since we assume that the government, as resource employer, must pay the opportunity cost to attract workers from agriculture, all workers will receive the same smaller income level $\mathrm{d}_{\mathrm{A}}=\mathrm{z}\left(\mathrm{e}\left(\mathrm{R}_{\mathrm{A}}\right)\right)<\mathrm{z}_{0}$. With smaller income, all workers will consume the same smaller quantity of private goods, $\mathrm{x}_{\mathrm{A}}=\mathrm{d}_{\mathrm{A}}$. Finally, because of the concurrent consumption characteristic of the public good, all individuals receive the same flow of services from the public good, $\mathrm{G}_{\mathrm{A}}$. It follows that because all individuals are affected equally, there will be no regional income or consumption heterogeneity across workers. All will vote for the same level of public good provision and all will be affected by the same amount of resulting harm. Hence the common solution for resource use can be found from the single representative individual choice problem described below.

\subsubsection{Individual Problem for Case A}

As described above, the household work and consumption choices are identical for each worker/voter as all employment opportunities result in the same compensation rate, $d_{A}$. Hence the only choice of interest is how the political system chooses the intensity to exploit the regions' natural resource. Under majority voting, this can be modelled by the median voter's optimal choice of how much labour should be used in the 
resource sector. Because the representative and median voter are the same in this case, the median voter maximizes his/her utility subject to the trade-off that $\mathrm{n}^{\mathrm{r}}$ proposes between $\mathrm{G}$ and $\mathrm{x}$. That is,

Choose $\mathrm{n}_{\mathrm{i}}^{\mathrm{r}}$ to maximize $\mathrm{U}=\mathrm{U}(\mathrm{x})+\mathrm{U}(\mathrm{G})$ subject to $(2.2)-(2.5)$.

Here the first order condition for that internal optimum is

$$
\mathrm{d} U / \mathrm{dn}_{\mathrm{i}}{ }^{\mathrm{r}}=\mathrm{U}_{\mathrm{x}} \mathrm{dx} / \mathrm{dn}_{\mathrm{i}}{ }^{\mathrm{r}}+\mathrm{U}_{\mathrm{G}} \mathrm{dG} / \mathrm{dn}_{\mathrm{i}}{ }^{\mathrm{r}}=0, \quad \text { where } \mathrm{U}_{\mathrm{x}}>0, \mathrm{U}_{\mathrm{G}}>0
$$

where i. $d x / d n_{i}{ }^{r}=d z[e(R(n))] / d n_{i}{ }^{r}=z_{e} e_{R} R_{n}<0$

and

$$
\text { ii. } \begin{aligned}
d G / d n^{r}=p R_{n}-d- & n\left[d d / d n=d x / d n=z_{e} e_{R} R_{n}\right] \\
= & p R_{n}-z(e)-n Z_{e} e_{R} R_{n} .
\end{aligned}
$$

Note that (2.7) above is the external cost of using one more unit of labour to produce the public good. Cost rises because producing more of the resource raises pollution, lowers the productivity of land and lowers the real earnings of all workers. From this it follows that the first term in (2.6) is the utility cost to the representative voter of choosing more of the public good.

The condition in (2.8), on the other hand, represents the additional quantity of the public good that can be produced by using an additional unit of labour in the resource sector. This is the net return from producing more of the resource at the unchanged cost 
of using labour (i.e. $\mathrm{pR}_{\mathrm{n}}-\mathrm{d}$ ) including the fact that more of the public good will result in more pollution, lower agricultural productivity and thus a lowering of the opportunity cost of the labour used to produce that public good $\left(\mathrm{nz}_{\mathrm{e}} \mathrm{e}_{\mathrm{R}} \mathrm{R}_{n}\right){ }^{6}{ }^{6}$ The second term in (2.6) then converts this quantity into units of utility.

Substituting (2.7) and (2.8) back into (2.6), we find

$$
U_{G}\left[p R_{n}-z(e)-n z_{e} e_{R} R_{n}\right]=U x\left[z_{e} e_{R} R_{n}\right]
$$

Since $\mathrm{z}_{\mathrm{e}}<0$,

$$
U_{G}\left[p R_{n}-z(e)+n z_{e} e_{R} R_{n}\right]=-U x\left[z_{e} e_{R} R_{n}\right],
$$

which implies a value for $n^{r}$.

\footnotetext{
${ }^{6}$ Note that this last term is negative so introducing a potential instability into the solution. That is, if the use of more labour in resource production generates so much additional pollution that (by destroying land and so lowering productivity in agriculture) aggregate labour costs fall by more than the net cost of employing the an additional worker, then resource use will expand to absorb all available labour. It follows that the second order condition for an internal solution to utility maximization requires the change in this
} 
Figure 1 : Optimal Choice of Exploration for Regions 1 and 2

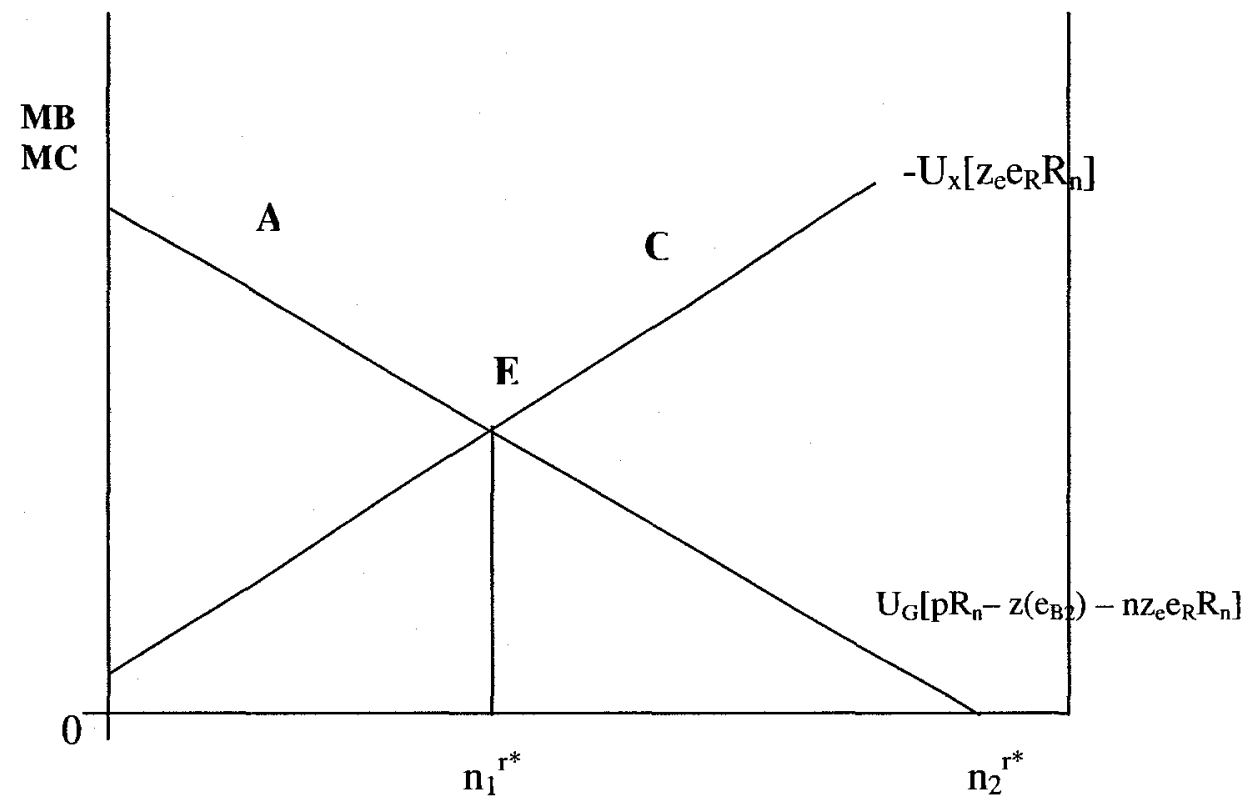

term be small relative to the fall in the traditional marginal benefit of producing more units of the public good 
In Figure 1 above, curve A represents the marginal utility (benefit) of the public good enjoyed by all residents. Curve $\mathrm{C}$ is the marginal disutility (cost) curve facing residents as a result of the externality from resource exploitation. The marginal cost curve reflects the impact of resource exploitation on private consumption. Point $\mathrm{E}$ is the equilibrium. Since everyone is equally impacted, this is the equilibrium in federal and unitary systems.

It is important to recognize that resource allocation implied by equation (2.9) and voted for by the median voter, i.e., $\mathrm{n}_{\mathrm{A}}^{\mathrm{r}}$, produces the socially optimal level of the public good/level of pollution. That is, the representative individual is directly affected by all dimensions of resource use so that voting to maximize individual self-interest also internalizes completely the social costs of production. The difference can be seen by asking what would the profit maximizing level of production be for a private firm who owned the rights to this natural resource. Here the privately optimal solution would set simply the first term in squared brackets in (2.9) above, the marginal net resources produced, equal to zero. That is, the private firm would consider only the residual that could be appropriated by itself and thus ignore the cost that this would impose on outside agricultural workers. It follows that by ignoring that external cost, too much of the natural resource will be produced and the country will experience too much pollution relative to the social optimum and to a realizable political equilibrium. Stated alternatively, in this case democratic majority voting outcome will result in the socially optimal allocation of resources within the country. In a political sense, this equilibrium also avoids internal conflict since all individual outcomes are equalized. 
Once $\mathrm{n}_{\mathrm{A}}^{\mathrm{r}}$ is solved, the level of the public good can be found by simply substituting $\mathrm{n}_{\mathrm{A}}^{\mathrm{r}}$ back into (2.3). That is,

$$
\mathrm{G}_{\mathrm{A}}=\mathrm{pR}\left(\mathrm{n}_{\mathrm{A}}^{\mathrm{r}}\right)-\mathrm{n}_{\mathrm{A}}^{\mathrm{r}} \mathrm{d}\left(\mathrm{n}_{\mathrm{A}}^{\mathrm{r}}\right) .
$$

It follows that in the absence of ideological differences or any other form of political heterogeneity, all voters will be affected identically and hence will choose to vote in the same way. Hence the democratic process will replicate the social optimum. This leads directly to Proposition 1.

Proposition 1: Without any form of productive heterogeneity arising across ethnic or geographic groups, the uniform incidence of the externality arising from resource exploitation will create no differences among or across affected groups. Hence unanimity will arise in the political responses to public policy and that political response will be independent of the institutional type. That is, a unitary system and a federal system will result in the same optimal level of resource use.

Proof: All individuals take into account all dimensions of the impact of resource exploitation on private consumption. Because all are impacted equally by it, all make the same choice. Since the issue space is single dimensional with individuals voting only on the number of people to be employed in the resource sector, (alternatively, the level of public good produced) the median voter is truly representative. Candidates will choose 
the level chosen by the median voter. A political equilibrium exists under both Federalism and Unitarism and their common solution coincides with the choice of the median voter. Here

$$
U_{I}^{A}=U_{I}\left(x_{1}, G_{A}\right)=U_{2}\left(x_{2}, G_{A}\right)=U_{2}^{A}
$$

Corollary 1.1: Where the externality is distributed evenly across a homogenous group, the level of resource exploitation chosen by the median voter will be efficient.

Finally, an increase in the external value of the resource (a rise in p) may alter the degree to which the natural resource is exploited, the quantity of the public good provided by the government, and the level of pollution endured by the population. However, because all individuals are affected equally, all will benefit to the same degree without distribution effects arising across individuals or regions. In this case, then, external forces play no role in increasing regional tension or the potential for conflict.

Proposition 2: External factors, such as an external rise in the price of the natural resource, do not in themselves initiate or aggravate conflict in resource rich countries.

Proof: External factors impact all regions and individuals in similar way where resources and externalities are distributed uniformly, and individuals fully internalize such external forces in the decision making process. See appendix 2.1 for the 
comparative statics of the impact of changes in the price of resource. An increase in the price of natural resources will reduce the relative price of agricultural produce and hence the opportunity cost for all individuals decreases. Therefore, all individuals will choose a higher level of resource exploitation in proportion to the increase in resource price. This shows that the unanimity in the system is preserved. This is true in both federal and unitary systems.

\subsection{Case B: A Unitary Political System with a Localized Externality}

Suppose the negative externality arising from natural resource production falls only on regon1, and that a unitary political system is used to determine the level of resource output produced, and hence the level of public good and externality. Here there are two possible cases -- $n_{1}>n_{2}$ and $n_{2}>n_{1}$. Under democratic majority voting, the two cases correspond to situations in which different sets of individuals make the decision over resource use. We assume that all individuals vote, and vote in their self-interest. The remainder of the chapter also deals with the case where mobility across region does not arise. The case of mobility is discussed in chapter 3.

\subsubsection{Case B(1): No mobility with $n_{1}>n_{2}$.}

The specificity of the externality means that differences will now arise across the individuals in the two regions and the absence of mobility will keep benefits (costs) from 
being equalized. Since individuals are identical within regions, they all will vote the same way. Hence, given that the individuals in the externality-impacted region are in the majority, the level of the public good produced will be chosen by the median voter residing in that region. And, because of their majority status within the nation, the political decision made (in the interests of voters in region 1) will be the same no matter whether the political decision making process is unitary or a federation. Under both political regimes, the larger voting population of region 1 guarantees that the level of $\mathrm{G}_{\mathrm{B} 1}$ and implicitly $R_{B 1}$ and $e_{B 1}$ will be chosen by the representative individual in region 1 .

More formally, then, the choices of $\mathrm{G}_{\mathrm{B} 1}$ and $\mathrm{e}_{\mathrm{B} 1}$ come from optimal resource use from the perspective of the representative voter in region 1. Moreover, because the benefits and costs accruing to the median voter are the same as in Case A above, the level of resource exploitation (through the choice of $n_{i}^{r}$ ) will again be determined by equation (2.9). This decision then maximizes the utility of region 1 voters subject to the constraints facing them and is made independent of the wishes of region 2 voters. This solution is illustrated in Figure 1 above that contrasts the outcomes under Cases A and B1 with the outcome that would arise under no externality at all.

Note that unlike the outcome in the previous case (i.e., Case A), individuals in region 2 are completely unaffected by the externality and so receive the level of utility, $\mathrm{U}_{2}\left(\mathrm{~d}=\mathrm{x}_{0}, \mathrm{G}_{\mathrm{B}}\right)$. They have no influence on the level of the public good produced nor do they bear any part of the pollution that arises from resource exploitation. From their perspective, however, the public good is always underprovided because the pollution cost of the public good is not borne by them. Hence individuals in region 2 will always vote 
for a higher level of the public good. However, despite feeling that public services are underprovided, residents in region 2 end up with a higher level of utility than those in region 1 . In region 1, pollution lowers agricultural productivity meaning that private consumption levels will be lower than in region 2 . Hence individuals receive only $\mathrm{U}_{1}\left(\mathrm{x}_{\mathrm{B} 1}\right.$ $\left.<\mathrm{x}_{0}, \mathrm{G}_{\mathrm{B} 1}\right)$ by having to absorb the pollution externality.

Because of these differences across groups, grounds for conflict arise. Individuals in region 1 are differentially affected by pollution and receive lower levels of real income. Individuals in region 2, on the other hand, feel disenfranchised and would prefer higher levels of the public good.

\subsubsection{Case $B(2)$ No mobility with $n_{2}>n_{1}$.}

In this case distinctly different outcomes will arise depending upon whether the country is organized as a unitary system or as a decentralized federation with two distinct regional governments. In the former case of a unitary system operating under majority rule, the decision over resource usage (level of the public good and pollution provided) will be made by the political majority arising in region 2 that is not impacted by the externality. In the latter case, the cost of the externality on the individuals in the impacted region will be taken into account by political decision-making within region 1 .

If we look first at the unitary majority voting solution, $\mathrm{n}_{\mathrm{i}}{ }^{\mathrm{r}}$ will be chosen by voters from region 2 as the outcome of the following maximization problem.

Choose $n_{i}^{r} \max U_{2}=U(x)+U(G)$ subject to (2.2) - (2.4) and $x=x_{0}$. 
The important difference in this case is that while the effect of pollution on the wage cost of the resource industry will be taken into account (i.e., $d_{e}<0$ ), the fact that pollution reduces the earning potential of agricultural workers in region 1 and hence utility levels there will not be taken into account.

Hence the first order condition for an internal optimum for individual voters in region 2 is

$$
\mathrm{dU} / \mathrm{dn}_{\mathrm{i}}^{\mathrm{r}}=\mathrm{U}_{\mathrm{G}} \mathrm{dG} / \mathrm{dn}_{\mathrm{i}}^{\mathrm{r}}=0,
$$

where once again (from equation (2.8) earlier)

i. $\quad d d / d n_{i}^{r}=d z[e(R(n))] / d n_{i}^{r}=z_{e} e_{R} R_{n}$ and

ii. $d G / d n^{r}=p R_{n}-z(e)-n z_{e} e_{R} R_{n}$

Thus combining terms, we find that the voting equilibrium, $\mathrm{n}_{\mathrm{B} 2}$, is determined by the condition

$$
U_{G} d G / d_{i}^{r}=U_{G}\left[p R_{n}-z\left(e_{B 2}\right)-n z_{e} e_{R} R_{n}\right]=0,
$$

which, in turn, implies $\quad \mathrm{pR}_{\mathrm{n}}=\mathrm{z}\left(\mathrm{e}_{\mathrm{B} 2}\right)-\mathrm{nz}_{\mathrm{e}} \mathrm{e}_{\mathrm{R}} R_{\mathrm{n}}$.

Equation (2.13) and (2.14) state that the optimal solution, $\mathrm{n}_{\mathrm{B} 2}{ }^{\mathrm{r}^{*}}$, from the point of view of region 2 voters is to maximize the potential profit that can be realized by the natural resource and use those profits entirely to produce the public good. Compared to 
the earlier solutions this results in producing too much of the natural resource, level of pollution and level of the public good by ignoring the harm imposed by the externality upon the residents of region 1. The impact of the externality on the agricultural land productivity, and private consumption in region 1 is not taken into account in choosing the level of resources to be exploited ${ }^{7}$. Note that in this case the previous problem faced by voters in region 2 has been eliminated (from their perspective). That is, region 2 voters now get their preferred consumption bundle by being able to use the political process to increase the output of the public good until the marginal benefit to them equals their marginal cost. The marginal cost curve facing region 2 , in terms of private consumption, coincides with the horizontal axis. Compared to Case B1 above, their utility is now higher (i.e., $\mathrm{U}_{\mathrm{B} 2}=\mathrm{U}\left(\mathrm{x}_{0}\right)+\mathrm{U}\left(\mathrm{G}_{\mathrm{B} 2}>\mathrm{G}_{\mathrm{B} 1}\right)$, with $\left.\mathrm{n}_{2}^{\mathrm{r}} * \mathrm{n}^{\mathrm{r}}{ }^{*}\right)$. However, the problem faced in region 1 is exacerbated. That is, by losing their ability to set the level of the public good, individuals in region 1 have higher levels of pollution imposed upon them. The result is a reduction in their agricultural earnings and private consumption by more (in terms of utility) than the rise from the higher level of the public good now produced [i.e., $\mathrm{U}_{\mathrm{B} 1}>\mathrm{U}_{\mathrm{B} 2}=\mathrm{U}\left(\mathrm{x}_{\mathrm{B} 2}<\mathrm{x}_{\mathrm{B} 1}\right)+\mathrm{U}\left(\mathrm{G}_{\mathrm{B} 2}>\mathrm{G}_{\mathrm{B} 1}\right)$ ]. When the two changes are put together it is apparent that utility differences across regions are now increased relative to the gap arising in Case B1. This difference arises from the fact that in case B1, individuals in region 1 having the political, and also suffering the externality, make the political decision to equate marginal benefit of resource exploitation $(\mathrm{G})$ to the marginal

\footnotetext{
${ }^{7}$ Note that the resource allocation is the same as if a private owner operated the resource. The only difference is that the residual is used to fund $\mathrm{G}$, whereas in the private ownership case the residual would be transferred to the private owner for use.
} 
cost of resource exploitation (negative impact on private consumption). Individuals in region 2 take the $G$ as given, with no external cost imposed on them.

In case B2, with political power shifting to region 2 (since they are in majority), the decision on exploitation is taken without consideration for the negative externality. Since the marginal cost of producing $\mathrm{G}$ imposed on region 2 is zero, the marginal benefit is driven to coincide with their marginal cost. Individuals in region 1 also benefit by the increase in $\mathrm{G}$ relative to the case in B1, however, because we know the solution at B1 was optimal, it must follow that the decrease in utility due to externality (reduction in private consumption) is more than the increase due to higher G. Individuals in region 2 experience increase in utility, hence, compared to case B1, the gap between individuals in regions 1 and 2 is greater.

If $\mathrm{n}_{2}>\mathrm{n}_{1}$ and the country is organized as a federation politically so that each region has political control over its own resources, the solution for the level of resource use will again revert to that of Case B1 above. If region 1 inhabitants alone can vote on the level of resource exploitation in region 1 (and thus on the level of public good provision), then the level of resource use (and pollution) again ignores the wishes of region 2 individual's for higher levels of the public good. There is, however, an important difference with Case B1. That is, the number of individuals who would prefer a larger quantity of the public good now exceeds the number who chose to impose the lower output limit and this difference in numbers will generate an additional tension within any democracy. That is, the denial of the wishes of the national majority is bound to create new political tensions within a federation where differences already arise across regions. 
Figure 2: Extra cost to Region 1 and Benefit to Region 2

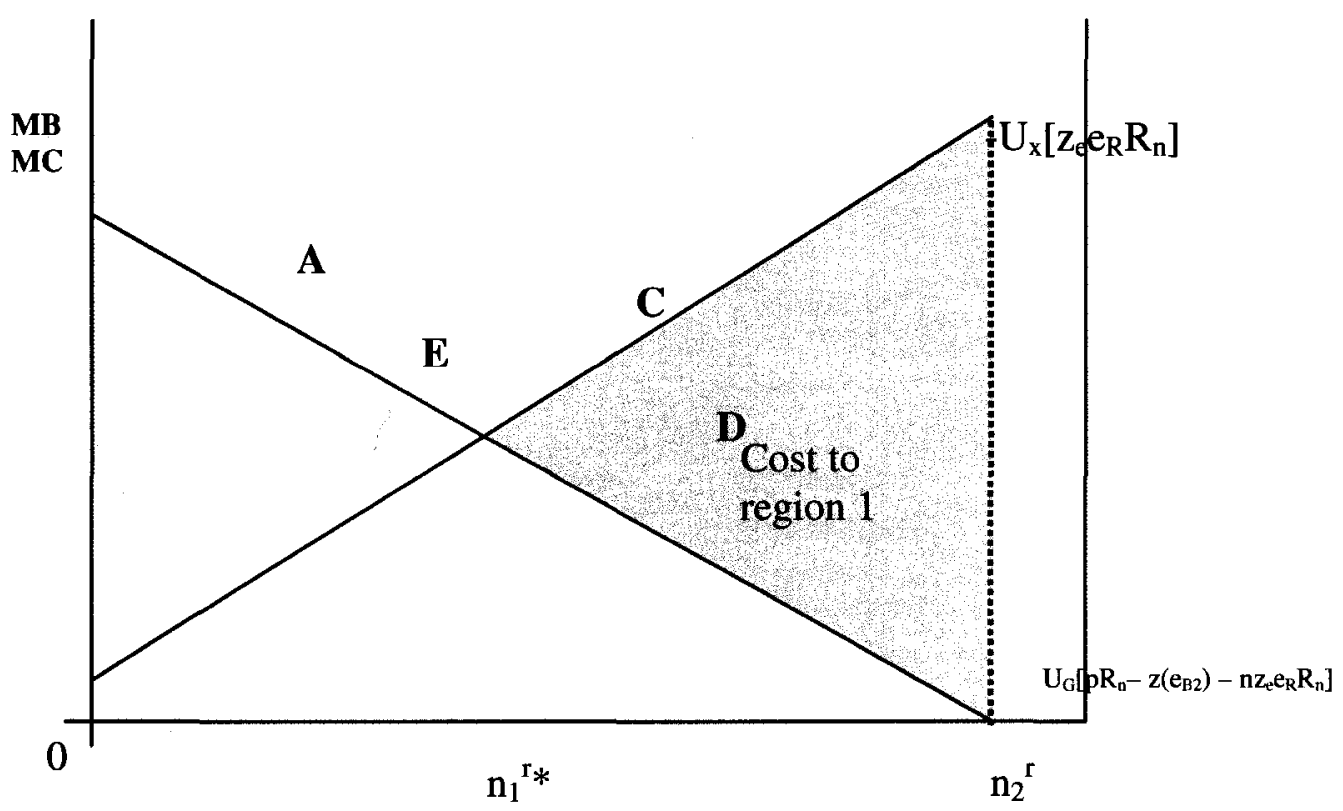

Figure 3: Wage Levels in Regions 1 and 2

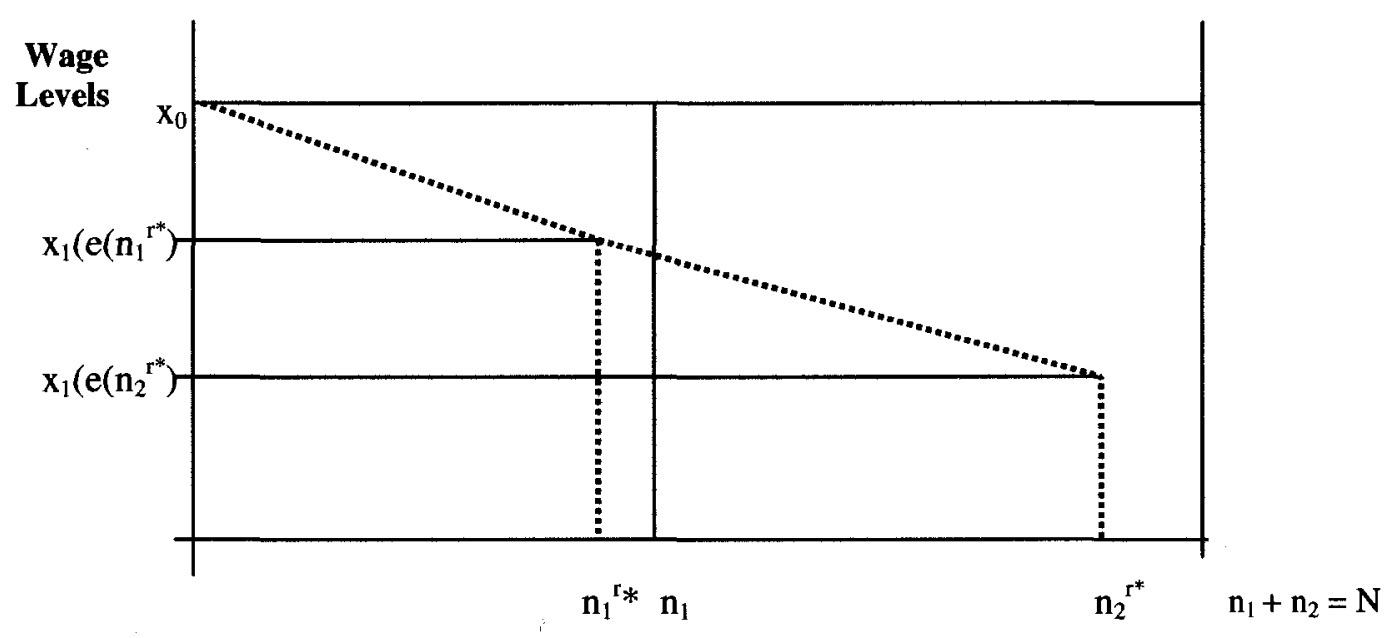


Note that even though we have assumed that ethnic differences across individuals in different regions keep mobility from arising, the political problem of difference will be only heightened if mobility is reintroduced into the problem. That is, although individuals in region 2 prefer higher levels of public good, they also experience higher levels of utility relative to those in region 1 . Hence to the extent that individuals can move, there will be movement from the polluted to the non-polluted region, which will only increase the number of individuals coming to feel disenfranchised with respect to choosing levels of the public goods. Finally, it should also be noted that political attempts to resolve "representational inequalities" within the country as a whole will work to heighten regional inequalities. In this sense creating greater political equality across regions would result in more of the public good being provided which in turn heightens the economic differences across the regions. This increases rather than decreases the conflict potential that such differences create across regions.

\subsection{Case C: A Federal (Decentralized) System with a Localized Externality}

In a federal (decentralized) system with localized resource and externality, the regions have jurisdiction to determine the level to produce of resources within their regions. Since the resources are only in region 1 and only this region suffers the externality, under a federal system, region 1 sets the level of the public good, without 
input from region 2 . The political choice is similar to the choice made under a unitary system in which the population of region 1 is higher than the population of region $2\left(n_{1}>\right.$ $\mathrm{n}_{2}$ ). Hence the level of the public good and externality produced in these systems are similar. The equilibrium in a unitary system with the majority in region 1 has been discussed in section 2.4.1, and so will not be repeated here since it is similar.

The distinct characteristic of the equilibrium and public good level in a federal system is that the size of the resources, and hence the public good, produced does not depend on the relative population size of the two regions. Here, even with a lower population than region 2 , region 1 has the politically effective vote on resources found in it. Therefore it sets the level of the public good that internalises the external cost of resource production, as in case $\mathrm{B}(1)$, section 2.4.1. The equilibrium is given by equation (9), repeated below for convenience

$$
U_{G}\left[p R_{n}-z(e)+n z_{e} e_{R} R_{n}\right]=-U x\left[z_{e} e_{R} R_{n}\right]
$$

\subsection{Social Optima}

If we adopt a social welfare function for the country as a whole, we can compare these political outcomes to a social optima. Does the pursuit of a social optima have the capacity to reduce the region of conflict? Can it provide policy makers a region within which to negotiate a level of resource exploitation that may be accepted by both regions? Assuming a utilitarian social welfare function, the major source of inefficiency is that the 
minority does not consider the consumption benefit to the majority in its choice of the optimal level of resource exploitation. Also the majority does not consider the production externality suffered by the resource-producing jurisdiction in their choice of the level of resource exploitation.

The social optima in this case is given by the level of exploitation which simultaneously internalizes the external cost to the minority and the external benefit to the majority, of resource exploitation.

Suppose that all individuals in jurisdiction 1 suffer the externality, and all individuals across the country benefit from the public good. Then the optimal level of public good is obtained by choosing the level $\mathrm{n}^{\mathrm{r}}$ to maximize the net benefit to society.

Choose $n_{i}{ }^{r} \max S W=n_{1}\left[U^{1}(x)+U^{1}(G)\right]+n_{2}\left[U^{2}(x)+U^{2}(G)\right]$ subject to $(2.2)-(2.5)$. Here the FOC for an internal optimum is

$\mathrm{dSW} / \mathrm{dn}_{\mathrm{i}}^{\mathrm{r}}=\mathrm{n}_{1}\left[\mathrm{U}_{\mathrm{x}} \mathrm{dx}_{1} / \mathrm{dn}_{\mathrm{i}}^{\mathrm{r}}+\mathrm{U}_{\mathrm{G}} \mathrm{dG}_{1} / \mathrm{dn}_{\mathrm{i}}^{\mathrm{r}}\right]+\mathrm{n}_{2}\left[\mathrm{U}_{\mathrm{x}} \mathrm{dx}_{2} / \mathrm{dn}_{\mathrm{i}}^{\mathrm{r}}+\mathrm{U}_{\mathrm{G}} \mathrm{dG}_{2} / \mathrm{dn}_{\mathrm{i}}^{\mathrm{r}}\right]=0$, where $U_{\mathrm{x}}>0$ and $\mathrm{U}_{\mathrm{G}}>0$

where i. $\mathrm{dx}_{1} / \mathrm{dn}_{\mathrm{i}}^{\mathrm{r}}=\mathrm{dz}[\mathrm{e}(\mathrm{R}(\mathrm{n}))] / \mathrm{dn}_{\mathrm{i}}^{\mathrm{r}}=\mathrm{z}_{\mathrm{e}} \mathrm{e}_{\mathrm{R}} \mathrm{R}_{\mathrm{n}}<0$,

$$
\text { ii } \mathrm{dx}_{2} / \mathrm{dn}_{\mathrm{i}}^{\mathrm{r}}=0
$$

iii. $\mathrm{dG}_{1} / \mathrm{dn}^{\mathrm{r}}=\mathrm{pR} \mathrm{R}_{\mathrm{n}}-\mathrm{d}_{1}-\mathrm{n}\left[\mathrm{dd}_{1} / \mathrm{dn}=\mathrm{dx} \mathrm{x}_{1} / \mathrm{dn}=\mathrm{z}_{\mathrm{e}} \mathrm{e}_{\mathrm{R}} \mathrm{R}_{\mathrm{n}}\right]$ 


$$
=p R_{n}-d-n z_{e} e_{R} R_{n} .
$$

From (2.15)-(2.18), we have that

$$
\begin{aligned}
& n_{1}\left[U_{x} z_{e} e_{R} R_{n}+U_{G}\left(p R_{n}-d-n z_{e} e_{R} R_{n}\right)\right]+n_{2} U_{G}\left[p R_{n}-d-n z_{e} e_{R} R_{n}\right]=0 \\
& \left(n_{1}+n_{2}=N\right) U_{G}\left[p R_{n}-d-n z_{e} e_{R} R_{n}\right]=-n_{1} U_{x} z_{e} e_{R} R_{n} \quad z_{e}<0 ;
\end{aligned}
$$

Equation (2.20) shows that at the social optima, the social benefit and social cost are fully internalized. The marginal utility of the public good attainable at the social optima is given by

$$
\begin{aligned}
& \mathrm{NU}_{\mathrm{G}}\left[\mathrm{pR}_{\mathrm{n}}-\mathrm{d}-\mathrm{nz}_{\mathrm{e}} \mathrm{e}_{\mathrm{R}} \mathrm{R}_{\mathrm{n}}\right]-=-\mathrm{n}_{1} \mathrm{U}_{\mathrm{x}} \mathrm{Z}_{\mathrm{e}} \mathrm{e}_{\mathrm{R}} \mathrm{R}_{\mathrm{n}} \\
& \mathrm{U}_{\mathrm{G}}^{\mathrm{s}}\left(\mathrm{n}^{\mathrm{r}}\right)\left[p R_{n}-d-n^{r} z_{e} e_{R} R_{n e}\right]=\frac{-\mathrm{n}_{1} z_{e} e_{R} R_{n}}{N} U_{x}=-\left(\frac{\mathrm{n}_{1}}{N}\right) z_{e} e_{R} R_{n} U_{x}
\end{aligned}
$$

Notice that the term in bracket $\left(n_{1} / N\right)$ in equation (2.22) equals one in the case $B 1$, and zero in case B2, representing two extremes of the resource exploitation level. Thus, the social optimum is a weighted average of two extremes. Notice also that the social optima, though socially efficient, does not eliminate the possibility of conflict, given our set of assumptions. While the social welfare may be larger at the social optimum, the rules of political exchange do not readily let this solution to come about. That is, if the 
constitution allows one region to determine the resource us, there are too few margins in the model to allow the mutual gains from changing resource us to be realized, as proposed by the social optimum. If differences in tax and/or benefit rates (in societies where taxation is easier) cannot be made different, then it is hard to see how this preferred solution can be brought about. However, see appendix 2.2 for analysis of the impact of altruism on the level of resource use.

\subsection{Summary of Results under Non-Uniform Externality}

\section{Social Optima}

$$
\mathrm{U}_{\mathrm{G}}^{\mathrm{s}}\left(\mathrm{n}^{\mathrm{r}}\right)\left[p R_{n}-d-n^{r} z_{e} e_{R} R_{n}\right]=\frac{\mathrm{n}_{1}}{\mathrm{~N}} U_{x}\left(-z_{e} e_{R} R_{n}\right)
$$

\section{Federalism}

$$
\mathrm{U}_{\mathrm{G}}^{\mathrm{f}}\left(\mathrm{n}^{\mathrm{r}}\right)\left[p R_{n}-d-n^{r} z_{e} e_{R} R_{n}\right]=U_{x}\left(-z_{e} e_{R} R_{n}\right)
$$

\section{Unitarism}

$$
\begin{aligned}
& n_{1}<n_{2} \\
& U_{G}^{u}\left(n_{u}{ }^{r}\right)\left[p R_{n}-z(e)-n^{r} z_{e} e_{R} R_{n}\right]=0
\end{aligned}
$$


Figure 4: Social Optimum with Utilitarian Welfare Function

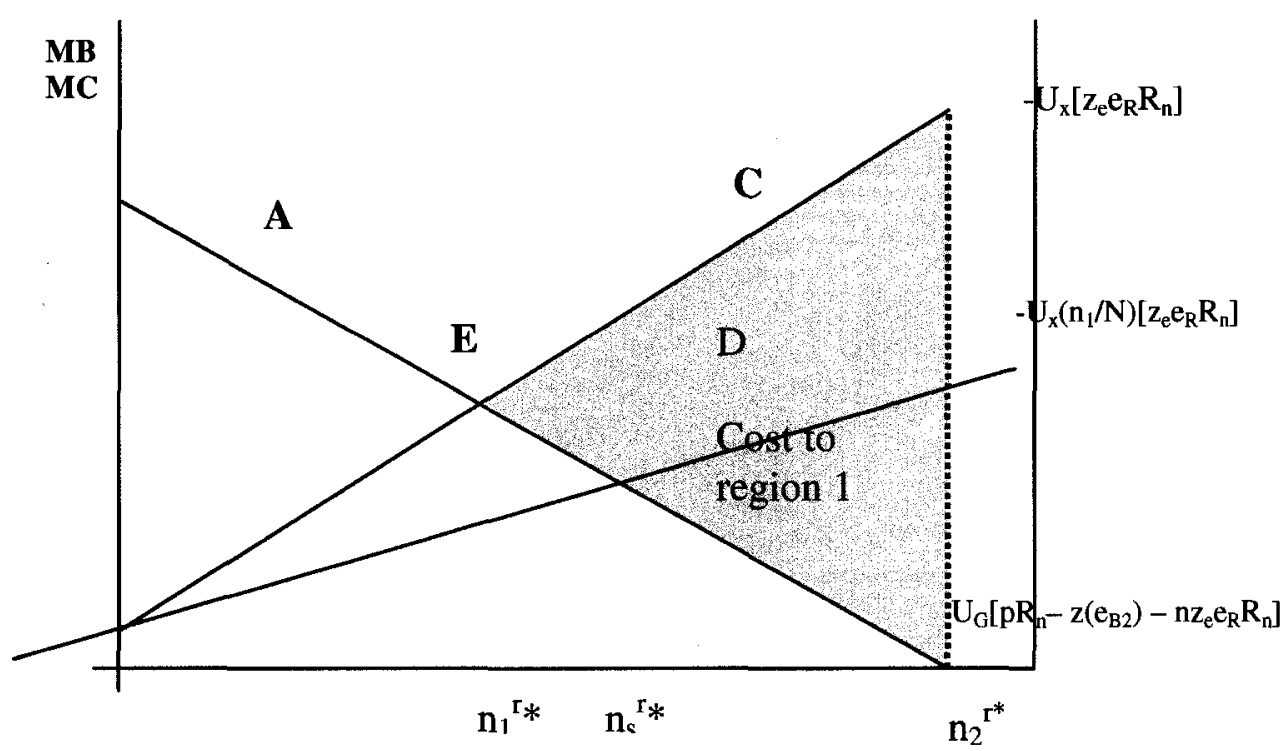

Figure 5: Wage Levels under the Social Optimum

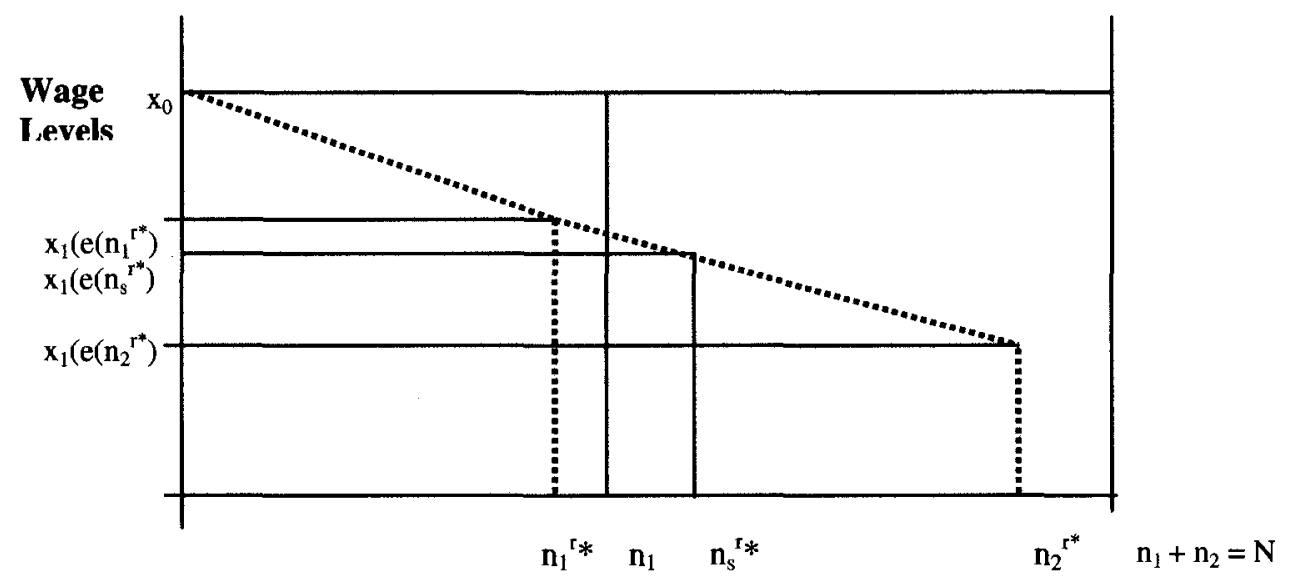


Equations (2.9), (2.13), and (2.22) express the desire and exploitation levels of the resources under federalism, unitarism, and the social optimal level respectively. The significance of equation (2.22), describing the social optima level of resource exploitation is in the fact that it lies between the federal and unitary optimal solutions, where only the minority region suffers the exploitation externality. It also shows that the federal and unitary systems in this setting deviate from social efficiency, and are thus inefficient from social standpoint. Especially because this socially optimal level of exploitation differs from the levels obtainable under federal and unitary systems, it does not eliminate conflict. However, it could be seen as a middle ground and a possible reference point for any non-economic resolution to conflict arising from resource exploitation. Since it represents a shift in economic equilibrium for both the federal optima and unitary optima in resource exploitation, enough incentive must be created to effect a non-economics transition to this equilibrium. In our model, presently there is no mechanism to effect this transition to the socially efficient equilibrium, and purely economic considerations cannot achieve this equilibrium. Hence, policy makers must look to non-economic instruments to create a convergence to the social optima. Although the socially efficient level does not eliminate the possibility of conflict, it is a middle ground, and in this regard provides opportunity for a negotiated political resolution of potential conflict. Starting from federalism, the social optimum actually increases the utility difference between the two regions as explained above. However, starting from a unitary system, the social optimum reduces the utility difference between the regions. Hence, the acceptability of the socially 
efficient level of exploration by both regions (especially the impacted region) is strongly dependent on the starting point.

The level of inefficiency in the federal optima results from the fact that it ignores the consumption benefit enjoyed by the majority by an extra unit of public good produced. The inefficiency of the unitary system stems from the fact that it ignores the negative externality suffered by the minority regions due to the exploitation of an extra unit of the resources.

Proposition 3: Given the assumptions of the model used, both Unitary and Federal systems give evidence of inefficiency when the externality from resource exploitation is not uniformly distributed. Compared to the social optimum under a utilitarian social welfare function, there is under supply of the public good under federalism, and there is over consumption (over supply) under unitarism.

Proof: It suffices to prove that federalism and unitarism prefer levels of employment in the resource sector that are different from the level of employment under social optimum, and that the level of exploitation allowed under unitary system does not take into account the adverse effect on private consumption experienced by individuals in the impacted region. Federalism ignores the benefit of the public good enjoyed by individuals in the non-impacted region, who are also excluded in the decision making process under federalism. 
(i) Federalism undersupplies the public good

$$
\begin{aligned}
& \mathrm{U}_{\mathrm{G}}^{\mathrm{s}}\left(\mathrm{n}^{\mathrm{r}}\right)=\frac{\mathrm{n}_{1} z_{e} e_{R} R_{n}}{N\left(p R_{n}-z(e)-n^{r} z_{e} e_{R} R_{n e}\right)} U_{x}<\mathrm{U}_{\mathrm{G}}^{\mathrm{f}}\left(\mathrm{n}^{\mathrm{r}}\right)=\frac{z_{e} e_{R} R_{n}}{\left(p R_{n}-z(e)-n^{r} z_{e} e_{R} R_{n e}\right)} U_{x} \\
& \Rightarrow \frac{\mathrm{n}_{1}}{N\left(R_{n}-z(e)-n^{r} z_{e} e_{R} R_{n e}\right)}<\frac{1}{p R_{n}-z(e)-n^{r} z_{e} e_{R} R_{n e}}
\end{aligned}
$$

This holds because

$\frac{n_{1}}{N}<1 \quad N=n_{1}+n_{2}$

Since

$\mathrm{U}^{\mathrm{s}}{ }_{\mathrm{G}}\left(\mathrm{n}^{\mathrm{r}}\right)<\mathrm{U}_{\mathrm{G}^{\mathrm{f}}}^{\mathrm{f}}\left(\mathrm{n}^{\mathrm{r}}\right)$

$\Rightarrow \mathrm{n}_{\mathrm{s}}^{\mathrm{r} *}>\mathrm{n}_{\mathrm{f}}^{\mathrm{r} *}$

Reason: Concavity

Corollary 3.1: As the proportion of groups or individuals impacted by externality approaches the total population, federalism becomes socially optimal and efficient, in the absence of any other form of difference, except ethnic (geographic) differences.

(ii) Unitarism oversupplies the public good

$$
\begin{aligned}
& \mathrm{U}_{\mathrm{G}}^{\mathrm{u}}\left(\mathrm{n}^{\mathrm{r}}\right)\left[\left(p R_{n}-z(e)-n^{r} z_{e} e_{R} R_{n e}\right)\right]=0<\mathrm{U}_{\mathrm{G}}^{\mathrm{s}}\left(\mathrm{n}^{\mathrm{r}}\right)\left[\left(p R_{n}-z(e)-n^{r} z_{e} e_{R} R_{n e}\right)\right] \\
& =\frac{n_{1}}{N} U_{x}\left[-z_{e} e_{R} R_{n}\right] \\
& z_{e}<0, \text { and } U_{x}>0 \\
& \Rightarrow \mathrm{U}_{\mathrm{G}}^{\mathrm{s}}\left(\mathrm{n}^{\mathrm{r}}\right)>0
\end{aligned}
$$

Since for $\mathrm{pR}_{\mathrm{n}}>z(e)+n^{r} z_{e} e_{R} R_{n}$

$$
\begin{aligned}
& \mathrm{U}_{\mathrm{G}}^{\mathrm{u}}\left(\mathrm{n}_{\mathrm{u}}^{\mathrm{r}^{*}}\right)<\mathrm{U}_{\mathrm{G}}^{\mathrm{s}}\left(\mathrm{n}_{\mathrm{s}}^{\mathrm{r}^{*}}\right) \\
& \mathrm{n}_{\mathrm{u}}^{\mathrm{r} *}>n_{\mathrm{s}} *
\end{aligned}
$$

The marginal utility of the public good diminishes 
Corollary 3.2: A unitary system of resource exploitation in a democracy may be efficient where no individual is impacted by externality, if resources are evenly distributed, and in the absence of any other form of difference, except ethnic differences.

In figures 2 and 3 above, curve A represents the marginal utility (benefit) of the public good enjoyed by residents of region 1 , and 2. Curve $\mathrm{C}$ is the marginal disutility (cost) curve facing residents of region 1 as a result of the externality from resource exploitation. The marginal cost curve reflects the impact of resource exploitation on private consumption in region 1 , which is not faced by region 2 . The shaded portion of the graph, $\mathrm{D}$, is the net damage faced by only residents of region 1 when the exploitation of the resources is driven to the point where the marginal utility of the public good is zero- the point favoured by the unimpacted region 2 . Point $\mathrm{E}$ is the equilibrium for those in region 1 (in a federal system). The size of area $\mathrm{D}$ indicates the degree of disagreement on resource level. The social optimum represents the best (most efficient) solution, as has been shown, this solution does not eliminate the potential for conflict.

Another result is that the difference between the social optimal level and the other levels (federal and unitary) may be determined by the proportion of impacted population $\left(n_{1} / N\right)$; a higher proportion tends to reduce the difference between the social optima and the level under federalism, while a lower proportion reduces the difference between the optimal solution and the unitary level of exploitation. 
A feature of regions-in-conflict as a result of natural resources is low levels of education and low levels of information pass-through ${ }^{8}$. It must, therefore, be noted that voters in both regions might be ignorant of the impact of the exploitation in other regions. Understanding pollution and the relationship between natural resource exploitation and poverty require reasonable level of education. In this case where the negative impact is felt in the other region, it is likely that voters in unimpacted region 2 are not well informed on the true nature of the damage done in region 1 . In this sense, even if voters in region 2 were altruists, and would like to take into consideration the consumption level in region 1, they may not do so because they are not informed, and are ignorant of the impact in region 1. In countries with low levels of education, this presents a credible opportunity for policy makers and politicians.

In the appendix 2.2 , the impact of public education is examined by introducing altruism in the utility function. The motivation is to see how public education as an instrument acting through altruism could be used to create a convergence between the federal and unitary solutions. We shall also show if this type of instrument will be more effective in federal or unitary system, and what incentive is there for politicians and policy makers from both regions to use this instrument. In this regard it examines why such instrument is not used very often.

\footnotetext{
${ }^{8}$ Information pass-through in the sense I have used it refers to the ease with which information at the higher tiers of government passes down to the lower tiers, and individuals. And how well government policies are communicated to, and understood by individuals.
} 


\section{Appendix 2.1: Comparative Statics: The response of resource exploitation to changes in the price of the natural resource.}

The purpose of this appendix is to present in detail the comparative statics of a change in the market value of resources and its effect on the level resource exploitation. The focal point is to show how the change in the value of the resource being exploited is not in itself a sufficient cause of either more intensive resource exploitation or greater inter-regional difference. Only in the case where region 2 maintains control over resource use will it inevitably be the case that higher resource prices increase the scale of the resource externality. Should region 1 maintain control, the level of resource use may actually decline in the presence of a price rise. Hence this analysis investigates how the two regions would respond differently to such change in the value of resources when they have separate control of the level of resource use.

\section{Case 1: Region 1 has control over resource use}

If region 1 has control of the level of resource use, we know from the first order condition determining optimal resource use (equation (2.9)) that employment will be expanded in the resource industry until the following condition is met

$$
\mathrm{U}_{\mathrm{G}} \mathrm{G}_{\mathrm{n}}=\mathrm{U}_{\mathrm{x}} \mathrm{z}_{\mathrm{n}} .
$$


It follows that if we maintain optimal decision making and investigate the effect on resource use of a change in the (exogenously given) price of the resource, then it must be true that

$$
\begin{aligned}
& G_{n} U_{G G} \frac{\partial G}{\partial p} d p+U_{G} \frac{\partial G_{n}}{\partial p} d p+G_{n} U_{G G} \frac{\partial G}{\partial n} d n+U_{G} \frac{\partial G_{n}}{\partial n} d n \\
& -z_{n} U_{x x} \frac{\partial z}{\partial n} d n-U_{x} \frac{\partial\left(z_{n}\right)}{\partial n} d n=0 \\
& \Rightarrow G_{n} G_{p} U_{G G} d p+U_{G} G_{n p} d p+\left(G_{n}\right)^{2} U_{G G} d n+U_{G} G_{n n} d n \\
& =\left(z_{n}\right)^{2} U_{x x} d n+U_{x} z_{n n} d n \\
& \Rightarrow\left[G_{n} G_{p} U_{G G}+U_{G} R_{n}\right] d p=-\left[\left(G_{n}\right)^{2} U_{G G}+U_{G} G_{n n}-\left(z_{n}\right)^{2} U_{x x}-U_{x} z_{n n}\right] d n \\
& \Rightarrow \frac{d n_{1}^{r^{*}}}{d p}=-\frac{G_{n} G_{p} U_{G G}+U_{G} G_{n p}}{\left(G_{n}\right)^{2} U_{G G}+U_{G} G_{n n}-\left(z_{n}\right)^{2} U_{x x}-U_{x} z_{n n}}
\end{aligned}
$$

It follows that the effect of a change in the resource price will depend upon the sign of this complicated expression. Note first, however, that the denominator of equation (A2.2) is the second order condition for maximization and this condition requires the denominator to be negative. Hence the sign of (A2.2) depends only on the sign of the numerator in equation (A2.2) -- if the term in the numerator is positive, the overall sign is positive, and if negative, the sign is negative. 
At the end of this appendix we derive in detail the sign of each of the terms in this expression. Here it is sufficient to note that the first term in the numerator is negative, while the second term is positive. That is,

$$
\mathrm{G}_{\mathrm{n}} \mathrm{G}_{\mathrm{p}} \mathrm{U}_{\mathrm{GG}}<0 \text {, and } \mathrm{U}_{\mathrm{G}} \mathrm{G}_{\mathrm{np}}=\mathrm{U}_{\mathrm{G}} \mathrm{R}_{\mathrm{n}}>0 \text {. }
$$

It follows immediately that the numerator can be either negative or positive depending on absolute size of these two effects. When region 1 is in control of resource use, the effect of resource exploitation on agricultural productivity is internalized. Hence the rise in the resource price has two offsetting effects on decision making. First, the rise in the resource price increases the revenue generated from the same level of resource exploitation and thus increases the amount of the public good that can be produced from the same level of effort. Then because more public goods encounter diminishing returns, there is the possibility that net gains can be made by transferring employment from the natural resource back into agriculture. This is the meaning of the first term $G_{n} G_{p} U_{G G}<0$. On the other hand, the rise in the resource price also increases the productivity of labour use in the resource sector and since more resource use generates utility through more public goods its overall effect is positive, i.e., $U_{G} G_{n p}=U_{G} R_{n}>0$. For these reasons, a rise in the price of resource may not lead to further increase in resource exploitation, with region 1 in control of resource use. Depending on the strength of these two effects, with $\mathrm{G}_{\mathrm{p}}>0$ region 1 may use the increase in revenue from the increase in resource price to increase both the level of the public good (decrease $\mathrm{U}_{\mathrm{G}}$ ) and increase private consumption by cutting back on resource exploitation (increase $R_{n}$ and $z(e)$ ) to maintain the equilibrium defined by the FOC. It follows that an increase in price of resources may 
actually lead to a decrease in resource exploitation, when region 1 controls resource use under federalism, or with region 1 in majority under unitarism. This need not come at the expense of region 2. Since more of the public good will be produced in either case, region 2 only gains from any resource price increase.

By relaxing the condition that the second order condition for a first order maximum holds, we see from equation (A2.2) that the sign denominator depends on the marginal utilities of the public and private goods. This in turn depends on the level of resource that has already been produced. $U_{x 1}$ is high when private consumption in region 1 is low (high resource exploitation and externality), and it is low at low levels of externality. Hence the since of the denominator and also equation (A2.2) may strongly depend on the level of resource use.

\section{Case 2 Region 2 has control of resource use}

Region 2 is unaffected by the externality produced by resource exploitation and so does not take this consideration into account when setting optimal resource use. Hence when region 2 is in control of resource use, the response to changes in the price of resource, from the first order condition (equation (2.13)) will be given by

$$
\mathrm{U}_{\mathrm{G}} \mathrm{G}_{\mathrm{n}}=0
$$

The comparative static effect of a change in the resource price on the optimal level of resource exploitation for region 2 can then be solved in the same way. That is, preserving 
the equality while taking the differential of (A2.4) (and allowing only $p$ and $n$ to vary) we find

$$
\begin{aligned}
& G_{n} G_{p} U_{G G} d p+U_{G} G_{n p} d p=-\left(G_{n}\right)^{2} U_{G G} d n-U_{G} G_{n n} d n \\
& \Rightarrow \frac{d n_{2}^{r^{*}}}{d p}=-\frac{G_{n} G_{p} U_{G G}+U_{G} G_{n p}}{\left(G_{n}\right)^{2} U_{G G}+U_{G} G_{n n}}
\end{aligned}
$$

Once again the denominator of (A2.5) is the second order condition now for region 2 and for maxima, its sign must be negative. Again, the overall sign will depend upon the sign of the numerator that appears to be the same as above. The appearance is deceptive, however, because the levels of resource use are quite different in the two cases.

To sign the numerator, note that the second term of the numerator of (A2.5) is positive as before. On the other hand, from the first order condition, because $U_{G} G_{n}=0$, and $\mathrm{U}_{\mathrm{G}}>0$, it follows that

$$
\mathrm{G}_{\mathrm{n}}=\mathrm{pR}_{\mathrm{n}}-\left(\mathrm{z}+\mathrm{n}^{\mathrm{r}} \mathrm{z}_{\mathrm{n}}\right)=0 .
$$

It follows that an increase in the price of resources by increasing productivity in the resource sector will trigger an expansion of the resource sector so that in the new equilibrium $R_{n}$ falls and $n^{r}$ rises. Thus the response is to invariably increase resource production if the optimality condition is to hold for region 2 . Thus, by imposing the region 2's optimality condition equation (A2.5) reduces to 


$$
\begin{aligned}
& \Rightarrow \frac{d n_{2}^{r^{*}}}{d p}=-\frac{U_{G} G_{n p}}{U_{G} G_{n n}}>0 \\
& \Rightarrow \frac{d n_{2}^{r^{*}}}{d p}=-\frac{G_{n p}}{G_{n n}}=-\frac{R_{n}}{G_{n n}}>0 \\
& \text { for } G_{n}=0 ; \quad G_{n n}<0 ; G_{n p}=R_{n}>0
\end{aligned}
$$

The salient issue here is that if all regions suffered equally the externality from resource use, or if mobility across regions were seamless and without hindrance, the response to this change in resource value would be common and underscored by voter unanimity. The divergence in the proposed responses by the various regions, which in only some cases will add fuel to the conflict is due to the fact that the externality is not suffered by all and mobility to escape it was limited.

Detailed derivation of the signs of the comparative static terms used above:

Recall the assumptions of the model:

$\mathrm{z}_{\mathrm{e}}<0 ; \mathrm{e}_{\mathrm{R}}>0 ; \mathrm{R}_{\mathrm{n}}>0$, and

$\mathrm{z}_{\mathrm{ee}}<0 ; \mathrm{e}_{\mathrm{RR}}>0 ; \mathrm{R}_{\mathrm{nn}}<0$

$\mathrm{z}_{\mathrm{n}}=\mathrm{z}_{\mathrm{e}} \mathrm{e}_{\mathrm{R}} \mathrm{R}_{\mathrm{n}}<0$

then

$z_{n n}=z_{e e}\left(e_{R} R_{n}\right)^{2}+z_{e} e_{R R}\left(R_{n}\right)^{2}+z_{e} e_{R} R_{n n}<0$

$\mathrm{G}=\mathrm{pR}(\mathbf{n})-\mathrm{nd}$ 
Recall also that for regions 1 and 2, the first order conditions (foc) for utility maximization are given, for region 1 by

$U_{G} G_{n}-U_{x} z_{n}=0$

and for region 2 by

$\mathrm{U}_{\mathrm{G}} \mathrm{G}_{\mathbf{n}}=0$

If the focs define a maxima, then the socs are all negative. That is, for region 1

$\mathrm{U}_{\mathrm{GG}}\left(\mathrm{G}_{\mathrm{n}}\right)^{2}+\mathrm{U}_{\mathrm{G}} \mathrm{G}_{\mathrm{nn}}+\left[\mathrm{U}_{\mathrm{xx}}\left(\mathrm{z}_{\mathrm{n}}\right)^{2}+\mathrm{U}_{\mathrm{x}} \mathrm{z}_{\mathrm{nn}}\right]<0$

Similarly for region 2

$\mathrm{U}_{\mathrm{GG}}\left(\mathrm{G}_{\mathrm{n}}\right)^{2}+\mathrm{U}_{\mathrm{G}} \mathrm{G}_{\mathrm{nn}}<0$

Since in regions with resource conflicts, which are mostly poor, the levels of the public good is such that

$\mathrm{U}_{\mathrm{G}}>0$,

Thus for region 1 , the optimal level of resource exploitation, taking into account the externality, is defined by

$\mathrm{U}_{\mathrm{G}} \mathrm{G}_{\mathrm{n}}=\mathrm{U}_{\mathrm{x}} \mathrm{z}_{\mathrm{n}}$

hence

$\mathrm{G}_{\mathrm{n}}=\mathrm{pR}$ n $-\mathrm{z}-\mathrm{nz}_{\mathrm{n}}>0$

And for region 2

$\mathrm{G}_{\mathrm{n}}=\mathrm{pR} \mathrm{R}_{\mathrm{n}}-\mathrm{z}-\mathrm{nz} \mathrm{z}_{\mathrm{n}}=0$

$\mathrm{G}_{\mathrm{nn}}=\mathrm{pR} \mathrm{R}_{\mathrm{nn}}-2 \mathrm{z}_{\mathrm{n}}-\mathrm{nz}_{\mathrm{nn}}<0$

$G_{n p}=R_{n}>0$. 


\section{Appendix 2.2: Altruism and Resource Related Conflict}

As noted in section 2.1, the level of education has been found to be low in most resource rich, conflict-laden countries. This is compounded by the fact that the negative externality from resource exploitation is not evenly distributed across jurisdictions. How might the individual voting pattern be impacted by higher levels of education and information on the negative impact of externality in the resource producing jurisdictions? Would a cross-geographical contact and interaction impact the individual voting decision? To what extent would conditions such as deeper relationships among individuals across jurisdictions impact the region of conflict in terms of the level of resources to exploit? What form of political decision making, federalism or unitarism, would be more efficient when cross-jurisdictional contact and education on externality are encouraged and implemented? This section will investigate these questions by introducing altruism and information level in the inter-jurisdiction model of section 2.4.

In this section, it will be shown that in a country where individuals care about the general well being of all inhabitants, public education serves as a powerful instrument in the resolution of resource related conflicts. However, it is not in the interest of vote maximizing politicians from the majority region to deploy such truthful public education instrument, because it creates an opportunity for politicians from the minority, externality suffering regions to win national elections based on level of resource exploitation.

Recall the equations (2.1)- (2.5)

$$
\mathrm{U}_{\mathrm{i}}(\mathrm{x}, \mathrm{G})=\mathrm{U}(\mathrm{x})+\mathrm{U}(\mathrm{G}) \quad \text { where } \mathrm{U}_{\mathrm{x}}, \mathrm{U}_{\mathrm{G}}>0, \mathrm{U}_{\mathrm{xx}}, \mathrm{U}_{\mathrm{GG}}<0 .
$$




$$
\begin{aligned}
& R=R\left(n^{r}\right) \quad \text { where } R(n) \text { satisfies the Inada conditions } \\
& G=p R\left(n^{r}\right)-n^{r} d \\
& e=e(R) \quad \text { with } e(0)=0, e_{R}>0, e_{R R}>0 \\
& \text { and } \quad x=d=z(e) \quad z_{e}<0, z_{e e}<0 .{ }^{1}
\end{aligned}
$$

Introducing the extra assumption that voters care about absolute level of private consumption in both regions, and the higher the better. Let $\tau$ be the proportion $[0 \leq \tau \leq 1]$ of informed voters and $1-\tau$ is the proportion of uninformed voters. Hence, the probability that a randomly selected voter is informed of the negative impact of externality due to resource exploitation is $\tau$.

Let $\theta$ be a binary indicator, zero (0) if voter is uninformed and one (1) if voter is informed.

Let $\alpha_{\mathrm{ij}}$ be the marginal impact on the utility of a typical individual in jurisdiction $\mathrm{i}$, due to a unit private consumption by an individual in jurisdiction $\mathrm{j}\left(0 \leq \alpha_{\mathrm{ij}} \leq 1\right)$. For simplicity we assume that $\alpha_{\mathrm{ij}}=\alpha_{\mathrm{ji}}=\alpha$. Individuals in any region care equally about consumption level in the other region. Hence,

$$
U_{i}=U\left(x_{i}\right)+\theta U\left(\alpha x_{j}\right)+U(G)
$$


The representative individual randomly chosen is informed with probability $\tau(\theta=1)$, or is uninformed with probability $1-\tau(\theta=0)$. Assume that policy makers and politicians know the proportion of informed voters, but do not know the individual voter that is informed or uninformed. Hence, the utility of a typical resident of region 2 that is unimpacted by resource exploitation is given by:

$\mathrm{U}_{2}=\tau\left[\mathrm{U}\left(\mathrm{x}_{2}\right)+\mathrm{U}\left(\alpha \mathrm{x}_{1}\right)+\mathrm{U}(\mathrm{G})\right]+(1-\tau)\left[\mathrm{U}\left(\mathrm{x}_{2}\right)+\mathrm{U}(\mathrm{G})\right]$

It is important to note that since the private consumption of individuals in region 2 is not impacted by resource exploitation, the optimal level chosen by residents of region 1 who are impacted in the presence of altruism does not differ from the level chosen without altruism. For this reason we shall concentrate on the equilibrium shifting decision, which is the analysis of the optimal level chosen by residents of jurisdiction 2 , the unimpacted region, whose utility is affected by the level of private consumption of residents of region 1 . The private consumption of region 1 residents is negatively impacted by the level of resource exploitation.

Choosing $\mathrm{n}^{\mathrm{r}}$, we maximize the utility of a typical resident of region 2 ,

$\mathrm{U}_{2}=\tau\left[\mathrm{U}\left(\mathrm{x}_{2}\right)+\mathrm{U}\left(\alpha_{\mathrm{x}}\right)+\mathrm{U}(\mathrm{G})\right]+(1-\tau)\left[\mathrm{U}\left(\mathrm{x}_{2}\right)+\mathrm{U}(\mathrm{G})\right]$

Subject to the constraints defined in equations (2.2) - (2.5).

Here the first order condition for that internal optimum is 
$\mathrm{dU}_{2} / \mathrm{dn}_{\mathrm{i}}^{\mathrm{r}}=\tau\left[\mathrm{U}_{\mathrm{x}}\left(\mathrm{x}_{2}\right) \mathrm{dx} \mathrm{x}_{2} / \mathrm{dn}_{\mathrm{i}}^{\mathrm{r}}+\alpha \mathrm{U}_{\mathrm{x}}\left(\alpha \mathrm{x}_{1}\right) \mathrm{dx}_{1} / \mathrm{dn}_{\mathrm{i}}^{\mathrm{r}}+\mathrm{U}_{\mathrm{G}} \mathrm{dG} / \mathrm{dn}_{\mathrm{i}}^{\mathrm{r}}\right]+(1-\tau)\left[\mathrm{U}_{\mathrm{x}} \mathrm{dx}_{2} / \mathrm{dn}_{\mathrm{i}}^{\mathrm{r}}+\mathrm{U}_{\mathrm{G}}\right.$ $\left.\mathrm{dG} / \mathrm{dn}_{\mathrm{i}}^{\mathrm{r}}\right]=0$, where $\mathrm{U}_{\mathrm{x}}>0$ and $\mathrm{U}_{\mathrm{G}}>0$

where i. $\mathrm{dx}_{1} / \mathrm{dn}_{\mathrm{i}}^{\mathrm{r}}=\mathrm{dz}[\mathrm{e}(\mathrm{R}(\mathrm{n}))] / \mathrm{dn}_{\mathrm{i}}^{\mathrm{r}}=\mathrm{z}_{\mathrm{e}} \mathrm{e}_{\mathrm{R}} \mathrm{R}_{\mathrm{n}}<0$

$$
\text { ii. } \mathrm{dx}_{2} / \mathrm{dn}_{\mathrm{i}}^{\mathrm{r}}=0
$$

and iii. $d G / d n^{r}=p R_{n}-d-n\left[d d / d n=d x / d n=z_{e} e_{R} R_{n}\right]$

$$
=p R_{n}-z(e)-n z_{e} e_{R} R_{n} .
$$

Equation (B2.2) becomes

$$
\tau \alpha U_{\mathrm{x}}\left(\alpha \mathrm{x}_{1}\right) \mathrm{dx_{1 }} / \mathrm{dn}_{\mathrm{i}}^{\mathrm{r}}+\mathrm{U}_{\mathrm{G}} \mathrm{dG} / \mathrm{dn}_{\mathrm{i}}^{\mathrm{r}}=0
$$

Hence,

$$
\begin{aligned}
& \tau \alpha U_{x}\left(\alpha x_{1}\right) z_{e} e_{R} R_{n}+U_{G}\left[p R_{n}-z(e)-n z_{e} e_{R} R_{n}\right]=0 \\
& \Rightarrow U_{G}\left[p R_{n}-z(e)-n z_{e} e_{R} R_{n}\right]=\tau \alpha U_{x}\left(\alpha x_{1}\right) z_{e} e_{R} R_{n}
\end{aligned}
$$

Recall the following equations

Social Optima without altruism and information on externality

$$
\mathrm{U}_{\mathrm{G}}^{\mathrm{s}}\left(\mathrm{n}^{\mathrm{r}}\right)\left[p R_{n}-d-n^{r} z_{e} e_{R} R_{n}\right]=\frac{\mathrm{n}_{1}}{N} U_{x}(x)\left[-z_{e} e_{R} R_{n}\right]
$$

Federalism with and without altruism

$$
\mathrm{U}_{\mathrm{G}}^{\mathrm{f}}\left(\mathrm{n}^{\mathrm{r}}\right)\left[p R_{n}-d-n^{r} z_{e} e_{R} R_{n}\right]=U_{x}(x)\left[-z_{e} e_{R} R_{n}\right]
$$




\section{Unitarism without altruism}

$$
\begin{aligned}
& n_{1}<n_{2} \\
& U_{G}^{u}\left(n_{u}{ }^{r}\right)\left[p R_{n}-z(e)-n^{r} z_{e} e_{R} R_{n}\right]=0
\end{aligned}
$$

The significance of altruism (being-thy-brother's-keeper) and level of information in resolving resource related conflict lies in the following:

a) Given the proportion of informed voters $\tau$ and the degree to which voters care about poverty $\alpha$, the term $\alpha \tau<1$ measures the degree to which the voters from region 2 agree with the socially optimal level of exploitation $\left(n_{1} / \mathrm{N}\right)$, and the position of voters from impacted region. Voters from region 2 seek to apply a factor, $\alpha \tau$ (a partial consideration) to the negative impact of resource exploitation, governed by the degree to which they care $(\alpha)$, and the proportion of informed voters $(\tau)$. Voters from region 1 , insist on full consideration of the negative impact of resource exploitation by applying a factor of one. The socially optimal level applies a factor reflective of the proportion of impacted population to benefiting population.

b) It is highly improbable that individuals will care about the private consumption of others as well as they care about their own consumption. Thus it is highly unlikely that $\alpha$ will ever reach one. Also, in countries characterized by low levels of education and incomplete information $\tau$ will not equal one. Finally, the cost of fully informing every individual in the country on the 
impact of negative externality due to resources exploitation is excessively high. For these reasons, since $n_{1} / N<1$, it becomes easier to achieve $\alpha \tau=n_{1} / N$ (the majority agreeing with the socially optimal level), than it is to achieve $\alpha \tau=1$ (majority agreeing with the minority, on the terms of the minority impacted region).

c) To the extent that voters from region 2 care about poverty in region 1, and to the extent they are informed on the impact of the resource exploitation, are willing to vote for a lower level of exploitation, to lower levels of poverty. Concavity of the utility function encourages this trade-off at high levels of public good. Hence, as $\alpha \tau$ approaches $n_{1} / \mathrm{N}$, the majority position approaches the socially optimal level of exploitation. Since in a unitary system this majority dictates public policy, it follows that under the assumption of altruism, and information on negative impact of exploitation, social efficiency in resource exploitation becomes more likely under unitarism than under federalism. This is because of the fact that the private consumption of the majority is not impacted by the exploitation, and the public good produced is consumed by residents of impacted and unimpacted regions in similar manner. Therefore, the optimization result of residents of region1 with altruism is similar to that without altruism. This makes the solution under federalism unchanged irrespective of the introduction of information and altruism in the utility function. 
d) This result with altruism makes it increasingly difficult for politicians to win elections on the platform of excessively high resource exploitation, a situation favoured by politicians from majority region in the model without altruism and informed voters. Hence, under unitarism, politicians from minority or majority region standing on the platform of exploitation near the socially optimal level have better chance of winning a national election than those clinging to excessively low, or excessively high levels of exploration. In this sense, altruism and the flow of information among the voters in the majority region forces a convergence of policy platforms towards the socially optimal level. This nature of convergence holds the potential for conflict resolution in countries suffering from resource related conflict. It dissolves the geographic heterogeneities fuelling the conflict in a crucible of altruism and voters education.

e) Policy instruments which can be deployed to encourage altruism in the sense of caring about the level of poverty across regions are those which support cross-country (cross-cultural) contact among residents of a country. For instance intercultural marriages, sports, national integration policies, etc.

Altruism and voter information lead the majority of voters from the unimpacted region to choose a more centrist exploitation level, a position near the social optima level. This expands the political space for national majority enjoyed by politicians from the majority region, because politicians from the minority who are centrist can now solicit majority votes. It becomes clear that such politicians will use voters' information and 
education on the negative impact of resource exploitation as an instrument to win more votes, especially the majority vote in national elections. These candidates will support voter education as public policy measure in resolving resource related conflict. However, politicians from the majority region, who do not wish to expand the majority political space to more competition, especially from minority candidates, will be less likely to support voter education, since this erodes their support base, and opens them to more competition. Their opposition to voter education and information, which is rational from a vote maximizing point of view, will continue to keep the wedge between residents of impacted, and unimpacted regions. This keeps the conflict going. 


\section{CHAPTER 3}

\section{Mobility and Welfare in Resource Developing Democracies with Externality}

\subsection{The role of mobility and welfare in the resolution of resource- related conflict}

As noted in Chapter 2, the degree of mobility of individuals between regions is often low in the resource rich, conflict-laden countries of the south and its incorporation into the model adds realism at the cost of removing one of the traditional means by which income inequality can be minimized. Moreover, the problem created by the lack of worker mobility is often compounded by the uneven spatial distribution of negative externalities arising from resource exploitation. How would resource use and income distribution be affected by higher levels of mobility across regions? Would the ability of individuals to relocate to escape the negative externality influence voting outcomes? Would cross-geographical contact and interaction impact the individual voting decision for better or worse? To what extent would conditions fostering deeper relationships among individuals across jurisdictions impact the region of conflict in terms of the level of resources to exploit? What form of political decision making, federalism or unitary, would be more socially efficient when cross-jurisdictional contact and mobility are in effect? This chapter investigates these questions by allowing both changes in the 
willingness of individuals to relocate and changes in the net value received once relocation is realized.

Recall that in the absence of mobility, our model is characterised by equations (1) - (5), repeated for convenience below.

$$
\begin{aligned}
& U_{i}(x, G)=U(x)+U(G) \quad \text { where } U_{x}, U_{G}>0, U_{x x}, U_{G G}<0 \\
& R=R\left(n^{r}\right) \quad \text { where } R(n) \text { satisfies the Inada conditions } \\
& G=p R\left(n^{r}\right)-n^{r} d \quad \text { with } e(0)=0, e_{R}>0, e_{R R}>0 \\
& e=e(R) \quad z_{e}<0, z_{e e}<0
\end{aligned}
$$

Here the absence of mobility across regions means that there is no reason why utility across individuals across regions will be equalized.

I now allow for the possibility that individuals can migrate across jurisdictions by letting $\rho_{i}(k)$ be the utility premium needed by individual $k$ in region $i, \rho \geq 1$, to leave his or her home region for region $\mathrm{j}$ if the opportunity arose. I assume that the premium above the level of utility received in the home region is unique to each individual and that individuals can be ordered such that $\rho_{\mathrm{i}}(\mathrm{k})$ becomes a strictly decreasing function of $\mathrm{k}$, 
ordered from $1 . . n_{i}$. More formally, $\rho(0)=\infty$ when $k=0, \rho^{\prime}(k)<0$ and $\rho(k)=1$ for $k=n_{i}$. The assumptions imply that at the beginning of our analysis, there is at least one individual in each region who would leave for any positive income differential and, that to induce more individuals to leave, the income premium must increase. $\rho(k)$ then captures all of the objective and idiosyncratic traits and preferences considered by an individual who is faced with the decision to relocate. Note that if at time $t$ we knew or could determine $\rho\left(k^{*}+1\right)$, the equilibrium value of the mobility premium paid to the marginal mover, then $\mathrm{k}^{*}$ would represent the number of individuals choosing to remain in region $i$ and $n_{i}-k^{*}$ the number moving to region $j$ this period. Hence at the beginning of the next period, $\mathrm{n}_{\mathrm{i}, t+1}=\mathrm{k}_{\mathrm{t}}{ }^{*}$ and $\mathrm{n}_{\mathrm{j}, t+1}=\mathrm{n}_{\mathrm{j}, \mathrm{t}}+\left(\mathrm{n}_{\mathrm{i}, t} \mathrm{k}_{\mathrm{t}}{ }^{*}\right)=\mathrm{N}-\mathrm{k}_{\mathrm{t}}{ }^{*}$. Where $\mathrm{N}$ is the total population of the country. This also implies that those who leave are those with less of a commitment to regional culture, language, etc. so that migration from a region leads to a certain type of homogenization of the population about individuals with stronger attachment to regional specific ethnic, cultural and/or language differences.

I also assume that not only do individuals face a cost of leaving but there is also a cost of arrival. That is, not only do departing individuals leave their family, friends and culture behind, but in their new location they face the challenge of gaining a degree of acceptability which makes integration into the new region costly. Cultural, linguistic, religion, and ethnic barriers and differences make the process of resettlement and integration difficult. This cost is assumed to be common to all immigrants across cultures and regions within the country. This is reflected in the discounting of the utility received from otherwise similar income by some factor $\beta_{\mathrm{ij}}, 0 \leq \beta_{\mathrm{ij}} \leq 1$. For convenience we call $\beta_{\mathrm{ij}}$ 
the acceptance barrier that a typical individual in jurisdiction $i$ faces when moving to region $\mathrm{j}$. For simplicity we assume that $\beta_{\mathrm{ij}}=\beta_{\mathrm{ji}}=\beta$, that is, individuals in any region face the same acceptance barrier to mobility. We begin then by assuming that $1 / \beta$ is the exogenous parameter representing the premium that would be needed by residents of region 1 before they considered consumption in region 2 to be equivalent to their current income.

Thus the acceptance cost of mobility, in the sense I wish to use it, refers to the disadvantage experienced by individuals willing to relocate from one geographical region to another within a country. This involves the cost of not gaining cultural and occupational acceptance, together with the costs of being unable to integrate without experiencing some loss of identity or encountering other difficulties related to culture, ethnicity, language, and religion. The case where $\beta=1$ would represent a world of perfect (costless) acceptance among regions where the welfare received from the same level of income in any region is a perfect substitute for income received in the home region. Should the individual feel no particular attachment to their home region, individuals would simply move to any region where income was higher and immediately enjoy that income advantage without experiencing any loss in welfare from leaving home. At the other extreme, $\beta=0$, means that the acceptance cost of relocation is perceived to be prohibitive so that no mobility will actually arise. The utility received by residents of region 1 depend only on the income received and consumed in region 1 and no utility can be gained from earning income in any region other than home. $\beta=0$ then represents the extreme case where strong and distinctive cultural, ideological, language, 
religion, and ethnic differences create prohibitive barriers to the movement and integration of people across geographical and jurisdictional lines. From the point of view of the model, mobility increases in $\beta$. From the point of view of each individual, $\beta$ is exogenous to individual's decision.

Under these assumptions, an individual in region 1 will move to region 2 , if he or she first receives a premium sufficient to consider moving and, second, if that premium income is sufficient to overcome the anticipated acceptance barrier. Moreover, mobility will continue as long as there are individuals for whom these conditions do not hold with equality. That is, the mobility decision rule is for individual $\mathrm{k}$ to move to region 2 if and only if

$$
U\left(x_{2}\right)+U(G)>\rho(k)\left[U\left(x_{1}\right)+U(G)\right]
$$

and

$$
U\left(x_{1}\right)+U(G)<\beta\left[U\left(x_{2}\right)+U(G)\right]
$$

Combining the two mobility constraints, the mobility rule is to move if

$$
U\left(x_{1}\right)+U(G)<(1 / \rho(k)) \beta\left[U\left(x_{2}\right)+U(G)\right], \text { where } 0 \leq 1 / p(k) \leq 1 \text {. }
$$

From the foregoing, it becomes clear that in each time period, each individual now has to make three types of decisions. The first two involve allocative decisions based on the geographic area of residence (how much to work and what level of government public good provision to vote for--the level of resource exploitation and concomitant level of externality) and the third is whether or not to move. 


\section{2 The Choice of Level of Resource Exploitation, and the Choice of Relocation.}

As we have seen, at any particular point in time the equilibrium number of individuals who chose to remain in region $\mathrm{i}$ is $\mathrm{k}_{\mathrm{t}}$ and the equilibrium premium needed to induce movement by the individual at that margin is $\rho\left(\mathrm{k}_{\mathrm{t}}^{*}\right)$. The number exiting region $\mathrm{i}$ and moving to region $\mathrm{j}$ is $n_{\mathrm{it}}-\mathrm{k}_{\mathrm{t}}$. It follows that ex ante the proportion of individuals in region $\mathrm{i}$ who choose to move to region $\mathrm{j}$ in period $\mathrm{t}$ is given by $\left(\mathrm{n}_{\mathrm{it}}-\mathrm{k}_{\mathrm{t}} *\right) / \mathrm{n}_{\mathrm{it}}$ and denoted by $\lambda_{\tau}$. That is,

$$
\lambda_{\mathrm{t}}=\left(\mathrm{n}_{\mathrm{it}}-\mathrm{k}_{\mathrm{t}} *\right) / \mathrm{n}_{\mathrm{it}}
$$

Given that the individual characteristics leading to the need for a mobility premium are unobservable, $\lambda$ can also be interpreted as the probability at the beginning of period $t$ that a randomly selected individual will choose to leave region i. Individuals, themselves, know whether or not they will move, but this information is private not pubicparticularly to policy makers.

Since $\lambda_{\tau}$ depends on $k_{t}{ }^{*}$, it also depends on $\beta$ and $\rho\left(k_{t}{ }^{*}\right)$. Hence all else unchanged, the higher the value of $\beta$, the less opposition there is to all individuals who leave the impacted region and arrive in the unaffected region. This reduces the size of the required mobility premium, $\rho\left(\mathrm{k}^{*}\right)$, increases the number of individuals who seek to leave, $n-k^{*}$, in turn raising $\lambda_{t}$. However, by the end of period $t$ and whatever the value of 
$\rho$, the movement of individuals out of the region will take place until $n_{i}=k_{t} *$ is achieved. Should $\mathrm{k}^{*}$ remain the same in the following period (so that $\rho\left(\mathrm{k}_{\mathrm{t}}^{*}\right)=\rho\left(\mathrm{k}_{\mathrm{t}+1} *\right)$ ), then $\mathrm{n}_{\mathrm{it}+1}=$ $\mathrm{k}_{\mathrm{t}+1} *$ and $\lambda_{\mathrm{t}+1}=0$ in period $\mathrm{t}+1$. Thus for every $\beta$ in period $\mathrm{t}$, there will be a corresponding value of $\rho\left(\mathrm{k}_{\mathrm{t}}^{*}\right)$ which implies, temporarily, a probability of movement by the representative individual out of the impacted region into the unaffected region. $\lambda_{t}$. Should movement itself be instantaneous, in period $t+1$ the mobility premium $\rho$ available for the next low cost mover will be just insufficient to attempt leaving so that no new mobility arises and the probability of further movement falls to zero, i.e., $\lambda_{t+1}=0$. Should movement require a longer period of time, $\lambda_{t+m} \rightarrow 0$ as $\mathrm{m}$ approaches the number of periods required for readjustment.

It follows that for any combination of a given $\beta$ and a distribution of $\rho(k)$ 's, there will be an equilibrium value of $\mathrm{k}^{*}$ such that a transition probability arises in the short run. In the new equilibrium the returns across regions are equalized for the marginal mover. In that equilibrium, described above as in period $t+1$, the marginal potential mover from region $i$ (i.e., individual $k$ ) will have the utility level that satisfies the following equilibrium condition,

$$
U_{k}=U\left(x_{1}, G\right)=\beta / \rho\left(k^{*}\right) U\left(x_{2}, G\right) .
$$

All other (even higher cost) potential movers from region 1 who choose to remain experience the same level of utility as the marginal mover, i.e., $U_{i}=U\left(x_{1}, G\right)$ for all $i=$ 
1...*. This implies that only to the marginal mover (voter), will the utility received in region 1 be a perfect substitute for the utility realizable in region 2 , although at any given period the individual can either be in region 1 or 2, but not both.

In region 2, incumbent residents continue to receive the utility level

$$
\mathrm{U}_{\mathrm{j}}=\mathrm{U}\left(\mathrm{x}_{2}, \mathrm{G}\right) \quad \forall \mathrm{j}=\mathrm{n}_{\mathrm{i}}, \ldots \mathrm{N}, \text { or } \mathrm{n}_{2} \text { in total. }
$$

Finally, those individuals who have emigrated from region 1 to region 2 (i.e., $\mathrm{n}_{1}-\mathrm{k}^{*}$ individuals) experience an intermediate level of utility, That is,

$$
\mathrm{U}_{\mathrm{i}}=[\beta / \mathrm{\rho}(\mathrm{i})] \mathrm{U}\left(\mathrm{x}_{2}, \mathrm{G}\right) \quad \forall \mathrm{i}=\mathrm{k}+1 \ldots \mathrm{n}_{1},
$$

where for individual $i=n_{1}$, the discount from the level of utility realized by region 2 incumbents is equal to $\beta / \rho$ and this falls successively for arrivals until the level of utility received by the $\mathrm{k}+1$ individual is $[\beta / \rho(\mathrm{k}+1)] \mathrm{U}\left(\mathrm{x}_{2}, \mathrm{G}\right)$ which is only marginally above the utility level received by those remaining in region 1 .

Because we have assumed that productivity is constant in the unaffected agricultural region 2 and no taxes are paid, the level of consumption that can be achieved by any worker in region 2 is $x_{2}$, independent of the number of workers in region 2 . Thus unless the movement of individuals across regions results in a different level of the public good produced (and because of this a different level of the externality and hence $x_{1}$ ), then the only individuals who gain from mobility are the actual movers themselves whose 
utility will rise by a degree that depends upon the discount factor $[\beta / \rho(i)]$. The gain is largest for the lowest cost mover (i.e., $\mathrm{n}_{1}$ ) and the gain falls to zero as we approach $\mathrm{j}=$ $k+1$.

The analysis then distinguishes three different cases:

i. When the original difference in utility across regions is small and/or regional differences across groups so large that no mobility ever arises. In this case,

$$
\mathrm{U}\left(\mathrm{x}_{2}, \mathrm{G}\right)>\mathrm{U}\left(\mathrm{x}_{1}, \mathrm{G}\right) \text { but }\left[\beta / \rho\left(\mathrm{n}_{\mathrm{i}}\right)\right] \mathrm{U}\left(\mathrm{x}_{2}, \mathrm{G}\right)<\mathrm{U}\left(\mathrm{x}_{1}, \mathrm{G}\right) \text {. }
$$

The model discussed in Chapter 2 assumes that this condition holds so that the implications of this case have already been discussed. The rest of this chapter then considers the implications of cases ii and iii.

ii. When the original difference in utility across regions is large enough to induce some mobility but not enough to induce a change in the voting majority across regions. This can occur either because $n_{2}>n_{1}$ originally, or because $n_{1}>n_{2}$ and $\mathrm{n}_{1}-\mathrm{k}^{*}$ is relatively small so that $\mathrm{k}^{*}>\mathrm{n}_{2}+\left(\mathrm{n}_{1}-\mathrm{k}^{*}\right)$. In this case,

$$
\mathrm{U}\left(\mathrm{x}_{2}, \mathrm{G}\right)>\left[\beta / \rho\left(\mathrm{n}_{\mathrm{i}}\right)\right] \mathrm{U}\left(\mathrm{x}_{2}, \mathrm{G}\right)>\mathrm{U}\left(\mathrm{x}_{1}, \mathrm{G}\right) .
$$

iii. When the original difference in utility across regions induces enough migration that the majority shifts from the impacted region 1 to the unaffected region 2 . 
This case introduces two additional effects. First, the change in the location of the democratic majority to region 2 means that in a unitary system, the majority now votes for a larger level of G. Hence the G in equation (3.15) is larger. Second, that higher level of $\mathrm{G}$ implies more pollution and hence a lower level of productivity in region 1. This in turn means that the level of consumption achievable in region $1, x_{1}$, will fall which will induce even more migration to region 2. Together these conditions mean that in the new equilibrium

$$
\mathrm{U}\left(\mathrm{x}_{2}, \mathrm{G}^{\prime}\right)>\left[\beta / \rho\left(\mathrm{k} *^{\prime}\right)\right] \mathrm{U}\left(\mathrm{x}_{2}, \mathrm{G}^{\prime}\right)=\mathrm{U}\left(\mathrm{x}_{1}{ }^{\prime}, \mathrm{G}^{\prime}\right)<\mathrm{U}\left(\mathrm{x}_{1}, \mathrm{G}\right)
$$

where $x_{1}{ }^{\prime}<x_{1}, G^{\prime}>G$, and $U\left(x_{1}{ }^{\prime}, G^{\prime}\right)<U\left(x_{1}, G\right)$ so that $k^{* \prime}<k^{*}$.

In the next two sections the impact of this migration on the political and social stability ${ }^{9}$ and on the individual and social welfare will be examined in more detail.

Recall from equation (3.11) that the individual, $\mathrm{k}$, at the margin of the migration decision is just indifferent between living in region 1 or region 2 so that

$$
U_{k}=U\left(x_{1}, G\right)=\beta / \rho(k *) U\left(x_{2}, G\right) .
$$

However, while utility stays constant, the way the individual will vote may depend upon

\footnotetext{
${ }^{9}$ Here political stability implies a stable political equilibrium underlined by voters' decision to sustain a given democratic electoral outcome when faced with similar set of alternatives. It means that when voters vote for a given platform in a given election, the outcome of the next vote cycle is predictable from the choice made by voters in the current cycle. Social stability is used to capture the deviation from (or
} 
their region of residence. For example, if that individual stays behind, then the voting choice for the optimal level of $\mathrm{G}$ through $\mathrm{n}^{\mathrm{r}}$ remains unchanged. But if the marginal mover does move into region 2 , then level of $\mathrm{G}$ that is now optimal may change (as will be the case for all other intra-marginal movers). This is because the productivity of labour they now experience is higher in the region unaffected by pollution. Hence the level of consumption they will receive is now higher. Overall, the intra-marginal immigrants will be subject to two offsetting effects. First, like other region 2 residents who have been in place for generations, there will be a tendency to want more government services and hence vote for more resource output (since the resulting pollution will not now affect them). On the other hand, because the value of the higher income received and government services must be discounted (because their consumption takes place in a community that is not familiar and somewhat uninviting) this means that the marginal value of government services will also be lower.

More formally, those individuals who move to region 2 now would wish to choose the $\mathrm{n}^{\mathrm{r}}$ that maximizes the utility given by

$$
\mathrm{U}_{1}=\beta / \rho\left(\mathrm{k}^{*}\right)\left[\mathrm{U}\left(\mathrm{x}_{2}\right)+\mathrm{U}(\mathrm{G})\right]
$$

subject to the constraints defined in equations (3.2) - (3.5).

Here the first order condition (FOC) for an internal optimum is

rejection of) a constitutional provision, or electoral outcome brought about by individual or group 
$\mathrm{dU}_{1} / \mathrm{dn}_{\mathrm{i}}{ }^{\mathrm{r}}=\beta / \rho\left[\mathrm{U}_{\mathrm{x}}\left(\mathrm{x}_{2}\right) \mathrm{dx} \mathrm{x}_{2} / \mathrm{dn}_{\mathrm{i}}{ }^{\mathrm{r}}+\mathrm{U}_{\mathrm{G}} \mathrm{dG} / \mathrm{dn}_{\mathrm{i}}{ }^{\mathrm{r}}\right]=0$,

where $U_{x}>0$ and $U_{G}>0$

where

i. $\mathrm{dx}_{2} / \mathrm{dn}_{\mathrm{i}}^{\mathrm{r}}=0$

and ii. $d G / d n^{r}=p R_{n}-d-n\left[d d / d n=d x / d n=z_{e} e_{R} R_{n}\right]$

$$
=p R_{n}-z(e)-n z_{e} e_{R} R_{n} .
$$

Equation (3.18) becomes

$$
\beta / \rho^{*} \mathrm{U}_{\mathrm{G}} \mathrm{dG} / \mathrm{dn}_{\mathrm{i}}^{\mathrm{r}}=0
$$

or,

$$
\left[\beta / \rho^{*}\right] U_{G}\left[p R_{n}-z(e)-n z_{e} e_{R} R_{n}\right]=0
$$

where $\beta / \rho \leq 1$ (the mobility factor), since $\beta \leq 1$ and $\rho(k) \geq 1$. Note that since the cost of leaving differs across individuals, the gap between the optimal level of $\mathrm{G}$ chosen by region 2 voters and the marginal immigrant increases in the number of individuals arriving.

Notice that when mobility $\beta=0$, or $\rho$ is very large relative to $\beta$ (the cost to individual is very large relative to the opportunities afforded by movement), the case for prohibitive 
barriers to mobility, or when regional differences are so large that no mobility ever arises, the solution given by equation (3.22) coincides with the solution of federalism given by

$U_{G}\left[p R_{n}-z(e)-n z_{e} e_{R} R_{n}\right]=U_{x}\left(x_{1}\right) z_{e} e_{R} R_{n}$

This is because the marginal voter does not move, thus, this voter votes with the impacted region as discussed in chapter 2, enjoying equal benefits and suffering similar externality cost with those in region 1.

In Figure 6 below, curve A represents the marginal utility (benefit) of the public good enjoyed by residents of region 1, and original residents of region 2. Curve B is the marginal utility (benefit) of public good enjoyed by original residents of region 1 who have migrated to region 2 . It shows the discounted marginal utility due to resistance to mobility and degree of acceptability in the new region 2. Curve B is everywhere below curve A because residents of region 1 who migrate to region 2 suffer integration challenges, both for their attachment to their region 1, and the degree to which they are accepted by residents of region 2. Curve A and B converge at the point where the marginal utility of the public good is zero for all residents. The significance of this point lies in the fact that in the vote for public good, this is the optimal point for residents of region 2 who are not affected by the negative externality. This is also the point chosen by those individuals who have moved from region 1 to region 2 . Since these individuals have now escaped the externality, in order to maximize their private utility from the public good, they chose this level of public good where the marginal utility is zero, this is 
the point of political convergence between the original residents of region 2 and the new migrants to region 2 .

Curve $\mathrm{C}$ is the marginal disutility (cost) curve facing residents of region 1 as a result of the externality from resource exploitation. The marginal cost curve reflects the impact of resource exploitation on private consumption in region 1 , which is not faced by region 2 . The shaded portion of the graph, $\mathrm{D}$, is the net damage faced by only residents of region 1 when the exploitation of the resources is driven to the point where the marginal utility of the public good is zero- the point favoured by the unimpacted region 2 . 
Figure 6: Optimal Exploration Level and Welfare of Migrants

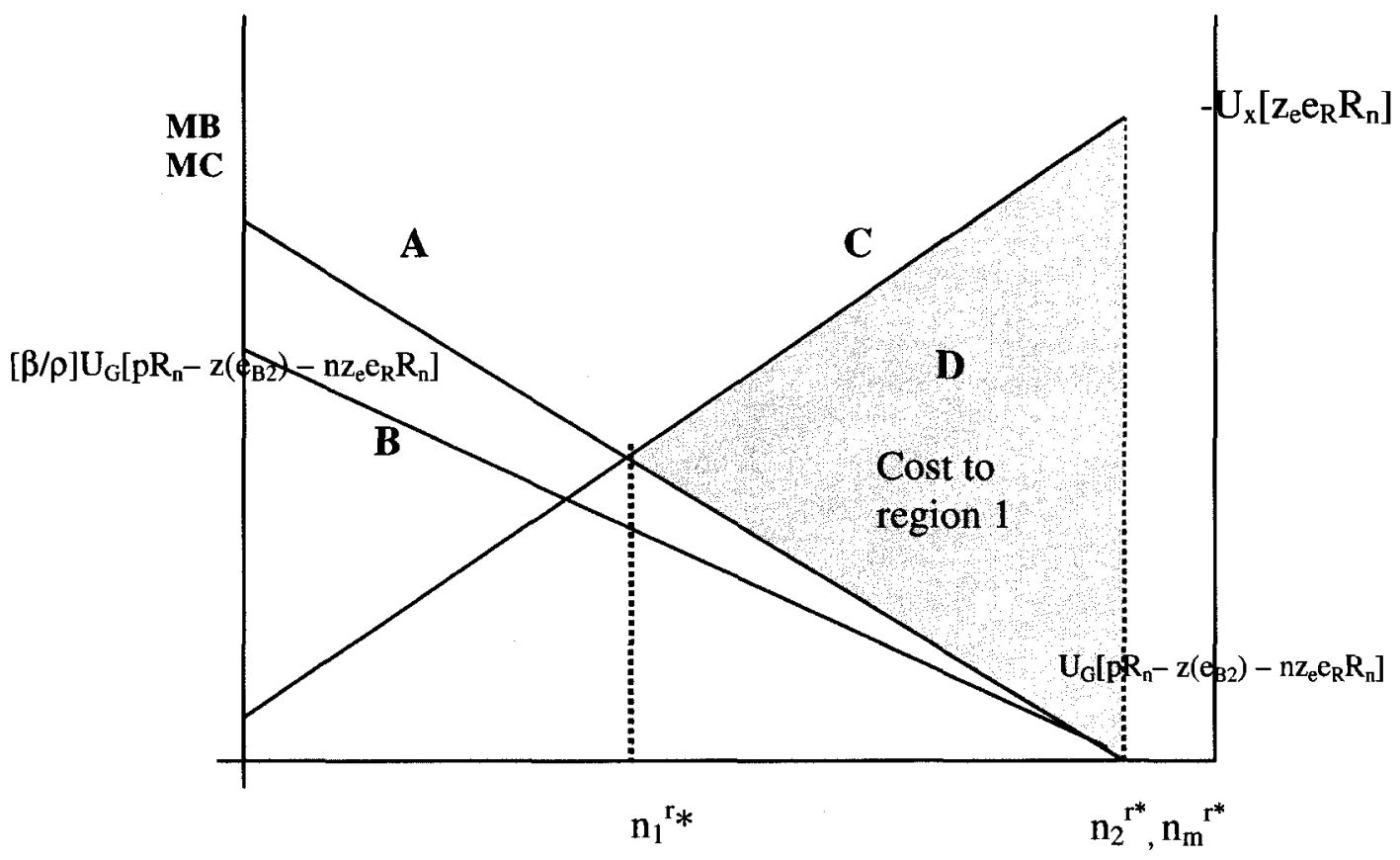


Each individual in region 1 will choose whether to leave or not depending on

a) their particular value of $\rho(k)$

and

b) the common discounting of the utility of income (i.e. $\beta$ ) because of others' acceptance of their cultural, linguistic, religious, and ethnic difference.

Then the mobility decision for individual $\mathrm{k}$ would be to leave if, and only if, both circumstances covered the cost, that is if, and only if,

$$
\mathrm{U}\left(\mathrm{x}_{1}(\mathrm{e})\right)+\mathrm{U}\left(\mathrm{G}\left(\mathrm{n}^{\mathrm{r}}\right)\right)<\beta / \rho\left(\mathrm{k}^{*}\right)\left[\mathrm{U}\left(\mathrm{x}_{2}\right)+\mathrm{U}\left(\mathrm{G}\left(\mathrm{n}^{\mathrm{r}}\right)\right)\right]
$$

Moreover, individuals would leave region 1 until this condition is met with equality. Hence the condition

$$
\mathrm{U}\left(\mathrm{x}_{1}(\mathrm{e})\right)+\mathrm{U}\left(\mathrm{G}\left(\mathrm{n}^{\mathrm{r}}\right)\right)=\beta / \rho\left(\mathrm{k}^{*}\right)\left[\mathrm{U}\left(\mathrm{x}_{2}\right)+\mathrm{U}\left(\mathrm{G}\left(\mathrm{n}^{\mathrm{r}}\right)\right)\right]
$$

determines $\mathrm{k}^{*}$, the individual on the margin who is indifferent between leaving and staying. This will imply 
a) a specific total number of movers (all $k$ for whom $\rho(k)<\rho\left(k^{*}\right)$

and

b) leave behind all those who have a $\rho(k)>\rho\left(k^{*}\right)$ i.e., are those for whom the ability to move is the lowest, since $\beta$ is common to all individuals in region 1.

\subsection{Mobility, Welfare, and Political Stability}

In this section the nexus connecting social welfare, mobility, and political stability is examined. Does increase in social welfare from resource exploitation invariably reduce the probability of political conflict? Under what circumstances does mobility aggravate the likelihood of political instability? When does mobility improve social welfare and when does it decrease social welfare in resource producing countries?

Here, we define, for our purpose, political stability as a stable political equilibrium underlined by voters' decision to sustain a given democratic electoral outcome when faced with similar set of alternatives. It means that when voters vote for a given platform in a given election the outcome of the next vote cycle is predictable from the choice made by voters in the current cycle. Political instability occurs when the same set of voters vote in a manner that is inconsistent in two consecutive voting cycles over the same set of alternatives. This may be due to information update on the alternatives. Social instability is used to capture the deviation from (or rejection of) a constitutional provision, or 
electoral outcome brought about by individual or group dissatisfaction with a given electoral outcome and a positive expected net gain in doing so.

Where mobility across region is allowed, as discussed in section 3.1 above, the dynamics of social welfare and political stability are impacted by the individual premium on cost of movement, and the mobility barrier. Recall equation (3.24), the last mover, at the margin, is only marginally better off than those in region 1 who have not moved. At the margin, all those remaining in region 1 experience the same level of utility as the mover at the margin who is indifferent between moving and not moving. What those in region 1 suffer in terms of negative externality, this mover loses in region 2 owing to failure to fully integrate into region 2 .

$\mathrm{U}_{1}=\mathrm{U}\left(\mathrm{x}_{1}(\mathrm{e})\right)+\mathrm{U}\left(\mathrm{G}\left(\mathrm{n}^{\mathrm{r}}\right)\right)=\beta / \rho\left(\mathrm{k}^{*}\right)\left[\mathrm{U}\left(\mathrm{x}_{2}\right)+\mathrm{U}\left(\mathrm{G}\left(\mathrm{n}^{\mathrm{r}}\right)\right)\right]$

We have seen that all else unchanged, the higher the value of $\beta$, the less opposition there is to all individuals who leave the impacted region and arrive in the unaffected region. This high level of acceptability implies that those who do not move, have a very high premium or experience a very high cost of movement, $\rho\left(k^{*}\right)$, hence, $\rho$ is a function of $\beta$, as $\rho\left(\beta, k^{*}\right)$. Movements invariably mean higher welfare for those who have moved, and at the margin, a higher $\rho$ for those who remain in region 1. Individuals remaining in region 1 are those for whom the cost of movement $(\rho)$ is very high or those who have very strong ties with region 1 . Individuals with very high $\rho$ are those with strong cultural, linguistic, religious ties to the region. From equation (3.24), an increase in 
$\rho$ means an increase in the cost of movement, even if relative welfare across regions has not changed. The impact of mobility on the welfare of those who have moved depends largely on the value of $\rho$, the cost to movement. If $\rho$ is high, there is high individual premium placed on movement, then the marginal mover's welfare upon movement, and hence the welfare of individuals left in region 1 , is very low compared to the welfare of original residents of region 2 . When $\rho$ is low, then the ratio $\beta / \rho$ is close to 1 and mobility does not significantly alter the welfare of the individual at the margin of movement. This is the situation where attachment to individual's original region is very low, and individuals are willing to relocate with low premium and cost of doing so, coupled with high acceptability in the other region. In this case, mobility is stability enhancing, and there is a strong positive relationship between mobility and social welfare. And migrants experience a level of welfare close to the welfare of original residents of region 2

\subsubsection{Political Stability and Welfare under Federalism and Unitarism when migration across regions does not change the level of resource exploitation}

\section{a) Political choices}

As we have seen from Chapter 2, when mobility is absent and $n_{1}>n_{2}$ the level of resource exploitation that will arise under both federalism and unitarism is determined by equation (2.9), 


$$
\mathrm{U}_{\mathrm{G}}^{\mathrm{s}}\left(\mathrm{n}^{\mathrm{r}}\right)\left[p R_{n}-z(e)-n^{r} z_{e} e_{R} R_{n}\right]=U_{x}(x)\left[-z_{e} e_{R} R_{n}\right]
$$

where the level of resource exploitation in equilibrium is the level chosen by the median voter in the impacted region 1 . This level equates the marginal utility (benefit) of the public good to the marginal cost in terms of externality impact on private consumption for the representative individual in region 1. Under federalism, this will be chosen because the level of resource use is assumed to be determined by the median voter within the region possessing the natural resource. Individuals in region 2 would prefer a higher level of resource use and higher output of the public good but have no direct influence on region 1's choice because of the federal structure. It follows that the addition of mobility will not change the optimal choices and so under federalism the same equilibrium outcome will arise.

Under unitarism, however, the equilibrium political outcome could and would change with a sufficient high level of emigration from region 1. However, when the level of migration across regions is relatively small so that $\mathrm{k}^{*}>\mathrm{n}_{2}+\left(\mathrm{n}_{1}-\mathrm{k}^{*}\right)$, the median voter will remain in region 1 and those voters will continue to make the same optimal choices. Hence the introduction of mobility in this case will have no effect on the location of the political majority and hence no effect on the level of natural resource exploitation and/or output of the public good in equilibrium.

In the case where $n_{2}>n_{1}$, the addition of mobility also does not change the location of the median voter and hence there is no change produced by mobility on the political equilibrium. That is, under a federal structure, the level of resource use is 
determined in region 1 alone and the introduction of migration means only that there will be a smaller number of individuals remaining behind to choose the level of resource output. Since migration has no effect on the marginal conditions, individuals in region 1 continue to impose the solution described above on their now more numerous fellow countrymen in region 2 .

Finally, when $n_{2}>n_{1}$ and we have a unitary democratic system, the level of resource exploitation will be given by the optimal condition for those individuals in the majority, those living in region 2. As we have seen, this is given by equation (2.13), as

$$
\mathrm{U}_{\mathrm{G}}^{\mathrm{s}}\left(\mathrm{n}^{\mathrm{r}}\right)\left[p R_{n}-z(e)-n^{r} z_{e} e_{R} R_{n}\right]=0
$$

for those originally resident in region 2 , and equation (3.22)

$$
\frac{\beta}{\rho} \mathrm{U}_{\mathrm{G}}^{\mathrm{s}}\left(\mathrm{n}^{\mathrm{r}}\right)\left[p R_{n}-z(e)-n^{r} z_{e} e_{R} R_{n}\right]=0
$$

for those who moved from region 1 to region 2.

The introduction of mobility will only increase the size of the majority residing in region 2 and hence produce no change in political outcome. In all these cases, then, the introduction of mobility leaves political choices unchanged even as they change the aggregate level of welfare and the potential for instability. 


\section{b) Social Welfare}

In all these cases mobility has had no effect on the political choices made. Yet the economic outcome is not invariant to migration since migration will produce a change in economic welfare. In particular, even though in these cases we know that mobility produced no change in $n^{\mathrm{r}}$ and/or $\mathrm{G}$, those individuals leaving region 1 are leaving lower productivity jobs for higher productivity jobs in region 2 . This corresponds to an increase in income for those individuals who migrate. And, even though mobility costs reduce the welfare gain associated with higher income, the mobility condition derived above guarantees that all intramarginal movers must experience a rise in welfare. That is, because

$$
U\left(x_{2}, G\right)>\left[\beta / \rho\left(n_{i}\right)\right] U\left(x_{2}, G\right)>U\left(x_{1}, G\right),
$$

and because in these cases $x_{1}, x_{2}$, and $G$ are unchanged with mobility, then the level of utility received by new immigrants to region 2 must exceed the level they leave behind.

It follows that in simple economic terms, the introduction of mobility appears to have only improved the outcome for the country as a whole. It is true that neither those who remain behind in region 1 nor those who were already in region 2 gain anything from permitting mobility, but all intramarginal movers must win.

Conclusively, where movement does not lead to a change in the political power welfare of immigrants increases. The welfare of the deciding voters in both regions is unchanged. 


\subsubsection{Political Stability and Welfare under Federalism and Unitarism when migration across regions results in a change in the political equilibrium and the level of resource exploitation}

A change in equilibrium and in the level of resource exploitation occurs only under unitarism, when region 1 initially had a higher voting population, and a sufficient number of individuals move to region 2. Movement across to region 2 leads to shrinking of region 1's population and swelling of region 2's population, which eventually changes the population balance in favour of region 2 . Initially $n_{1}>n_{2}$, however, $n_{2}+\left(n_{1}-k^{*}\right)>k^{*}$. Consequently, only this case will be discussed in this section.

\section{a) Political choices}

Since the externality-impacted region 1 was in majority when $n_{1}>n_{2}$, the initial equilibrium under unitarism would coincide with the level chosen under federalism, given by the equation (2.9), as

$$
\mathrm{U}_{\mathrm{G}}^{\mathrm{f}}\left(\mathrm{n}^{\mathrm{r}}\right)\left[p R_{n}-z(e)-n^{r} z_{e} e_{R} R_{n}\right]=U_{x}(x)\left[-z_{e} e_{R} R_{n}\right]
$$

Individuals in region 1, initially, set the resource level to balance the cost and benefit at the margin. Since welfare in region 2 is higher at any positive level of resource use, no barriers to movement will result in a population drift from region 1 to region 2. This process dynamically reduces the population of region 1 while at the same time increasin 
the population of region 2. At the immigration equilibrium, a new population distribution across the regions is realized when equation (3.24) holds.

$$
\mathrm{U}\left(\mathrm{x}_{1}(\mathrm{e})\right)+\mathrm{U}\left(\mathrm{G}\left(\mathrm{n}^{\mathrm{r}}\right)\right)=\beta / \rho\left(\mathrm{k}^{*}\right)\left[\mathrm{U}\left(\mathrm{x}_{2}\right)+\mathrm{U}\left(\mathrm{G}\left(\mathrm{n}^{\mathrm{r}}\right)\right)\right]
$$

If this mobility across regions results now in $\mathbf{n}_{\mathbf{2}}>\mathbf{n}_{1}$, the median voter moves to region 2 and the political outcome is changed in the next vote cycle for level of resource use. Hence the movement of individuals across regions changes the resource equilibrium.

Recall that under federalism the resource use equilibrium is unchanged irrespective of the initial and final population distribution, even though a greater number of individuals will feel disenfranchised since minority makes the decision for an increasing majority. Under unitarism, however, the new resource equilibrium, upon realization of the population distribution that gave region 2 the democratic majority, will coincide with the level chosen by the unimpacted region 2 , given by equation (2.13), as

$$
\begin{aligned}
& n_{2}+\left(n_{1}-k^{*}\right)>k^{*} \\
& U_{G}^{u}\left(n^{r}\right)\left[p R_{n}-z(e)-n^{r} z_{e} e_{R} R_{n}\right]=0
\end{aligned}
$$

for original residents, and for new immigrants by equation (3.22)

$$
\begin{aligned}
& n_{2}+\left(n_{1}-k^{*}\right)>k^{*} \\
& \frac{\beta}{\rho} U_{G}^{u}\left(n^{r}\right)\left[p R_{n}-z(e)-n^{r} z_{e} e_{R} R_{n}\right]=0
\end{aligned}
$$


The location of the deciding median voter under this unitary democratic system has now shifted from region 1 to region 2 .

\section{b) Social Welfare}

The impact of this sudden change in the political and social equilibrium on the social welfare is more dramatic. From an initial social welfare at level of resource exploitation set by the impacted region $\left(\mathrm{n}_{1}>\mathrm{n}_{2}\right.$ initially) the movement from region 1 to region 2 is welfare improving to the individuals who chose to relocate. However, those who remain in region 1, and individuals originally in region 2 do not experience any change in their welfare. Therefore, social welfare initially only improves.

However, the change in the politically decisive region, the new location of the democratic majority, will trigger further changes in individual and social welfare. Individuals in region 2 will, necessarily, become better off because the new $\mathrm{G}^{\prime}=\mathrm{G}_{2}{ }^{*}$, and $\mathrm{G}^{\prime}>\mathrm{G}=\mathrm{G}_{1}{ }^{*}$, as the public good, $\mathrm{G}$, is increased. Individuals in region 1 , on the other hand, now suffer a loss to private earning, as $\left(\mathrm{x}_{1}>\mathrm{x}_{1}{ }^{\prime}\right)$. Moreover, because the previous equilibrium in this region just balanced the private cost and benefit of resource exploitation, this sudden change immediately decreases the individual and regional welfare in region 1, irrespective of the size of the increase in G. Whether overall social welfare in the country improves, or worsens, depends on the new population distribution, and the degree of concavity of the social welfare function. Suffice it to say that all individuals in region 2 , including new migrants, experience improved welfare. 
Following the new political equilibrium, there will be a new wave of migration from region 1 to 2 . This is because at the new political equilibrium

$\left[\beta / \rho\left(k^{*}\right)\right] U\left(x_{2}, G^{\prime}\right)>U\left(x_{1}^{\prime}, G^{\prime}\right)$

This movement continues until

$\left[\beta / \rho\left(k *^{\prime}\right)\right] U\left(x_{2}, G^{\prime}\right)=U\left(x_{1}^{\prime}, G^{\prime}\right)$

holds at

$\rho\left(\mathrm{k}^{\prime}\right)>\rho(\mathrm{k} *) . \mathrm{k}^{*}<\mathrm{k}^{*}$

The new wave of movement across the regions (from region 1 to region 2), following this change in the political equilibrium, only worsens the regional disparity in wealth and welfare. This is because those who now remain in region 1 experience more pollution and hence lower private consumption and because of diminishing marginal utility, the new increase in $\mathrm{G}$ cannot make up for the loss associated with the reduction in $\mathrm{x}_{1}$ to $\mathrm{x}_{1}{ }^{\prime}$

$\mathrm{x}_{1}^{\prime}<\mathrm{x}_{1}$ and $\mathrm{G}<\mathrm{G}^{\prime} \mathrm{U}\left(\mathrm{x}_{1}^{\prime}, \mathrm{G}^{\prime}\right)<\mathrm{U}\left(\mathrm{x}_{1}, \mathrm{G}\right)<\mathrm{U}\left(\mathrm{x}_{2}, \mathrm{G}\right)<\mathrm{U}\left(\mathrm{x}_{2}, \mathrm{G}^{\prime}\right)$

Whether the social welfare is increased by the movement is unclear, and it depends on the number of individuals who have moved to region 2 , and in the increase in the level of the public good, which has invariably increased the welfare in region 2 . The relative size of the two regions after the movement also determines the net change in social welfare. What is invariably true is that the welfare gap across regions has increased. 
Proposition 4: Given the assumptions of the model, mobility may improve welfare without an increase in political instability if movement does not change the distribution of political power across regions. However, should movement lead to a change in the location of political majority from the impacted to the unimpacted region, then mobility can exacerbate the welfare difference across regions, making its impact on social welfare ambiguous. Even if this leads to a higher overall level of social welfare due to higher public good, it may increase social instability.

Corollary 4.1: Where individuals have low premium on movement and the cost of movement is low, with a high mobility factor, a reflection of high acceptability in unimpacted region, then movement reduces social instability. If individuals have high premium and/or cost to movement then the desire for higher welfare may be inconsistent with the desire for political and social stability.

Proof of proposition 4, and corollary 4.1:

In order to see how mobility impacts the likelihood of conflict in our model, consider the comparative static on equation.

$U\left(x_{2}, G\right)-U\left(x_{1}^{\prime}, G\right)>U\left(x_{2}, G\right)-U\left(x_{1}, G\right)$

We know that mobility leads to the movement of those with minimal cost of movement. Therefore a high mobility implies that those who are left, at the margin, in the impacted 
region are individuals with high $\rho$. The mover at the margin thus has a high level of $\rho$, at a high $\beta$. Under federalism, movement improves the welfare of the movers, and social welfare, and may have only marginal effect on political stability since the level of exploitation does not change. To the extent it improves welfare, it might be stability enhancing under federalism. However, under unitarism, and where mobility changes the location of political majority, mobility may increase political and social instability. If $\rho$ is high, there is high individual premium placed on movement, then the marginal mover's welfare upon movement, and hence the welfare of individuals left in region 1 is very low compared to the welfare of original residents of region 2 . When $1 / \rho$ and $\beta$ are high, then the ratio $\beta / \rho$ is close to 1 migrants experience a welfare level close to the welfare level of original residents. In fact, when $1 / \rho=1$ mobility invariably reduces social instability and social welfare improving. This is the situation where attachment to individual's original region is very low, and individuals are willing to relocate with low premium and cost of doing so, coupled with high acceptability in the other region. In this case, mobility is stability and welfare enhancing. 


\section{CHAPTER 4}

\section{Mobility, Political Change, and Stability in Resource Developing Democracies}

\subsection{A Theory of Political Change in Natural Resource Developing Economies}

In this chapter we discuss the different ways that political discontent can arise across regional groups within a natural resource rich developing country. This is done in recognition of the fact that individuals see themselves not only relative to their current physical and political constraints but also relative to what they could achieve should current constraints be eliminated or redefined. We do so within the framework developed in chapters 2 and 3, where only one of the regions in a country is impacted adversely by the negative externality arising in resource exploitation and where that resource is essential for financing a public good produced from net resource revenue. We continue to emphasize the restrictions on the ability of such governments to redistribute by retaining the assumption that traditional forms of taxation are prohibitively costly. In chapter 2 we examined how discontent can arise among individuals in the various regions under various democratic and resource exploitation regimes because of income differences across regions and the departure in the level of government services provided from what is seen as regionally optimal. We also examined, in chapter 3 , how mobility can affect the degree of discontent, and how mobility can exacerbate the regional welfare differences 
through its effect on the political equilibrium that can arise in a unitary regime. The homogenizing effect of cross-regional migration was also examined in chapter 3 . There it was established that as individuals with low attachment or low cost of movement move out of the impacted region, they leave behind a more politically cohesive group of disadvantaged individuals in the impacted region. The unaffected region, on the other hand, becomes more heterogeneous and less politically cohesive. It was also assumed that individuals in both regions had full information on regional disparities. The weakening of this assumption gives scope for political elites to manipulate information in the interests of either national unity or regional autonomy. The objective in this and the next chapter is to integrate all these elements into a framework to study how these elements of frustration can combine to produce political instability by changing the perceived benefits and costs of federalism versus unitarism.

Recall Figure 6, redrawn below for convenience, with the socially optimal level of resource exploitation also shown. In Figure 6, curve A represents the marginal utility (benefit) of the public good enjoyed by both the current residents of region 1 and the original residents of region 2. It falls because higher levels of $\mathrm{G}$ exhibit increasing cost and diminishing returns in terms of utility. Curve B represents the marginal utility (benefit) of the public good enjoyed by an original region 1 resident who has migrated to region 2 where because of the migrant's cost of leaving home and the utility loss associated with the inability to integrate costlessly into a new region, the marginal utility of $\mathrm{G}$ must be discounted. Hence Curve B must be below curve A. Note, however, that because migration costs are assumed to be proportional, Curves A and B will converge 
on the axis, the point where the marginal utility of the public good falls to zero for all residents. The significance of this point lies in the fact that in the voting for levels of the public good, the same point on the horizontal axis will be optimal for all residents of region 2. That is, once those individuals have moved to region 2 , they have escaped the effect of the externality on their productivity and so chose this level of public good where marginal utility falls to zero. This is the feature that generates political convergence within region 2 .

Curve $\mathrm{C}$ is the marginal cost curve facing residents of region 1 as a result of the externality in resource exploitation. The marginal cost curve reflects the fact that greater resource exploitation lowers the productivity within region 1 and hence private consumption. It follows that for region 1, the optimal level of the public good is that implied by the $\mathrm{G}$ corresponding to $\mathrm{n}_{1}{ }^{\mathrm{r}}$. This cost is not faced by residents of region 2 and this leads them to choose $\mathrm{n}_{2}{ }^{\mathrm{r} *}$. 


\section{Figure 6}

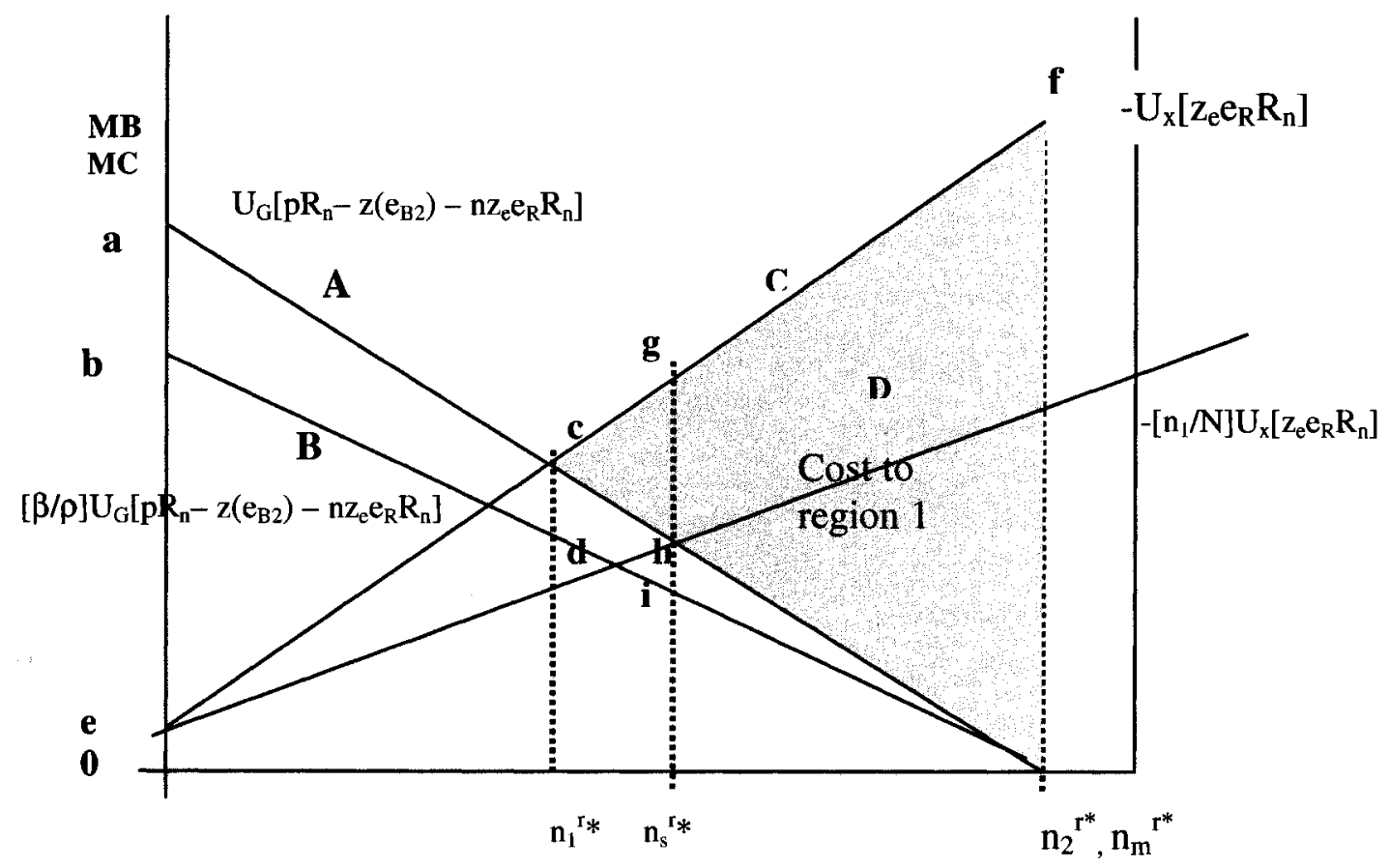


An important observation is the fact that the socially optimal level of resource use given by $\mathrm{n}_{\mathrm{s}}{ }^{\mathrm{r}^{*}}$ lies between the regions 1 and 2 optimal levels. This is because region 1 ignores the external consumption benefit to region 2 but fully internalizes the external cost to region 1 , on the other hand, region 2 ignores the external cost to region 1 but fully internalizes its own benefit. However, the socially optimal level simultaneously incorporates both the external cost to region 1 and external benefit to region 2 . This socially optimal level depends on the proportion of the total population impacted by the negative externality $\left(n_{1} / N\right)$. As was shown in chapter 2 , it is given by equation (2.22)

$U_{G}^{s}\left[p R_{n}-z\left(e_{s}\right)-n z_{e} e_{R} R_{n}\right]=\frac{n_{1}}{N} U_{x}\left[z_{e} e_{R} R_{n}\right]$

In the next section we consider the differences in total welfare that can arise from the different political equilibriums possible in our country and ask under what conditions would a region that felt sufficiently disenfranchised or discontented decide to initiate a unilateral course of action either within the constitutional framework of a country's democratic institutions or outside of this constitutional framework to achieve a "better" mix of private and social goods. Region 1 may do so if it does not have a political majority but believes that it can reduce the level of the resource externality. Region 2 may do so if federalism gives political choice to region 1 and there is a sufficiently high gain from increase in the level of the public good. Finally, we also consider what the 
migrants or potential migrants would do, should any one region take unilateral cause of action?

Using Figure 6 as the basic framework we now examine the equilibriums under different political regimes and the options and response of the regions to these political and constitutional outcomes.

\subsection{Regional Options, Strategies, and Stability Under Federalism}

Under federalism, irrespective of which region has a higher population, region 1 sets the level of resource use and public good, G. From the perspective of this region this level is efficient as it fully internalises the external pollution suffered by this region in exploiting the resources. From the perspective of region 2 this level is inefficient. This is so because region 2 does not suffer the externality, thus residents desire a higher $G$ at which their marginal utility is zero- the level that is optimal without the externality $\left(\mathrm{G}\left(\mathrm{n}_{2}{ }^{\mathrm{r}^{*}}\right)\right)$. Region 2 residents therefore feel disenfranchised, since their voting cannot achieve their desired level of the public good $\left(G_{2}{ }^{*}>G=G_{1}{ }^{*}\right)$. Potential emigrants in region 1 , observing that their welfare could be improved by moving to region 2 even at discounted welfare $((\beta / \rho)<1)$ from the welfare of original residents of region 2 , move to region 2. In equilibrium, because of the limited level of acceptance and individual specific attachment to region of origin and high cost of movement, there will always be some who are left in region 1 . Those remaining in region 1 continue to set the level of $G$ produced. With mobility, then an increasing number of individuals in region 2 , both new 
and old, feel discontented and disenfranchised, particularly if their desired level of G, as a majority, is rejected by the minority in region 1 . Note that their discontent arises not from an actual welfare difference, because welfare is higher in region 2, but from the potential welfare they could receive from the higher level of the public good they would produce in a unitary system. To elaborate further, we now discuss the welfare equilibrium under a federal system in the various regions.

Those in region 1 enjoy a net welfare equivalent to area aec in Figure 6, where

$$
a e c=\int_{0}^{n_{1}^{r^{*}}}\left\{U_{G}\left[p R_{n}-z\left(e_{1}\right)-n z_{e} e_{R} R_{n}\right]-U_{x}\left[z_{e} e_{R} R_{n}\right]\right\} d n^{r}
$$

Although this welfare level is lower than the level of welfare received by individuals in region 2 , this region is politically satisfied, because it can set its optimal level of the resource use that fully internalises the pollution externality. Furthermore, individuals who now reside in this region do not have any intention or incentive to move to region 2 at the current levels of acceptance $(\beta)$, and individual attachment to the region $(\rho)$. Region 1 thus seeks to defend the constitutionality of federalism. It could do no better under any other system that would increase the level of resource use.

Region 2, under federalism experiences a welfare level equivalent to area $a c n_{1}{ }^{r *} 0$, where

$$
a c n_{1}^{r^{*}} 0=\int_{0}^{n_{1}^{r^{*}}}\left\{U_{G}\left[p R_{n}-z\left(e_{1}\right)-n z_{e} e_{R} R_{n}\right]\right\} d n^{r}
$$

Although individuals in region 2 enjoy higher welfare than those in region 1, residents recognize that they can do even better under a unitary system either if their voting 
population is greater than the population of region 1 or if they believe their population, following immigration, will be higher than the population of region 1. Under a unitary system their welfare would be higher by an amount equivalent to the area $c n_{1}^{r^{*}} n_{2}{ }^{r^{*}}$, where

$c n_{1}^{r^{*}} n_{2}^{r^{*}}=\int_{n_{1}^{r^{*}}}^{n_{2}^{r^{*}}}\left\{U_{G}\left[p R_{n}-z\left(e_{2}\right)-n z_{e} e_{R} R_{n}\right]\right\} d n^{r}$

This gain provides the incentive that drives region 2 to want to undertake constitutional change. However, to achieve this extra level of welfare, it must impose a cost, on region 1 through extra pollution. The cost imposed on region 1 is measured by the area $c f_{2}{ }^{r *}$, where

$$
c f n_{2}^{r^{*}}=\int_{n_{1}^{r^{*}}}^{n_{2}^{r^{*}}}\left\{U_{G}\left[p R_{n}-z\left(e_{2}\right)-n z_{e} e_{R} R_{n}\right]-U_{x}\left[z_{e} e_{R} R_{n}\right]\right\} d n^{r} .
$$

From the perspective of region 1, region 2's desire to adopt the outcome of the unitary state is unconstitutional and unnecessary. It will then see itself as the defender of the constitution. Region 2, on the other hand, is forced to consider its probability of success and the expected gain of undertaking unilateral political steps to increase the public good. Should it fail in its attempt to achieve constitutional change peacefully, it could face, in extreme cases, a break up of the union and the possibility of receiving no G, at all. It also faces the possible destruction, temporary or permanently, of either the $G$ or the resources 
in a violent and prolonged conflict with region 1 . In either of these two cases it will lose the welfare it currently enjoys given by equation $(4.2)^{10}$.

Faced with the possibility of outright loss of $G$, region 2 may adopt an exit strategy of negotiating an intermediate solution, and one natural intermediate position would be the socially optimal solution given by

$$
U_{G}^{s}\left[p R_{n}-z\left(e_{s}\right)-n z_{e} e_{R} R_{n}\right]=\frac{n_{1}}{N} U_{x}\left[z_{e} e_{R} R_{n}\right]
$$

The social optimum considers simultaneously the external cost to region 1 and external benefit to region 2 (ignored under federalism). With this settlement region 2 gains welfare above what it enjoyed under federalism, an increase equivalent to area $c n_{l}{ }^{r} h n_{s}{ }^{r}$, where

$$
c n_{1}^{r^{*}} h n_{s}^{r^{*}}=\int_{n_{1}^{r^{*}}}^{n_{s}^{r^{*}}}\left\{U_{G}\left[p R_{n}-z\left(e_{2}\right)-n z_{e} e_{R} R_{n}\right]\right\} d n^{r}
$$

This settlement imposes a net welfare cost on region 1 , though lower than the cost under a unitary system, equivalent to area $c g h$, where

$$
c g h=\int_{n_{1}^{r^{*}}}^{n_{s}^{r^{*}}}\left\{U_{G}\left[p R_{n}-z\left(e_{2}\right)-n z_{e} e_{R} R_{n}\right]-U_{x}\left[z_{e} e_{R} R_{n}\right]\right\} d n^{r}
$$

The social optimum might also become a viable fallback option for region 1 if it viewed itself as facing the total destruction of $G$, and/or an outright victory by region 2 that could

\footnotetext{
${ }^{10}$ A decision tree for all regions is discussed after an exposition on the probability of success in section 4.4
} 
force it to acquiesce to region 2's optimal level (the unitary level). More generally, the movement from $\mathrm{n}_{1} \mathrm{r}^{*}$ to $\mathrm{n}_{\mathrm{s}}{ }^{\mathrm{F}^{*}}$ involves gains to individuals in region 2 in excess of the losses to those in region 1 . Hence in principle there are net gains being made in moving to the social optimum that could be used to provide partial or even complete compensation to those in region 1 . Further movement to increase the public good provides no such marginal gains and results in net loss. However, if the probability of victory by region 2 is low, region 1 may reject this socially optimal level and choose to defend the constitution and the political process that gave it control over the level of resource use at $\mathrm{G}_{1}{ }^{*}=\mathrm{G}$.

The role played by mobile individuals becomes critical when region 2 starts as the minority region but became the majority as a result of migration across regions. In this circumstance, region 2's claim for additional public goods gains moral standing (under democratic tradition) and adds to the probability of victory by the enhanced migration into its region. Under federal decision-making, the migrants that move to region 2 escape the externality, but receive a level of welfare lower than the welfare received by the original residents of region 2 . Because of the discount factor, $\beta / \rho$, their welfare is equivalent to the area $b d n_{l}{ }^{r *} 0$, where

$$
b d n_{1}^{r^{*}} 0=\int_{0}^{n_{1}^{r^{*}}}\left\{\frac{\beta}{\rho} U_{G}\left[p R_{n}-z\left(e_{1}\right)-n z_{e} e_{R} R_{n}\right]\right\} d n^{r}
$$


From the immigrant's perspective, a move from a federal to a unitary decision making political process would increase their welfare by a value equivalent to the area $d n_{l}^{r^{*}} n_{2}^{r^{*}}$. This is less than the welfare gain that would be enjoyed by the original residents of region 2. It appears as the area $c n_{1}{ }^{r^{*}} n_{2}{ }^{r^{*}}$ on Figure 6, where

$$
\begin{aligned}
& c n_{1}^{r^{*}} n_{2}^{r^{*}}=\int_{n_{1}^{*}}^{n_{2}^{*}}\left\{U_{G}\left[p R_{n}-z\left(e_{2}\right)-n z_{e} e_{R} R_{n}\right]\right\} d n^{r}>\int_{n_{1}^{*}}^{n_{2}^{*}}\left\{\frac{\beta}{\rho} U_{G}\left[p R_{n}-z\left(e_{2}\right)-n z_{e} e_{R} R_{n}\right]\right\} d n^{r} \\
& =d n_{1}^{r^{*}} n_{2}^{r^{*}}
\end{aligned}
$$

Immigrants then have a lower incentive to fight for constitutional change than do original residents of region 2 . Their situation may be even more complex given that these immigrants may face expulsion from region 2 in the event of a conflict. In our model this would appear as a fall in $\beta$ due to the conflict, and/or an increase in $\rho$ from political rhetoric or strategic bigotry. Hence, immigrants also face the possibility of being sent back to face the lower welfare and higher pollution they had escaped if conflict arises. To this group therefore, a peaceful victory would give them a welfare increase of $d n_{1}{ }^{r^{*}} n_{2}{ }^{r^{*}}$, but a failure by region 2 and their subsequent expulsion would result in their incurring a welfare loss of

$$
0 \operatorname{ecn} n^{r^{*}}=\int_{0}^{n_{1}^{r^{*}}}\left\{U_{x}\left[z_{e} e_{R} R_{n}\right]\right\} d n^{r}
$$

If the expected loss from a failure (and conflict) is greater than the expected gain should region 2 succeed, immigrants will not support region 2's effort to bring about unilateral 
constitutional change. That is, if the potential loss is less than the potential gain, the probability of victory by region 2 must be sufficiently high for this group to support such unilateral action. Moreover, in order to keep $\beta$ high enough for them to remain in region 2 , they will refuse to overtly support region 1 , their region of origin, because their welfare is higher in region 2. Finally should conflict lead all $\mathrm{G}$ to be destroyed, they lose everything that they had gained. Hence this group is interested in an intermediate negotiated settlement at or near the socially optimal level. At this level of the public good they can remain in region 2, and realize a higher level of welfare than would be experienced under rigid constitutional federalism. This group of immigrants could, therefore play a critical stabilizing role in the country. The greater the size of this group, the more critical its role would become, especially if region 2 started with a lower population size than region 1 . Suffice it to say that the size of the migrants depends critically on the mobility factor $(\beta / \rho)$.

Proposition 5: Without any other form of heterogeneity than geographic diversity, if the externality from resource exploitation does not impact evenly on all geographical jurisdictions, then there will be no regional unanimity on the optimal level of resource exploitation. The form of democratic decision-making may have little or no impact on this outcome. A unitary system and a federal system will produce different levels of resource use. This lack of unanimity and the desire for different levels of resource exploitation increases the likelihood of conflict. 
Proof: Those not impacted by the externality seek to over exploit the resources, leading to production inefficiency because the negative impact on private consumption is not taken into account in their optimization. Groups that are impacted negatively do not take into account the positive social impact of consumption by the non-impacted group. The median voter in each group chooses a given level of resource exploitation that is in conflict with the level chosen by the median voter in the other group. Under unitary system, since the majority is not impacted by the externality, a political platform coinciding with the position of the median voter in the majority group wins the election. This leads to a conflict with the median voter position of the minority, externalityimpacted group. Under federalism the minority controls the policy instrument and does not take into account the positive externality from consumption by the majority. The median voter's preferred level of exploitation in this case is too low, this leads to undersupply of public good. The result may lead to state failure and social unrest, since majority of the national population are disenfranchised, and the level of public good produced may not be sufficient for the whole national population. Under any one of these systems, even if there exits political stability, there may be no social stability. Hence the twin requirements of social and political stability cannot be guaranteed under these conditions. 


\subsection{Regional Options, Strategies, and Stability Under Unitarism}

The regional options, incentives, and strategies under unitarism differ from those under federalism. Even under unitarism, regional strategies and options differ depending on whether $n_{1}>n_{2}$ initially or $n_{2}>n_{1}$ as we shall show in this section.

\subsubsection{When $n_{2}>n_{1}$, so that the political equilibrium does not change}

Here we characterize the equilibrium when region 2, the unimpacted region, has the political majority from the outset of resource exploitation, such that movement across regions does not change the region with political majority.

In this case region 2 sets the level of the public good together with the level of resource use and pollution. As was shown in chapter 2 , region 2 , in setting the level of resource use, ignores the pollution externality experienced by region 1 . Region 2 therefore gets its desired level of public good by fully internalizing all its consumption benefits at $\mathrm{G}_{2}{ }^{*}=\mathrm{G}$. From its perspective the equilibrium is efficient. It attains a welfare level equivalent, in Figure 6, to area $a c n_{2}{ }^{r^{*}} 0$ given by equation (4.5). There is no alternative system of resource use under which region 2 would be better off. For this reason, it is region 2 that is satisfied with the status quo and will defend the constitution in the face of challenges to the status quo.

Those who migrated to region 2 from region 1have moved away from the externality and experience a welfare gain that is a discounted version of the welfare received by those originally resident in region 2 . They find welfare discounted by the 
factor $\beta / \rho$, given by equation (4.7). While this welfare level is lower than the welfare of original residents of region 2 , it is also higher than the welfare of residents of region 1 . Hence, given the current level of their acceptability in region $2,(\beta)$, and their individual attachment to their region of origin, $\rho$, their ability to move gives them the highest level of welfare. Therefore these residents would also uphold the status quo.

The residents that remain in region 1 are either unable or unwilling to move to escape the externality given current levels of $\beta$, and $\rho$. These individuals feel differently from the residents of region 2- immigrants and original. Under the unitary political regime, region 1 residents suffer the additional externality that has been avoided by residents in the rest of the country. From their perspective, resource exploitation is inefficient because it does not take the pollution they suffer into account. This results in an additional welfare difference across the regions, because the additional pollution generated decreases the productivity of agricultural land and decreases their private consumption. Although the level of the public good is equal across regions, the reduction in private consumption produces a further disparity in welfare across regions, with the welfare in region 1 lagging farther behind the welfare in region 2 . Knowing that their lower welfare was the result of the externality from the production of the public good, and knowing especially that their votes did not have a determining say in the level of the public good chosen (since they are in minority), region 1 feels disenfranchised and discontent. Their preferred level of the public good that internalizes the externality is less than the public good provided $\left(\mathrm{G}_{1}{ }^{*}<\mathrm{G}\right)$. Thus, even though the level of the public good provided is higher than region 1's desired level, the impact of the pollution externality on 
agricultural land productivity means that the net welfare of region 1 , given by equation (4.9), is smaller than it could be. It might even be negative. The area of net welfare is represented on Figure 6 by the difference in the two areas $0 \mathrm{an}_{2}{ }^{\mathrm{r}^{*}}$ and $0 \mathrm{efn}_{2}{ }^{\mathrm{r}^{*}}$, where

$$
\begin{aligned}
& 0 a n_{2}^{r^{*}}-0 e f n_{2}^{r^{*}}=\int_{0}^{n_{2}^{* *}}\left\{U_{G}\left[p R_{n}-z\left(e_{1}\right)-n z_{e} e_{R} R_{n}\right]-U_{x}\left[z_{e} e_{R} R_{n}\right]\right\} d n^{r} \\
& =e a c-c f n_{2}^{r^{*}}
\end{aligned}
$$

Region 1 observes that under the alternative political decision making regime, federalism, their welfare would be unambiguously higher because this regime would internalize the externality. Under federalism, region 1 would set the level of the public good and achieve their desired net welfare eac. Because the constitutional provision prevents that outcome, region 1 is discontent and feels disenfranchised.

Region 1's discontent can be expressed in four different ways. First, its desired level of the public good is unachievable under the current unitary regime. In this regime it does not have any effective decision making power, even though it suffers the externality. Secondly, region 1 observes that its welfare is lower than the welfare of individuals in region 2. Moreover, that lower welfare is due to the cost it alone bears in producing the public good. Thirdly, under the prevailing levels of $\beta, \rho$, no individual remaining in this region can take advantage of the economic opportunities in region 2. (Those remaining in region 1are not sufficiently accepted in region 2 , nor are they sufficiently detached from region 1, facing a higher cost of movement, to benefit from moving to region 2.) Finally, under federalism, their welfare would be higher and they would have more say in the production of the public good that negatively affected their welfare. Federalism would 
enable them to internalize the external cost of producing the public good, the cost that has been ignored under the status quo regime of unitarism. For these reasons, region 1 residents have no incentive to defend the current constitution; in fact, individuals in region 1 will actively seek a regime change from the unitary system to a federal system. Whether region 1 will seek a constitutional reform as an outcome of a consensual democratic process or attempt to proceed unilaterally will depend on the acceptability of constitutional reform by the other two groups and the potential cost to all groups of changes in the decision making rules.

In what follows we examine the regional gains and losses associated with a change from the current unitary regime to a federal regime in response to agitation by region 1. We again refer to Figure 6 and the analysis of chapters 2 and 3 for this purpose. The starting point in this case is the unitary equilibrium.

Note that welfare difference is a cause of discontent in this case, but not the only reason. In fact, welfare difference may crowd out the fundamental and root cause of the discontent, namely disenfranchisement (that individuals in region 1 do not have an effective political say in what negatively affects them). This and limited mobility $(\beta / \rho<1)$ are the factors at the root of region 1's discontent.

For the original residents of region 2 , any decrease in the level of the public good translates into a welfare loss. A change from the unitary regime to the federal regime gives decision making power to the affected region, which in turn reduces the public good. Furthermore, federalism ignores the consumption benefit that would have occurred in region 2. Overall, the regime change proposed by region 1 will result in a welfare loss 
equivalent to area $c n_{1}{ }^{r *} n_{2}{ }^{r *}$ in Figure 6, and given by equation (4.3). Therefore region 2 has no incentive to support the change.

Since region 2 has the political majority, any democratic process to change the political regime, as proposed by region 1, is likely to fail. However, if the proposed regime change were unilateral, then region 2 would have to weigh other outcomes that have now become probable. For example if the probability of victory by region 1 was higher, then region 2 might acquiesce to the demands of region 1, perhaps even facing the dissolution of the union. Alternatively, region 2 could face the outright destruction of G, temporarily or permanently, in a prolonged conflict with region 1 . If any of these possibilities is realised, then region 2 could lose the public good with no resources to produce it on its own. This would lead to a much lower welfare than what they would receive under federalism. The decision for region 2 , therefore, is to defend the unitary constitution only if the likelihood of dissolution of the union /destruction of $\mathrm{G}$ is sufficiently low, and/or region 1's probability of success without dissolution is sufficiently low.

The last group that would be affected by the change proposed by region 1 is the immigrant group. The cost in lost welfare to this group from the proposed changes is equivalent to area $d n_{1}{ }^{r *} n_{2}{ }^{r}$, which is somewhat less than the potential cost to original residents of region 2 . The loss is given by

$$
d n_{1}^{r^{*}} n_{2}^{r^{*}}=\int_{r_{1}^{r_{1}}}^{n_{2}^{r^{*}}}\left\{\frac{\beta}{\rho} U_{G}\left[p R_{n}-z\left(e_{2}\right)-n z_{e} e_{R} R_{n}\right]\right\} d n^{r}<\int_{r_{1}^{*}}^{r_{r}^{*}}\left\{U_{G}\left[p R_{h}-z\left(e_{2}\right)-n z_{e} e_{R} R_{n}\right] d n^{r}=c n_{1}^{r^{*}} n_{2}^{r^{*}}\right.
$$


Since the immigrants to region 2 have lower cost than do the original residents of region 2, from either constitutional or unilateral change it follows that these immigrants will have a lower incentive to defend the status quo. Moreover, should they be expelled from region 2 because of a decrease in acceptability as a result of the conflict, their cost is increased as they would now suffer the externality they had moved to escape. If region 1 succeeded and federalism were achieved, but immigrants were expelled as a result of the conflict, then those immigrants who were sent back to region 1 would now also suffer the externality. This extra cost from the perspective of the migrants would be avoided if federalism could be adopted without conflict.

As discussed in section 4.2, from the perspective of immigrants and the original residents of region 2 the socially optimal level is a viable option that dominates both the federal solution and the destruction of the public good, although it is in turn dominated by the unitary equilibrium. From the perspective of region 1, the socially optimal level dominates the unitary equilibrium, and the destruction of the resources, but it is dominated by the federal equilibrium.

\subsubsection{When $n_{1}>n_{2}$, and $n_{2}+\left(n_{1}-k^{*}\right)>k^{*}$, so that the political equilibrium changes under unitarism}

This is the situation where region 1 originally had a political majority. Although the constitutional provision was for a unitary resource exploitation, the resource exploitation equilibrium coincided with what would have arisen under federalism. However, as shown in chapter 3, the movement from region 1 to region 2, undertaken by 
individuals wishing to take advantage of the economic opportunities in region 2, now leads to a change in the political majority from region 1 to region 2 . Under the unitary system this means that the externality will be increased as the resource use now coincides with the level optimal to individuals in region 2 , who internalise the consumption benefit while ignoring the pollution externality. Under this changing equilibrium, regional strategies and options also change.

When $n_{1}>n_{2}$ region 1 had the political majority and so controlled the level of resource exploitation. The equilibrium and its incentive structure are the same as in our discussion of section 4.2, so will not be repeated here. What is different now is that, in anticipation of emigration region 1's, strategies and options may change in an effort to keep the level of the public good. Region 1's long-term strategy is to maintain resource use at the level that coincides with the federal solution, the level that fully internalises the externality to it. Region 1 could then use its original political majority to initiate constitutional change from unitarism to federalism. This will ensure that even with migration, the equilibrium will not change. Secondly, region 1 could move to reduce $\beta$, and increase $\rho$, such that individuals are not willing to move to region 2. This would ensure that there was not enough movement to change the political majority from region 1 to region 2 .

Should region 1 fail in its non-violent and strategic effort to prevent a change in the status quo, the change in the political equilibrium will lead to sudden changes in the welfare of both regions. The welfare of region 1 falls from the level described by equation (4.1) to that in equation (4.9), and $\mathrm{G}$ rises from $\mathrm{G}_{1}{ }^{*}<\mathrm{G}_{2}{ }^{*}$ to $\mathrm{G}_{2}{ }^{*}>\mathrm{G}_{1}{ }^{*}$. Region 
1, which was accustomed to a higher level of welfare than what it receives now, changes its strategy from working within the constitution to wanting an alternative system federalism, either unilaterally or as a negotiated solution. In pursuing these strategies, region 1 faces the incentives and options discussed in section 4.3.1.

From the perspective of region 2, unitarism even from an initial $n_{1}>n_{2}$, presents an opportunity to constitutionally change the level of the public good from $\mathrm{G}_{1}{ }^{*}<\mathrm{G}_{2}{ }^{*}$ to $\mathrm{G}_{2}{ }^{*}>\mathrm{G}_{1}{ }^{*}$. Region 2 observes that with the appropriate level of $\beta$, there would be sufficient immigration to ensure that in not too distant period $n_{2}+\left(n_{1}-k^{*}\right)>k^{*}$ will be true and it will have the political majority. Here $\mathrm{k}^{*}$ is the population of region 1 in the postmigration equilibrium and $n_{1}-k^{*}$ represents the number of individuals who move from region 1 to region 2. For this reason, the strategy of region 2 is to oppose any constitutional reform, and its campaign strategy is to encourage migration by working to increase $\beta$ and decrease $\rho$. However, in encouraging high levels of migration, region 2 is aware of the fact that high migration increases $\rho$, and political cohesion in region 1. For this reason, region 2 targets a level of $\beta$ that gives it political majority but not as high as to reduce cohesion in region 2 and increase political cohesion in region 1. As the equilibrium changes from $\mathrm{G}_{1}{ }^{*}$ to $\mathrm{G}_{2}{ }^{*}$, the incentive and strategy of region 2 changes to reflect the situation discussed in section 4.3.1.

The migrants moving to region 2 vote with region 2 , and to the extent that change is constitutional, they support individuals in region 2. However, as the equilibrium changes from $\mathrm{G}=\mathrm{G}_{1}{ }^{*}<\mathrm{G}_{2}{ }^{*}$ to $\mathrm{G}=\mathrm{G}_{2}{ }^{*}>\mathrm{G}_{1}{ }^{*}$, region 1 becomes discontent with the status quo and agitates for constitutional change to federalism - unilaterally or 
multilaterally. The immigrants' incentive to defend the new equilibrium becomes different from those of original residents of region 2 leading to a lower political cohesion in this region. The details of these were discussed in section 4.3.1.

Proposition 6: Under the assumptions of our model, federalism may be more stable than unitarism when migration across regions is allowed.

Proof: At any level of population distribution and resource, federalism locates the region with the deciding voter in region 1, the impacted region, and this does not change with migration. Under unitarism, and with an initial political majority in the impacted region 1, movement to escape the negative externality may lead to a change in political equilibrium with the majority moving to region 2. Moreover, the increase in the public good also increases the negative externality, which further raises the welfare gap across regions further increasing opposition to the current political regime. These may lead to further change in the resource regime as voter cohesion increases in the impacted region and falls in the other unaffected region.

\subsection{Probability of Conflict: The Role of Information and Politicians}

In this section we discuss how the median voter in each region makes the decision either to acquiesce in, or to resist, a unilateral action by the other region. It also highlights the role of information and the coordination dilemma that may lead to eventual 
instability. Salient issues also analysed are the role of politicians and the fluidity of the migrant voters. Especially how the decision by the migrant voter to join the unimpacted region to vote for a higher public good may be distinctly diametric to this voter's decision when it comes to whom to support in a decision that may lead to instability.

In order to begin the analysis we shall first discuss the probability of victory by any region should it decide to take a unilateral action. Then an analysis of the regional expected net gains from such unilateral reaction is carried out. Furthermore, a detail analysis of the factors influencing the probability of victory that lead to differing signals in the regions is undertaken. For instance, we discuss how the probability of victory gives each region a positive expected net gain that could lead to instability, moreover, how politicians may deliberately distort information that might lead to positive expected net gain from the perspective of both regions.

\subsubsection{The Probability of Unilateral Success}

At some point regions may feel sufficiently disenfranchised or discontented either to initiate strategic action within the context of current democratic institutions or to set aside democratic institutions and pursue a unilateral course of action in order to achieve their preferred level of the public good and/or level of natural resource use. Region 1 may do so if it can gain sufficiently from the reduction in the level of externality, and region 2 may do when it can gain from an increase in the level of resource exploitation and the public good. Whether they will do so, however, depends on their probability of success and expected net gain. 
To add structure to this analysis, I assume that should region 1 (or 2) decide to set aside current democratic practice and adopt unilateral action to achieve its first best outcome, the probability that region 1 will succeed in that unilateral action is independent of which region initiates the action and can be expressed in functional form as $\operatorname{Prob}($ region 1 is successful $)=\kappa_{1}\left[n_{1} / N, p\left(k^{*}, \beta\right), \beta\right]$. That is, the probability that region 1 's position will be adopted should any unilateral course of action be begun depends positively on the relative size of its population, $n_{1} / \mathrm{N}$, on the level of attachment its inhabitants have to their region (measured by the degree of attachment held by the individual on the margin of movement to region 2$), \rho\left(k^{*}, \beta\right)$, and finally in a somewhat more complicated way on $\beta$. The first term, the relative population size is perhaps the most straightforward in that the larger is the region's share of population, the stronger, ceteris paribus, will be its physical strength and its external democratic/moral case for success. The second factor, $\rho\left(k^{*}, \beta\right)$, represents the degree of cohesion among the population that remains in region 1 . A high $\rho$ means a high degree of attachment to the region and hence a high degree of cohesion and support for the region's claims. It allows its representatives a higher ability to speak with one unified voice. The probability of success by region $1, \kappa_{1}$, depends on $\beta$, in a more complex fashion. When $\beta$ is high, there is a high degree of acceptability of immigrants in region 2 . This means that the economic benefits enjoyed by migrants are not discounted by as much and hence are more conducive to movement from region 1 to 2 . On the one hand, such movement increases the population of region 2 and the locational willingness of region 1 emigrants to support region 2 will decrease $\kappa_{1}$, the probability of region 1 's success. On the other hand, a 
higher $\beta$ leads to a higher $\rho$ back in region 1 . That is, with the exit of those with less regional attachment, there is left a population with a higher degree of cohesion in region 1 which will increase $\kappa_{1}$. Furthermore, a higher $\beta$ will lead to a reduction in the population size of region $1, n_{1} / \mathrm{N}$, which decreases $\kappa_{1}$. Lastly, the higher number of migrants that follow from a higher $\beta$ will increase the regional mix in the population mix of region 2 and so decrease regional cohesion and weaken its ability to speak with one voice on issues of regional concern.

In what follows, we shall examine how and when regions may choose to initiate a strategic course of action within the democratic institutions, or a unilateral course of action setting aside the democratic institutions.

\subsubsection{Regional Expected Gains and Options}

\section{Federalism}

Under federalism, the political decision on the level of natural resource exploitation is made within the region where the resource is found. In our case, region 1 chooses the level of resource exploitation that produces $\mathrm{G}=\mathrm{G}_{1}{ }^{*}<\mathrm{G}_{2}{ }^{*}$ and this outcome will be unresponsive to the population difference arising between the two regions. We have earlier described this outcome as being production efficient and consumption inefficient, because the consumption benefit of the public good to region 2 is largely ignored. It follows that region 2 will feel somewhat disenfranchised (since its interests have been ignored) and discontented in the sense that with political control it could 
achieve a higher level of welfare. Both these factors are heightened the larger is its population share relative to region 1 .

For region 2 to now take action to change the decision making provisions of the constitution to its advantage and impose $\mathrm{G}_{2}{ }^{*}$, the expected gain from such an action must outweigh its expected cost. For region 1 to acquiesce to this extra-constitutional political usurpation of resource decision-making by region 2, the expected loss from acquiescing must necessarily be less than the expected losses associated with resistance. This in turn means that the level of resource use following the change in the political decision-making regime must result in a level of public good (and resource externality) that makes the threat to leave and/or destroy the natural resource by region 1 a non-credible one. This means that upon losing and having $\mathrm{G}_{2} *$ imposed, region 1 must still experience a positive net benefit from having the public good (i.e., the resource externality must not be so big that region 1 would prefer to have no public good at all).

It follows that if region 2 initiates unilateral action and the set of feasible outcomes includes only the possibilities that region 1 wins and institutes its optimal solution $\mathrm{G}_{1}$ * (with probability $\kappa_{1}$ ), or that region 2 can win and impose its optimal solution $\mathrm{G}_{2} *$ (with probability $\kappa_{2}$ ), or that neither wins and the resource is destroyed (with probability $\sigma$ ), then

$$
\kappa_{1}+\kappa_{2}+\sigma=1 .
$$

For region 2, however, there is one more possibility. Should region 1 win after region 2 begins extra-constitutional action, region 2 could find itself expelled from the previous union and so lose even $\mathrm{G}_{1} *$ from the new arrangement. Hence for region 2 , the win by 
region 1 has two outcomes: the possibility that the union will be dissolved, with probability $v$, and the probability that $\mathrm{G}_{1} *$ will be re-imposed, with probability (1-v). Both of these possibilities must be taken into account in determining its optimal choice.

Incorporating all these possibilities, the expected gain to region 2 from unilateral action is the benefit it receives if it wins and gets $\mathrm{G}_{2}{ }^{*}$ with probability $\kappa_{2}$, plus the benefit it receives from continuing to get $G_{1} *$ with probability $\kappa_{1}(1-v)$, plus the receipt of no benefit at all should either region 1 win and expel region 2 or the conflict destroys the resource for both with probability $\kappa_{1} v+\sigma$, less the cost to it of unilateral action. In terms of our analysis this is given by

$E G_{2}^{f}=\kappa_{2} \int_{0}^{r_{r}^{*}}\left\{U_{G}\left[p R_{n}-z\left(e_{2}\right)-n z_{e} e_{R} R_{n}\right]\right\} d n^{r}+\left(\kappa_{1}(1-v)\right) \int_{0}^{r_{r}^{r}}\left\{U_{G}\left[p R_{n}-z\left(e_{2}\right)-n z_{e} e_{R} R_{n}\right]\right\} d n^{r}-C_{2}^{f}$

where $\mathrm{C}_{2}{ }^{\mathrm{f}}$ is region 2's cost of undertaking unilateral action. Under current arrangements, however, region 2 already receives

$\int_{0}^{n_{1}^{r}}\left\{U_{G}\left[p R_{n}-z\left(e_{2}\right)-n z_{e} e_{R} R_{n}\right]\right\} d n^{r}$

with certainty. Hence the expected net gain to region 2 of going ahead with unilateral action is

$$
E N G_{2}^{f}=E G_{2}^{f}-\int_{0}^{n_{1}^{r *}}\left\{U_{G}\left[p R_{n}-z\left(e_{2}\right)-n z_{e} e_{R} R_{n}\right]\right\} d n^{r}
$$




$$
\begin{aligned}
& =\kappa_{2} \int_{0}^{n_{2}^{*}}\left\{U_{G}\left[p R_{n}-z\left(e_{2}\right)-n z_{e} e_{R} R_{n}\right]\right\} d n^{r}-\left(\kappa_{2}+\kappa_{1} v+\sigma\right) \int_{0}^{n_{1}^{*}}\left\{U_{G}\left[p R_{n}-z\left(e_{2}\right)-n z_{e} e_{R} R_{n}\right]\right\} d n^{r}-C_{2}^{f} \\
& =\kappa_{2} \underbrace{\int_{r_{1}^{*}}^{r_{*}^{*}}\left\{U_{G}\left[p R_{n}-z\left(e_{2}\right)-n z_{e} e_{R} R_{n}\right]\right\} d n^{r}}_{\text {Gaining what it wants }}-(\underbrace{\left.\kappa_{1} V+\sigma\right) \int_{0}^{n_{1}^{*}}\left\{U_{G}\left[p R_{n}-z\left(e_{2}\right)-n z_{e} e_{R} R_{n}\right]\right\}}_{\text {Losing Everything }} d n^{r}-\underbrace{C_{2}^{f}}_{\text {Cost of action }}
\end{aligned}
$$

It follows that region 2 may initiate a conflict under federalism if equation (4.11) is positive. This will be true for any level of $\kappa_{2}>0$ when $\mathrm{C}_{2}{ }^{\mathrm{f}}, v$, and $\sigma$ are all equal to zero. That is, if there is no cost to region 2 starting a conflict under federalism, then region 2 will take unilateral action even when faced with a high probability of failure. On the other hand, if region 2 faces the complete destruction of the resources, and/or expulsion from the union should it fail, then unilateral action will require either a very low probability of failure, or a very large welfare gain upon success. More generally, unilateral action by region 2 will arise when the expected net gain $E N G_{2}^{f}$ in (4.11) is positive. If individuals are well informed of the welfare gains and losses, then the median voter in region 2 is more likely to vote for such a unilateral action the higher the expected gain and the lower is the likely cost of failure.

Under federalism region 1 will portray itself as the defender of the constitution because under current resource allocation rules region 1 can choose the level of resource use that internalises the resource externality and so achieve its optimal public/private outcome. Therefore it will not initiate extra-constitutional action. Its decision to defend the federal structure arises from the fact that if it acquiesces to the demand by region 2 to 
change to a unitary decision making regime then the externality that it suffers will not be taken into account. The resulting cost to region 1 in the unitary system where region 2 has the majority is given by equation (4.4). Thus if region 1 decides to defend federalism and it loses that conflict (with probability $\left(\kappa_{2}\right)$ ), the loss in equation (4.4) will result. However, with probability $\kappa_{1}$, it will win and federalism will be successfully defended. In this case its gain is the negative externality cost it would bear had region 2 been victorious, also given by equation (4.4), less the cost of undertaking the defence of federalism, $\mathrm{C}_{1}{ }^{\mathrm{f}}$. Moreover, if equation (4.9) is negative, then the size of the externality loss associated with higher resource exploitation will exceed the value of having the public good at all. In such case if the unitary solution results in a negative total welfare gain to region 1 as a result of the size of the externality associated with the increase in the public good, then destroying the public good (resources) will be a welfare improvement from the unitary level of the public good. In this case, region 1 will choose to defend constitutional federalism at any probability of winning $\kappa_{1} \geq 0$. Defending federalism is always optimal.

Mathematically, the expected gain to region 1 , if it resists, is given by

$$
\begin{aligned}
E G_{1}^{f}=\kappa_{1} \int_{0}^{n_{1}^{*}}\left\{U_{G}\left[p R_{n}-z\left(e_{1}\right)-n z_{e} e_{R} R_{h}\right]-U_{x}\left[z_{e} e_{R} R_{n}\right]\right\} d n^{r} \\
+\kappa_{2} \int_{0}^{n_{5}^{r}}\left\{U_{G}\left[p R_{h}-z\left(e_{1}\right)-n z_{e} e_{R} R_{n}\right]-U_{x}\left[z_{e} e_{R} R_{n}\right]\right\} d n^{r}-C_{1}^{f}
\end{aligned}
$$

If it acquiesces to the demands of region 2 , then with certainty it receives

$$
\int_{0}^{n_{2}^{*}}\left\{U_{G}\left[p R_{n}-z\left(e_{1}\right)-n z_{e} e_{R} R_{n}\right]-U_{x}\left[z_{e} e_{R} R_{n}\right]\right\} d n^{r} .
$$


The expected net gain from defending the constitution is therefore given by

$$
\begin{aligned}
& E N G_{1}^{f}=-K_{1} \int_{n_{1}^{\prime}}^{r^{*}}\left\{U_{G}\left[p R_{n}-z\left(e_{1}\right)-n z_{e} e_{R} R_{h}\right]-U_{x}\left[z_{e} e_{R} R_{h}\right]\right\} d n^{r} \\
& -\sigma \int_{0}^{r_{2}^{r}}\left\{U_{G}\left[p R_{n}-z\left(e_{1}\right)-n z_{e} e_{R} R_{n}\right]-U_{x}\left[z_{e} e_{R} R_{n}\right]\right\} d n^{r}-C_{1}^{f}
\end{aligned}
$$

Notice that the first and second terms of equation (4.13) could be positive. In such case, the incentive to defend federalism for region one is very high. Recall that under federalism, the resource exploitation regime is efficient from the perspective of region 1 , and it gains nothing by moving away from this equilibrium to any other equilibrium. For this reason, there is no incentive for region 1 to enter into a negotiation with region 2 that will peacefully resolve the issues of disenfranchisement raised by region 2. Moreover, if equation (4.11) is negative, then region 1 also knows that region 1 does not have incentive to start a unilateral process to change the decision-making regime. Region 1 therefore will only respond to an external threat from region 2 , for instance if equation (4.11) is positive. From this three cases are possible

i) If equation (4.11) is negative, then region 2 does not have incentive to carry out unilateral action. Since region 1 has the decision making power in federalism, this serves its interest and it does not have any incentive to concede any ground to region 2. However, even if region 2 feels disenfranchised there is no incentive for it to undertake any unilateral action, because its expected gain from doing so is negative. In this case region 2 does not have strong incentive within the model to fight for a change in the level of resource. This is the case where either the 
welfare gain to region 2 from success is low, or region 2 has low probability of victory, $\kappa_{2}$, or there is a high probability that the resource will be destroyed in a prolonged conflict. In this case, even with a higher population than region 1 , region 2 may simply acquiesce to the status quo in which region 1 , with a lower population, takes the decision on the level of resource use, concomitantly, the level of the public good.

ii) If equation (4.11) is positive and equation (4.13) is negative, then region 2 will attempt a unilateral action to change the decision-making regime to ensure its desired level of resource use is achieved. Region 1 does not have incentive to defend federalism, either because its probability of success is low or the external cost (in terms of reduced private consumption) of increasing the resource use is low. In this regard, region 1's response to the incentive facing region 2 is to act to reduce the incentive - returning equation (4.11) to zero or negative. Region 1 may do this by raising the cost (second term of equation (4.11)) peacefully through increasing the level of the public good, by moving towards the socially optimal level. This strategic action raises the cost of conflict to region 2 , and reduces the chances of region 2 starting a conflict. Suffice to say that without such an external threat, there is no incentive within the model for region 1 to peacefully give up its right to determine the size of the public good. 
Figure 7: Negotiating Equilibrium Under Federalism

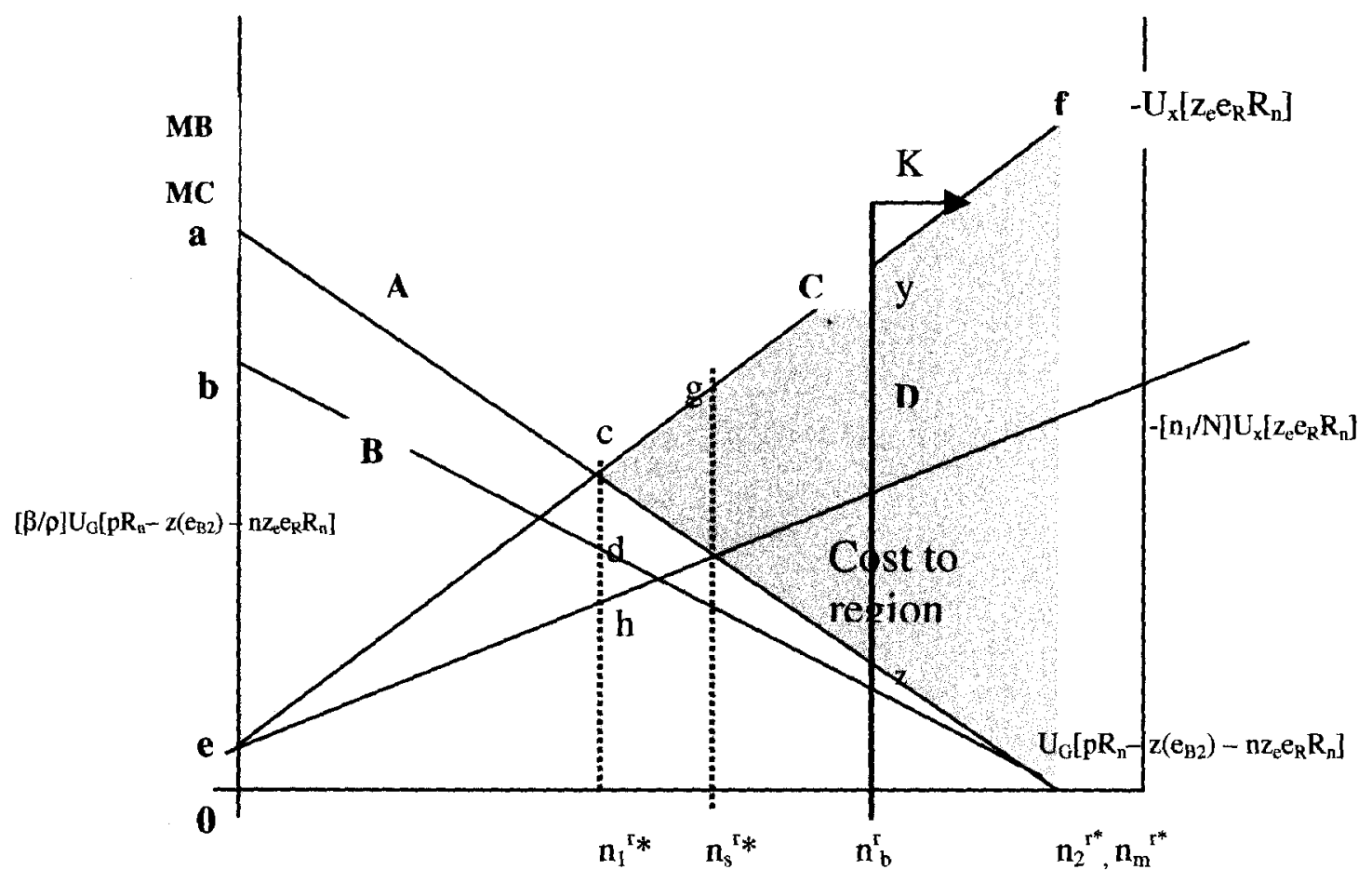


As region 1 increases the level of the public good the externality it suffers also increases and welfare decreases in this region. This increases the expected net gain, equation (4.13) for region 1 while decreasing the expected net gain, equation (4.11), for region 2. Further concession ceases when equation (4.11) and/or equation (4.13) becomes zero. At this point, region 1 will stop conceding to further demands from region 2 to increase exploitation levels.

iii) If equations (4.11) and (4.13) are both positive, then both regions have strong incentive to fight for their positions, and may not be willing to concede ground. This is the scenario with the highest probability of degenerating into a conflict situation. However, the credible threat of destroying the resources may encourage region 2 to concede some grounds to region 1 . Also the external threat of belligerence by region 2 may make region 1 to increase the level of the public good above $G_{1}{ }^{*}$. However, This willingness to avert a conflict on both sides may not exist, because there is no incentive to concede grounds, and internal mechanisms may fail to initiate genuine negotiations.

From equations (4.11) and (4.13), and Figure $7 \mathrm{~b}$ below, we describe here one case in which a double positive expected net gain for both regions may arise. Assume that in the event of a conflict the probability of victory for region 1 is very low compared to region 2's probability of victory, $\left(\kappa_{1} \ll<\kappa_{2}\right)$. Assume also that both $\sigma$ and $C_{2}^{f}$ are both very small, but positive such that $E N G_{2}^{f}$ is positive. From Figure 
$7 \mathrm{~b}$, if the total cost in externality to region 1 from acquiescing to the exploration level proposed by region 2 is higher than the total benefit in terms of welfare from the public good produced from the resources, then not having the public good produced is a welfare improvement from producing the public good at that level. That is, even if region 2 will outrightly be victorious in a conflict with region 1 to increase the level of exploration to $\mathrm{n}_{2}{ }^{\mathrm{r}^{*}}$, if area $\mathrm{g} f \mathrm{n}_{2}{ }^{{ }^{*}}>g a e$, then the certainty of losing the conflict to region 2 , should it decide to defend federalism, may even serve as an added incentive to go into conflict. Region 1 may do so not with a strategy of winning, because it will not, but with a strategy of destroying the resources, because doing so will result in a welfare improvement from a unitary exploration regime controlled by region 2 . However, starting from $n_{1}{ }^{r^{*}}$, the optimal point of region 1 , a negotiation between the regions may yield intermediate values of resource production $\mathrm{n}_{\mathrm{b}} \mathrm{r}^{*}$. Starting from an $E N G_{I}^{f}<0$ any value of $\mathrm{n}_{\mathrm{b}}{ }^{{ }^{*}}>\mathrm{n}_{1}{ }^{\mathrm{r}^{*}}$ will give rise to a lower $E N G_{2}^{f}$ while increasing $E N G f^{f}$. Whether region 2 will accept this intermediate value of resource use depends on the potential gain from increasing $\mathrm{n}_{\mathrm{b}}{ }^{\mathrm{r}^{*}}$ to $\mathrm{n}_{2}{ }^{\mathrm{r}^{*}}$ equivalent to area $w n_{b}{ }^{r^{*}} n_{2}{ }^{{ }^{*}}$ since $\kappa_{2}$ $>\kappa_{1}$, this potential gain is the dominant factor in making the decision to push for further increase in resource use. Similarly, for region 1 to acquiesce to further increasing $\mathrm{n}_{\mathrm{b}}{ }^{\mathrm{r}^{*}}$, it is critical that the net gain from resource use is positive. For this reason, the limit of negotiation becomes a value of resource production given by $\mathrm{n}_{\mathrm{bl}} \mathrm{r}^{\mathrm{r}^{*}}$, the limit of bargaining, such that the total benefit, equivalent to area gae, equals the total cost of such increase, equivalent to area ghs. Irrespective of the 
values of $\kappa_{2}$ and $\kappa_{1}, n_{b}{ }^{{ }^{*}}$ defines the limit of negotiation for region 1. Note from equations (4.13) that, even if $\kappa_{1}$ is very insignificant, as long as $\sigma$ is positive and $\mathrm{n}_{\mathrm{b}}{ }^{{ }^{*}}>\mathrm{n}_{\mathrm{b}}{ }^{\mathrm{r}^{*}}, E N G_{1}{ }^{f}$ may be positive, only constrained by the fixed cost of conflict $C_{1}^{f}$. This, coupled with a very high $\kappa_{2}$, may result in $E N G_{2}^{f}$ being positive also. In this case of double positive expected net gain, internal institutions may fail to resolve the potential conflict. Only external intervention may bring the two sides of the conflict to a negotiating table. Note that this result may not change even if information is complete and truthful. Region 1 may simply prefer no public good to the level of the public good proposed by the optimal position of region 2 . And region 2, knowing that it can win a unilateral action to enforce its optimal level of the public good, may have an incentive to push forward with an alternative proposal - unitarism.

It is also worth noting that this double positive expected net gain is the outcome of a total welfare consideration, the distribution of the externality, and unequal probability of victory. What is critical to this result of rational conflict is the separation of cost and benefit, non-substitutability of the two goods, and the limited mobility across regions. 


\section{Figure 7b : Limit of Negotiation Under Federalism}

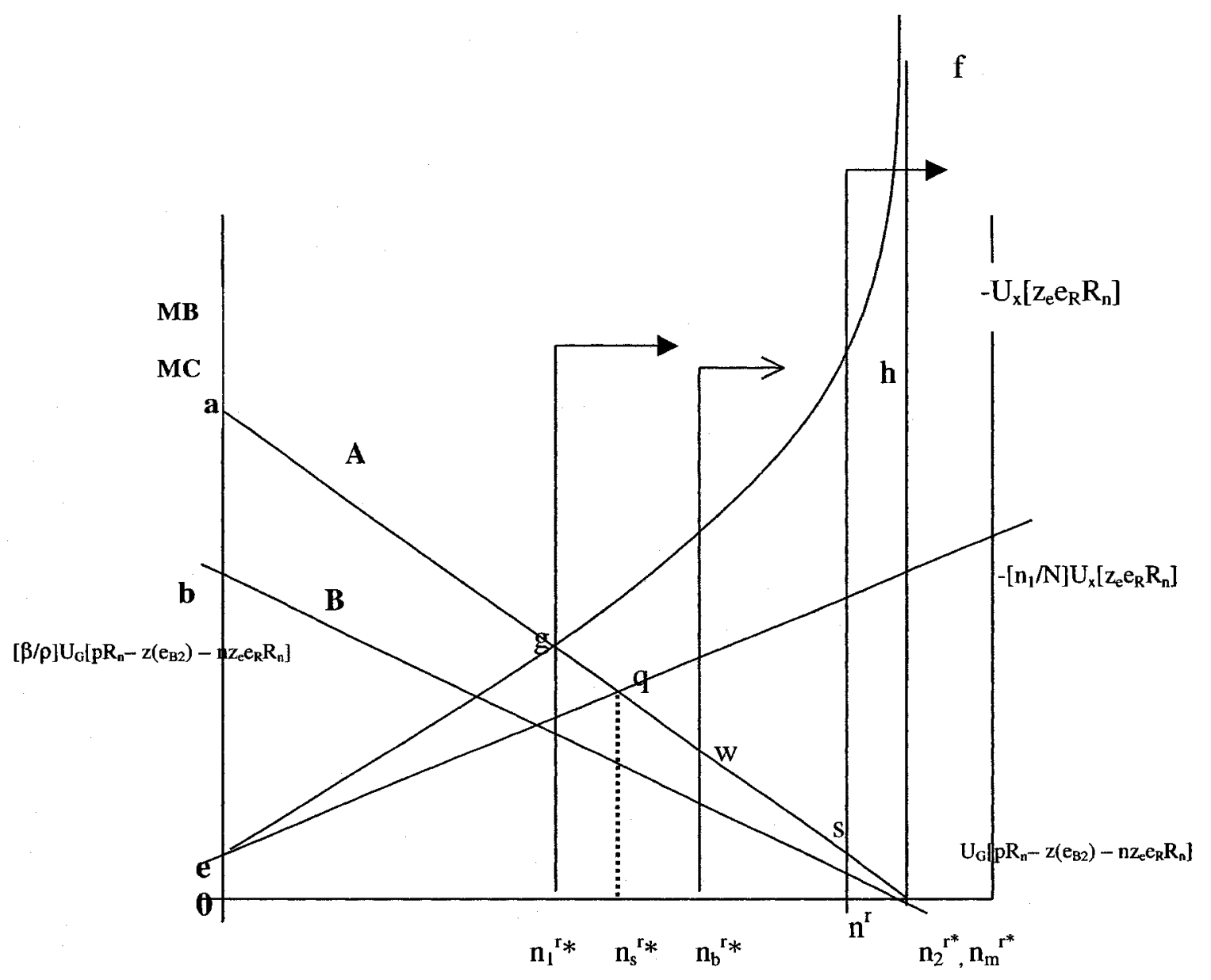


The incentives facing immigrant voters differ from the cases discussed thus far and are more complex. Assume that immigrants fully supported their new region of residence in its action, and so could not be expelled from region 2 as a result of the likely decrease in acceptance, $\beta$, due to the conflict that is likely to arise from unilateral action. Also assume that should the union be dissolved, immigrants could not go back to region 1. Then the expected net gain to the immigrants would be given by

$$
E N G_{m}^{f}=\frac{\beta}{\rho}\left\{\kappa_{2} \int_{n_{1}^{*}}^{n_{2}^{*}}\left\{U_{G}\left[p R_{n}-z\left(e_{2}\right)-n z_{e} e_{R} R_{h}\right]\right\} d n^{r}-\left(\kappa_{1} \nu+\sigma\right) \int_{0}^{n_{1}^{*}}\left\{U_{G}\left[p R_{n}-z\left(e_{2}\right)-n z_{e} e_{R} R_{n}\right]\right\} d n^{r}\right\}-C_{2}^{f}
$$

In this case, mobile voters have a lower expected net gain than do the original residents of region 2 since $\beta / \rho<1$. Therefore, immigrants to region 2 have a lower incentive to fight for higher public good and hence will be more reluctant to support a unilateral action than a typical original resident of region 2 . In the event that immigrants are allowed to remain in region 2 even with the conflict, the cost of conflict to them will be similar to those of original region 2 residents. if immigrants to region 2 broke their link with region 1 by openly supporting region 2 throughout the conflict, then the expulsion of region 2 would likely lead to their inability to relocate to region 1 .

Should region 2 be expelled from the union and immigrants did not break their links with their region of origin, these migrants may return to their region of origin. 
Hence in the case of dissolution, they would suffer the externality they had moved to escape, but would be able to consume the same level of public good as other residents of region 1. In this instance, their expected net gain will be given by

$$
\begin{aligned}
& E N G_{m}^{f}=\kappa_{2} \frac{\beta^{n_{2}^{r}}}{\rho} \int_{n_{1}^{r}}^{r}\left\{U_{G}\left[p R_{n}-z\left(e_{2}\right)-n z_{e} e_{R} R_{n}\right]\right\} d n^{r}-\kappa_{1} v\left(1-\frac{\beta}{\rho}\right)^{r_{1}^{r}}\left\{U_{0}^{r}\left[p R_{n}-z\left(e_{2}\right)-n z_{e} e_{R} R_{n}\right]\right\} d n^{r} \\
& -\sigma \frac{\beta}{\rho} \int_{0}^{n_{r}^{r}}\left\{U_{G}\left[p R_{n}-z\left(e_{2}\right)-n z_{e} e_{R} R_{n}\right]\right\} d n^{r}-\kappa_{1} v \int_{0}^{n_{r}^{r}}\left\{U_{x}\left[z_{e} e_{R} R_{n}\right]\right\} d n^{r}-C_{2}^{f}
\end{aligned}
$$

Finally, if immigrants do not support their new region in the action to increase the provision of public good, then they may be expelled from region 2 irrespective of the outcome of the conflict. This scenario increases the cost of the conflict to the mobile group. In this case, they inevitably suffer the externality they moved to escape irrespective of the outcome of the conflict. Moreover, if the conflict succeeded, they would be denied the expected benefit expressed in equation (4.14) or (4.15). If the conflict failed and federalism was successfully defended, then expelled migrants will regain the benefit lost due to the regional mobility discount, area $a b c d$, given by

$$
a b c d=\int_{0}^{n_{r}^{*}}\left\{U_{G}\left[p R_{n}-z\left(e_{2}\right)-n z_{e} e_{R} R_{n}\right]\right\} d n^{r}-\frac{\beta^{n_{n}^{*}}}{\rho} \int_{0}^{*}\left\{U_{G}\left[p R_{n}-z\left(e_{2}\right)-n z_{e} e_{R} R_{n}\right]\right\} d n^{r}
$$

The expulsion also brings back the externality this group moved to escape as a cost, equivalent to area $0 e n_{1}^{r}$, and given by 
$0 e c n_{1}^{r^{*}}=\int_{0}^{n_{1}^{*}}\left\{U_{x}\left[z_{e} e_{R} R_{n}\right]\right\} d n^{r}$

If region 2 succeeded in increasing the public good, and in the process, for lack of support or for suspicions of insufficient support if migrants were expelled, the expelled residents would have benefit of

$a b n_{2}^{r}=\left[1-\frac{\beta}{\rho}\right] \int_{0}^{n_{2}^{r^{*}}}\left\{U_{G}\left[p R_{n}-z\left(e_{2}\right)-n z_{e} e_{R} R_{n}\right]\right\} d n^{r}$

and suffer an external cost equivalent to

$0 e c n_{2}^{r^{*}}=\int_{0}^{n_{2}^{r^{*}}}\left\{U_{x}\left[z_{e} e_{R} R_{n}\right]\right\} d n^{r}$

Hence, with a certain expulsion facing migrants, if region 1 is victorious with probability $\kappa_{1}$, then the net gain of the conflict to the migrants is given by combining equations (4.16) to (4.19), thus

$$
\begin{aligned}
& E N G_{e m}^{f}=\kappa_{1}\left\{\left[1-\frac{\beta}{\rho}\right]_{0}^{n^{\prime r}}\left\{U_{G}\left[p R_{n}-z\left(e_{2}\right)-n z_{e} e_{R} R_{n}\right]\right\} d n^{r}-\int_{0}^{n_{1}^{\prime}}\left\{U_{x}\left[z_{e} e_{R} R_{n}\right]\right\} d n^{r}\right\}+ \\
& \kappa_{2}\left\{\left[1-\frac{\beta}{\rho}\right]_{0}^{n_{r}^{\prime}}\left\{U_{G}\left[p R_{n}-z\left(e_{2}\right)-n z_{e} e_{R} R_{n}\right]\right\} d n^{r}+\int_{n_{1}^{r}}^{n_{2}^{r}}\left\{U_{G}\left[p R_{n}-z\left(e_{2}\right)-n z_{e} e_{R} R_{n}\right]\right\} d n-\int_{0}^{n_{2}^{r}}\left\{U_{x}\left[z_{e} e_{R} R_{n}\right]\right\} d n^{r}\right\} \\
& -\sigma \frac{\beta}{\rho} \int_{0}^{n_{r}^{r}}\left\{U_{G}\left[p R_{n}-z\left(e_{2}\right)-n z_{e} e_{R} R_{n}\right]\right\} d n^{r}
\end{aligned}
$$


It follows that with a certain prospect of expulsion, migrants almost certainly face a negative net gain in the event of conflict, irrespective of which region is victorious. For this reason, migrants are the least likely to support or tolerate any attempt at a nonconstitutional regime change. This group of individuals may work actively to prevent conditions that may lead to an attempt at an affront on the constitution. Migrants may thus be considered agents of stability.

\section{Unitarism}

In a unitary system when region 1 has a majority so that $n_{1}>n_{2}$, region 1 has two options at its disposal. First, it may decide to use its present political majority to reform the constitution and to enshrine federalism in the constitution. This will ensure that the control of resource use will not move to region 2 even if migration means that the majority moves to region 2 . Second, it simply continues with the same unitary decision making process for resource management. If the first option is followed and region 1 is successful in its desired constitutional reform from a unitary to federal resource exploitation regime, then the analysis of federalism given above would apply should region 2 ever develop a majority. If constitutional reform is initially viewed as unlikely so that current arrangements continue under unitary majority rule, then the analysis given below will be appropriate.

Suppose then that region 1 continues under the unitary decision making regime. Since $n_{1}>n_{2}$ initially, region 1 will control the level of resource exploitation and set the level of public good for all other regions. The level of the public good it sets will 
internalise the value of the negative environmental externality to it, and since any other level will reduce its welfare, region 1 will defend the constitution and its decision-making provisions. In doing so, however, it ignores the positive consumption values received by individuals in region 2.

Region 2, with the lower population size, desires a higher level of the public good. It experiences none of the pollution damage and sees that the value of its public good consumption is external to the decision making process. However, it presently lacks the political majority to ensure this level of the public good will be produced. Region 2 then has two options to choose from in its pursuit of realizing its desired level of the public good. The first is to continue within the regime and ensure that a sufficient number of individuals will migrate from region 1 to region 2 so that original region 2 residents plus immigrants exceed the number remaining in region 1 , i.e., $n_{2}+\left(n_{1}-k^{*}\right)>k^{*}$. Because the level of migration will depend on the welfare difference arising across regions (due to the resource externality), $\beta$, and $\rho$, and because accurate information is costly to come by, region 2 may organise to supply information on the resource externality, $\beta$ and $\rho$ to potential migrants in region 1 . Although the information supplied on $\beta$, and $\rho$ may or may not be truthful, the provision of information is one non-violent means of bringing about the population movement needed under current constitutional decision-making rule. Hence it will be politically appealing to proclaim itself part of a glorious country where individuals have the right and freedom to relocate to any region within the country and to become fully integrated into that region. Politicians in region 2 will then have an incentive to de-emphasise ethnicity and other regional differences and focus on national 
unity to further opportunities for all individuals in all regions irrespective of region of origin. These political strategies target raising $\beta$ and lowering individual and group values of $\rho$ to ensure a sufficient flow of migrants from region 1 to region 2 in the hope of changing the balance of political power to region 2. Suppose that for the region collectively, the cost of political propaganda and information activism is $C P A_{2}$ and that it succeeds within the peaceful political process with probability $(1-\omega)$. Then the expected gain to region 2 from such activity less the cost, $C P A$, is given as

$$
E N G_{2}^{\mu p}=(1-\omega) \int_{n_{1}^{r^{*}}}^{n_{2}^{r_{2}^{*}}}\left\{U_{G}\left[p R_{n}-z\left(e_{2}\right)-n z_{e} e_{R} R_{n}\right]\right\} d n^{r}-C P A .
$$

In response to the strategic use of propaganda and information by region 2 , region 1 may resort to supplying its own information on $\beta$ and $\rho$ to persuade residents of region 1 who may consider migrating against taking such steps. In doing so, politicians from region 1 will emphasize information that suggests that $\beta$ is lower and $\rho$ is higher than might have been thought. Alternatively, efforts may be made to lower $\beta$ and/or raise $\rho$ directly. Knowing that the change in political majority from region 1 to region 2 will lead to higher pollution/lower productivity and hence a lower net gain from the public good, individuals in region 1 would be willing to pay a price to prevent such an outcome. If region 1 succeeds in preventing migration, with probability $\omega$, then the cost of its campaign, $\mathrm{CPA}_{1}$, would be subtracted from the gain of not losing welfare from region 2's choice of public good output. This is equal to 


$$
E N G_{1}^{u p}=\omega \int_{n_{1}^{r_{1}}}^{n_{2}^{r^{*}}}\left\{U_{G}\left[p R_{n}-z\left(e_{1}\right)-n z_{e} e_{R} R_{n}\right]-U_{x}\left[z_{e} e_{R} R_{n}\right]\right\} d n^{r}-C P A_{1}
$$

If region 1 fails to prevent sufficient migration, then its net loss from the change in the political majority to region 2 is given by the sum of these terms. Here $C P A_{1}$ is the cost of political activism to region 1 .

Region 1 may choose to not participate in the political process, and may instead try to take steps to ensure the level of the public good is not changed through the political process by threatening to fight any change in the regime. If region 2 threatens to defend, at all cost, the constitution then a negotiation may be possible before the change in the regime through migration. Assume that the expected gains expressed in equation (4.11) remains true. Then region 2 may choose a political and/or a unilateral strategy depending on the following possibilities.

i) If equation (4.21) is negative, then region 2 may not be able to change the level of the public good even in unitary regime either politically or through a unilateral process, because it does not have sufficient incentive to do either. In this case region 2 may as well accept the public good at the level set by region 1 under unitarism

ii) If equation (4.22) is negative but (4.21) is positive then region 2 does not have incentive to act unilaterally. Its best strategy is to work within the present constitutional framework and seek a political change to the level of the public good. Regions 2 may be able to change the political majority from region 1 to its region. This is because, the possibility of achieving a high enough immigration 
that would give it a majority is more probable. In this case, region 2's strategy is to encourage cross-regional migration and a strong constitutional democratic process, and discourage unilateral action by any region. In response to this, and knowing that it may lose the political game on migration, region 1 may choose to negotiate to fix the level of the public good at a mutually acceptable level rather than let migration change the current equilibrium.

iii) If equations (4.11) and (4.21) are both positive, then region 1 faces both a political and an extra-constitutional threat from region 2. Region 2 may choose to remain within the constitution to make its struggle constitutional since it may be able to achieve a majority through this means. Since region 1's strategy of increasing the public good also reduces the benefit of political action to region 2 , it may combine this with a threat to unilaterally change the decision making process to federalism, should the political majority changes to region 2 . With its cost of conflict raised by region 1 following an increase in the level of public good, if this eventually leads to a negative expected net gain from conflict (equation (4.11)), region 2 may stop further attempts at changing the political majority in order to increase the public good. Moreover, further emigration from region 1 may lead to a net decrease in equation (4.11) for region 2, as a result of increased cohesion in region 1.

Potential immigrants respond both to information supplied by regional politicians and to the reality of $\beta$ and $\rho$. When information on the true states of $\rho$ and $\beta$ is complete 
and accurate, then strategic political actions, misinformation, and/or propaganda will have no impact on the level of migration. This is because individuals are able to assess the externality impact of resource use and resulting regional welfare differences so that knowing the true values of $\beta$ and $\rho$, individuals make a fully informed decision on whether to migrate. In such a mobility equilibrium, regional populations are the outcome of fully informed decisions by individuals from observed welfare differences and actual levels of $\beta$ and $\rho$. Hence to alter these circumstances, political leaders in the regions must actually effect real and observable changes in $\beta$ and $\rho$. Thus individuals and/or political leaders in region 2 can improve their prospect of controlling decisions over resource use only by working to increase the degree of acceptability of immigrant workers, $\beta$, and by reducing the degree of regional ethnicity, $\rho$, in all regions and across all individuals. Similarly region 1 can retain its political majority and thus its control of resource exploitation only by encouraging attachment to geographic distinctiveness and ethnic difference and by emphasizing the cost of achieving acceptance upon moving. When information costs are low so that regional strategies are subject to competition, the real costs of political action is known and pronouncements become truthful since individuals and groups can and will verify conflicting claims. In such circumstances, the equilibrium that arises under mobility becomes stable.

When there exists information asymmetry on the nature of $\beta$ and $\rho$, and when individuals are not fully aware of cross regional welfare differences, opportunities are created for information management and strategic information dissemination. The result is that the migration equilibrium may become unstable. If information supplied by 
individuals and politicians from region 2 dominates that from region 1 , then more migrants will move to region 2 and a change in political majority could result artificially. Misinformed individuals, who relocate to region 2 to escape the externality and enjoy higher welfare, soon realise that either regional welfare differences were exaggerated or their acceptance levels in region 2 is lower than promised by political leaders in region 2 . Hence some portion of the new immigrants will move back to region 1 to work to undo whatever political changes arose as a result of their initial movement to region 2 . On the other hand, if information supplied by individuals and politicians from region 1 dominates the information space, then movement from region 1 to region 2 is artificially hindered and the political decision-making remains within region 1. This short run equilibrium may be more durable than the corresponding equilibrium that arose when the information space was dominated by politicians from region 2 . This is because individuals have not moved yet and hence are not in the same position to verify the truth concerning the asserted values of regional welfare differences and the values of $\beta$ and $\rho$. Hence if $n_{1}>n_{2}$ in a unitary system, then both regions may work within the constitution and political activism will be directed either at encouraging or discouraging migration in order to change or preserve the political majority.

In the long run, however, the information asymmetry will disappear and information will equalize across individuals. As a result, the mobility equilibrium will converge on the stable full information equilibrium discussed earlier. If under this equilibrium the political majority changes from region 1 to region 2 , then the level of resource exploitation will also change to reflect the new political reality. In this case, the 
provision of the public good is increased to $G=G_{2}{ }^{*}>G_{1}{ }^{*}$, the externality is increased, and the welfare gap across regions widens. It is now individuals from region 1 become aggrieved, first from losing political control over "its" resource, and secondly by the further deterioration in their welfare as a result of the new, higher resource exploitation level set by unimpacted region 2 . The new level of the public good and the larger welfare gap gives rise to a second wave of migration into region 2 that only consolidates the political majority in region 2 and erases any hope of region 1 regaining political control within the unitary framework.

It is then apparent that further movement increases ethnic attachment and builds regional political cohesion in region 1 while doing the opposite in region 2. Individuals in region 1 now recognize that their desires are no longer achievable within the current constitutional framework, and hence bolstered by the increased degree of political cohesion amongst themselves begin to consider unilateral actions to improve regional welfare and exert regional control of the resource. The increased degree of political cohesion that follows the exit of less committed neighbours will increase $\kappa_{1}$, the probability that region 1 will be victorious in such a unilateral struggle even as it losses population to region 2. However, with a gain in welfare equivalent to area $c f n_{2}{ }^{r^{*}}$ in Figure 6 , region 2 will wish to defend the constitutional framework and will succeed in doing so with probability $\kappa_{2}$. While it has gained in strength with immigration, the further polarization of regional positions increases the possibility that the resource may be destroyed in a prolonged conflict, with probability $\sigma$. Together these considerations point to some type of political compromise. 
Under unitarism, with the change in political majority from region 1 to region 2, accompanied by sudden worsening of the welfare of residents of region 1, region 1 may choose a unilateral action to institute federalism. Let the expected gain in doing so be given by

$$
\begin{aligned}
& E N G_{1}^{u}= \kappa_{1} \int_{0}^{n_{1}^{* *}}\left\{U_{G}\left[p R_{n}-z\left(e_{1}\right)-n z_{e} e_{R} R_{n}\right]-U_{x}\left[z_{e} e_{R} R_{n}\right]\right\} d n^{r} \\
&+\kappa_{2} \int_{0}^{n_{2}^{\prime *}}\left\{U_{G}\left[p R_{n}-z\left(e_{1}\right)-n z_{e} e_{R} R_{n}\right]-U_{x}\left[z_{e} e_{R} R_{n}\right]\right\} d n^{r} \\
&- \int_{0}^{n_{2}^{* *}}\left\{U_{G}\left[p R_{n}-z\left(e_{1}\right)-n z_{e} e_{R} R_{n}\right]-U_{x}\left[z_{e} e_{R} R_{n}\right]\right\} d n^{r}-C_{1}^{u} \\
& E N G_{1}^{u}=-\kappa_{1} \int_{n_{1}^{*}}^{n^{*}}\left\{U_{G}\left[p R_{n}-z\left(e_{1}\right)-n z_{e} e_{R} R_{n}\right]-U_{x}\left[z_{e} e_{R} R_{n}\right]\right\} d n^{r} \\
& \quad-\sigma \int_{0}^{n_{2}^{*}}\left\{U_{G}\left[p R_{n}-z\left(e_{1}\right)-n z_{e} e_{R} R_{n}\right]-U_{x}\left[z_{e} e_{R} R_{n}\right]\right\}-C_{1}^{u}
\end{aligned}
$$

and $\mathrm{C}_{1}{ }^{\mathrm{u}}$ is the cost to region 1 of undertaking the unilateral action unitary system. Notice that in equation (4.23) the first term will be positive if there is a negative welfare gain to region 1 due to the increase in resource use from the level optimal to region 1 , to a region 2 set unitary level. In which case destroying the resources becomes a viable option for region 1 . A region 2 victory only preserves the status quo unitary level of public good without the possibility of region 1 being expelled from the union, since the resource is in this region. It follows that except the increase from $\mathrm{G}_{1}{ }^{*}$ to $\mathrm{G}_{2}{ }^{*}$ leads to a welfare increase 
for region 1, equation (4.23) will almost always be positive. This is true if there is a high level of negative externality from increased resource us, except if the probability of a region 2 victory, $\kappa_{2}$, is very high, and the overall welfare to region 1 from the new level of the public good is positive. This positive expected net gain gives region 1 a strong incentive to seek a unilateral change to the status quo.

On the contrary, region 2 will seek to defend the current constitution and decision-making process with an expected net gain given by

$$
\begin{aligned}
E N G_{2}^{u}= & \kappa_{2} \int_{n_{1}^{r^{*}}}^{n_{2}^{*}}\left\{U_{G}\left[p R_{n}-z\left(e_{1}\right)-n z_{e} e_{R} R_{n}\right]\right\} d n^{r} \\
& -\left(\kappa_{1} V+\sigma\right) \int_{0}^{n_{1}^{r^{*}}}\left\{U_{G}\left[p R_{n}-z\left(e_{1}\right)-n z_{e} e_{R} R_{n}\right]\right\} d n^{r}-C_{2}^{u}
\end{aligned}
$$

From equations (4.23) and (4.24), three possible cases become apparent.

i) If equation (4.23) is negative, then region 1 has strong incentive to negotiate a compromise solution. This case reflects a situation where the public good is so important to region 1 that the impact of its destruction crowds out any expected gain from unilateral action. In this case region 1 does not have incentive to carry out unilateral action. Since region 2 has the decision making power in a unitary system with a majority in region 2, this serves region 2's interest and it does not have any incentive to concede any ground to region 1 . However, even if region 1 feels disenfranchised, and feels discontent with the status quo, there is no 
incentive for it to undertake any unilateral action, because its expected net gain from doing so is negative. In this case region 1 does not have strong incentive within the model to fight for a change in the level of resource. This is the case where either the welfare gain to region 1 from success is low, or it has low probability of victory, $\kappa_{1}$, or there is a high probability that the resource will be destroyed in a prolonged conflict and it views the public good as very important. In this case region 1 may simply acquiesce to the status quo in which region 2 , with a higher population, takes the decision on the level of resource use, concomitantly, the level of the public good.

ii) If equation (4.23) is positive and (4.24) is negative, then region 1 has a strong bargaining position. This is because the destruction of the resources might be welfare improving to region 1 , a possibility that may impose a huge cost on region 2. Region 2's strategy in this regard is to increase the cost of such destruction of the resources to region 1 . This is done by conceding to reducing the resource exploitation level to the level that will make equation (4.23) zero. At this level, region 1 becomes indifferent between conflict and no conflict. Especially by ensuring that the public good level results in a net gain to the welfare of region 1 residents, an improvement from the rigid region 2 - controlled unitary level, region 1 may find it welfare-reducing to destroy the resources. 
Figure 8: Negotiation Equilibrium and Limit of Negotiation Under a Unitary System

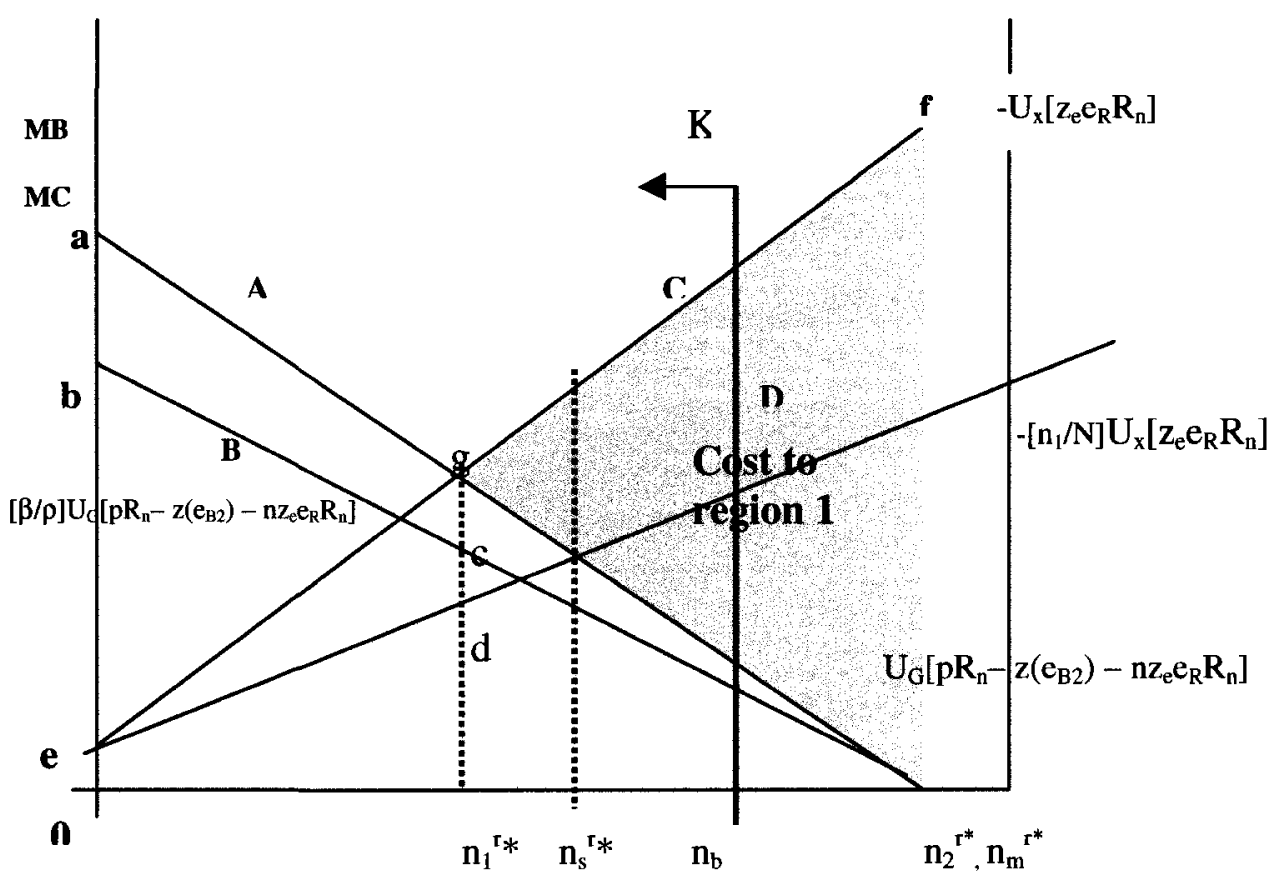


iii) If equations (4.23) and (4.24) are both positive, then the two regions do not have incentive to negotiate a peaceful resolution. However, the credible threat of destroying the resources offered by region 1 may force region 2 to concede some grounds to region 1 as discussed in case (ii) above.

We have discussed, in the section under federalism above, how a double positive expected net gain may arise, and the limit of negotiations and concession aided by internal institutions.

Proposition 7: If the possibility exists that working within the constitution can bring about desired regional change, even if this possibility is remote and the full achievement of regional demands unlikely, regions may prefer exploring this possibility within the existing constitutional and political framework and not seek unilateral action to achieve desired regional outcomes. The absence of marginal flexibility inhibits compromise so that strict and inflexible constitutional frameworks encourage unilateral extra-constitutional actions by aggrieved regions.

Corollary 7.1: Under certain conditions conflict may be the result of a rational decision, in which external intervention may be necessary to prevent a conflict.

Although the root causes of disagreements across regions are real, violent conflict and the failure to peacefully resolve the dilemma of inconsistent demands may be the result of asymmetric information on the problems fundamentals, or expressed differently, 
different perceptions of $\kappa_{1}$ (and $\kappa_{2}$ ). Since the probability of victory by region $1, \kappa_{1}$, is impacted positively by the increased level of cohesion and negatively by the rising population proportion $n_{2} / \mathrm{N}$ - the proportion of population resident in region 2- ambiguity exists on which factor will dominate. Moreover, as it has been shown, new migrants to region 2 have less incentive to support region 2 in conflict with region 1 to increase the public good and this is reflected in a weakening of political consensus relative to their rising population size. Hence a higher population share in region 2 may not necessary reflect a higher probability of victory by region 2 in a conflict with region 1 , even if the leaders/risk-taking entrepreneurs of region 2 may erroneously believe this to be true. Similarly, a somewhat smaller but more cohesive region 1 may give its leaders an erroneous signal on $\kappa_{1}\left(\kappa_{2}\right)$. Because both regions can believe they enjoy a higher probability of success and thus perceive higher than actual expected gains from the conflict, misperception can lead to conflict. Thus if information on regional welfare disparities, $\beta$, and $\rho$ is imperfect, and individuals are not aware of the true state of these factors, then, information activism and information mismanagement become viable strategies for political leaders from both regions, which can keep reasonable peaceful resolution unrealised. Hence with high information/verification costs, risk taking regional political entrepreneurs may see information management as an effective tool for promoting regional concerns. With competing risk taking political entrepreneurs misinforming individuals on the posture of mobile voters, regional cohesion, and welfare disparities, miscalculations in bargaining power may lead to decisions that escalate into 
violence. Other channels through which information asymmetry may lead to conflict in our model are analysed in chapter 5 .

Proposition 8: Under the assumptions of our model, when individuals are fully informed of regional welfare differences, cross-regional acceptability upon migration, and the displacement costs of moving, the presence of migration is stability enhancing. However, if there exist information asymmetries on regional welfare differences, acceptability, cost of movement, then mobility can provoke political instability as the result of strategic non-truthful information supply.

Proposition 8 follows from the fact that, as explained above, if the true cost of migration is not contained in the information set supplied to potential migrants, then information updating may take place upon migration. If the updated information on the true cost of migration, cross-regional acceptability and welfare difference across regions differ substantially from what was thought before migration, then such updated information may lead individuals to change their attitude towards resource exploitation at its current levels. This may also lead to individuals voting for a different level of resource use in the next election cycle. If migration based on the initial set of information led to a change of political majority from one region to another, then the reversal of the direction of movement due to updated information may lead to another change of the political majority. 
The conclusions of this analysis and the proposition that rational conflict is possible derive from the following critical assumptions. First, the public good produced from resource revenues is not a substitute for a private good. Second, resource revenues must be used to produce a public good. Third, other forms of transfer are blocked. Thus while all regions enjoy the benefits from any increase in the public good, the externality from resource production is strictly local. Furthermore, the fact that revenues from the resource do not go to providing a private good for any region makes it infeasible for the unaffected region to use some of the revenue to pay for the externality. It follows that paying the impacted region with part of the proceeds of resource exploitation does not make any one better off. This is because it reduces the public good to all with no benefit to the region not impacted by the externality. Also, because of the convexity of the cost function both sides are necessarily worse off than they would be were the extra unit of the resources that generated the revenue not produced. Furthermore, by limiting mobility across regions, traditional means of minimizing welfare differences are blocked. That is, mobility has the effect of enabling those affected by the externality to escape by emigrating to the other region, since the marginal productivity of land in this region is unaffected by the resource externality. 


\section{CHAPTER 5}

\section{Measuring Stability and Predicting Conflict}

\subsection{The Development of a Stability Index}

In this chapter we develop a function to express the relationship not between individuals or groups within the current political equilibrium but the relationship between the characteristics of the current political equilibrium and the probability of conflict across regions (initially when there is no mobility). By invoking conflict, the analysis now introduces non-traditional forms of bargaining, what we call extra-constitutional forms of regional interaction. In our sense, then, the potential for conflict arises when individuals and groups begin to compare what currently is with what might be. Because this relationship involves the comparison of counterfactuals, we measure the probability of conflict by the degree of discontent with the status quo. Hence the probability of conflict function is fundamentally an increasing function of the difference between the welfare generated by the status quo equilibrium and the welfare achieved in the alternative equilibrium proposed by regions--the expected net gain to each region in pursuing a unilateral, extra-constitutional course of action to achieve its regional optima. In addition, we include as a separate term the absolute value of the welfare difference across regions weighted by the number of individuals who experience the lower welfare level. This second term is viewed as capturing the discontent arising from current differences in welfare. 
It follows that even when the current and potential status of all agents is perfectly understood, there are sources of discontent so that the potential for conflict will exist. However, because present differences are costly to determine and the alternatives to the status quo are unobservable and currently counterfactual, the measure of the welfare differences is inherently difficult to determine and hence subject to potential misrepresentation. For this reason we make the probability of violence also depend upon a parameter, $\lambda$, used as a measure of the accuracy of individuals' knowledge (or degree of bias in what is thought to be known). This will include knowledge of the difference in welfare that arises between the status quo and the regional optimum; the expected net gain arising to other regions in the event of unilateral action and potential conflict; and the degree to which individuals from every region are aware of current differences in welfare arising across regions. It is for these information problems that otherwise negotiable equilibria may fail to be realized and result in conflict.

Expressing these considerations in terms of a Stability Index, our discussion implies that

$$
\mathrm{SI}=\mathrm{SI}\left\{\xi\left(\mathrm{n}_{1} / \mathrm{N}\right), \lambda, \mathrm{ENG}_{1}, \mathrm{ENG}_{2}\right\}
$$

where $\left[\mathrm{U}_{1}-\mathrm{U}_{2}\right] \equiv \xi$ and where $\frac{\partial S I}{\partial \xi}>0$ and $\frac{\partial S I}{\partial \lambda} \geq 0$. (an increase in $\lambda$ signifying more bias) 
The factor $\xi$ incorporates the fact that any increase in resource exploitation will produce more $\mathrm{G}$ only at the cost of increasing the negative externality.

In what follows, we shall analyse the behaviour of the stability index first in the case when the externality affects all regions equally. Then discuss the specific cases when resource exploitation results in negative externality specific to one region, with mobility and without.

\subsubsection{Stability Index without Externality or when Externality Affects All Regions}

Recall the discussion on the optimal levels of resource exploitation in chapter 2 . It was shown there that when the median voter in all regions suffers the same externality, then the response to the level of public good produced from the resources is common, and unanimous. The optimal level of resource production was shown to be

$$
U_{G}\left[p R_{n}-z(e)+n z_{e} e_{R} R_{n}\right]=-U x\left[z_{e} e_{R} R_{n}\right]
$$

Similarly, in the special case where there is no externality associated with resource production, and all of the net revenue from resource use goes to produce the public good for all, then the optimal level of resource production is a modified version of equation (2.9). That is, when $z_{\mathrm{e}}=0$

$$
\mathrm{U}_{\mathrm{G}} \mathrm{dG} / \mathrm{dn}_{\mathrm{i}}^{\mathrm{r}}=\mathrm{U}_{\mathrm{G}}\left[\mathrm{pR} \mathrm{R}_{\mathrm{n}}-\mathrm{z}\right]=0,
$$


which, in turn, implies $\quad \mathrm{pR}_{\mathrm{n}}=\mathrm{z}$

where $\mathrm{z}$ is the value of the marginal productivity in the agriculture sector that ensures optimal allocation of labour between the agricultural and resource sectors.

All these cases imply no welfare differences across individuals across regions, and

$$
U_{1}=U_{l}\left(x_{l}, G\right)=U_{2}\left(x_{2}, G\right)=U_{2}
$$

Moreover, there will be a common response to changes in the market value of the resource, as shown in appendix 2.1 . Hence price change will not contribute to instability. It follows that in these cases, the term $\xi$, which measures the discontent arising from welfare difference across regions, will disappear from equation (5.2), and not contribute to instability.

$$
\begin{aligned}
\mathrm{SI}=\mathrm{SI} & \left\{\xi\left(\mathrm{n}_{1} / \mathrm{N}\right), \lambda, \mathrm{ENG}_{1}, \mathrm{ENG}_{2}\right\} \\
= & \mathrm{SI}\left\{0, \lambda, \mathrm{ENG}_{1}, \mathrm{ENG}_{2}\right\}
\end{aligned}
$$

$\left[\mathrm{U}_{1}-\mathrm{U}_{2}\right] \equiv \xi=0$

Next, recall from chapter 4 the terms for $E N G i$. Where everyone suffers the same degree ofh the externality, the optimal level of resource exploitation is unique across individuals, and this implies that any level of resource use that is different is inferior in terms of its welfare outcome. More specifically, if all regions suffer the externality, then the optimal level of resource is the level implied by 


$$
U_{G}\left[p R_{n}-z(e)+n z_{e} e_{R} R_{n}\right]=-U_{x}\left[z_{e} e_{R} R_{n}\right]
$$

Under any political decision-making regime - federalism or unitarism- this will be the level chosen by the median voter. This also means that irrespective of the probability of victory in a unilateral action by any region, the expected net gain in moving away from this level to any other lower or higher level of externality will be negative and result in a lower welfare for those proposing it. This negative expected net gain would also result if no externality were produced from resource use. It follows that no region would seek an alternative resource exploitation regime that would result in a different level of resource use from that favoured by the median voter in both regions if information is complete and clear, and if all regions suffer the same externality from resource use.

To see this more explicitly, consider the expected net gain given in (4.13a) and (4.11a) as

$$
\begin{aligned}
E N G_{e x t}= & -\kappa_{1} \int_{n_{1}^{*}}^{n_{2}^{* *}}\left\{U_{G}\left[p R_{n}-z\left(e_{1}\right)-n z_{e} e_{R} R_{n}\right]-U_{x}\left[z_{e} e_{R} R_{n}\right]\right\} d n^{r} \\
& -\sigma \int_{0}^{n_{2}^{* *}}\left\{U_{G}\left[p R_{n}-z\left(e_{1}\right)-n z_{e} e_{R} R_{n}\right]-U_{x}\left[z_{e} e_{R} R_{n}\right]\right\} d n^{r}-C_{e x t}
\end{aligned}
$$

and

$$
\begin{aligned}
& E N G_{n o e x t}=\kappa_{2} \int_{n_{1}^{r^{*}}}^{n_{2}^{r^{*}}}\left\{U_{G}\left[p R_{n}-z\left(e_{2}\right)-n z_{e} e_{R} R_{n}\right]\right\} d n^{r} \\
& -\left(\kappa_{1} V+\sigma\right) \int_{0}^{n_{1}^{r_{1}^{*}}}\left\{U_{G}\left[p R_{n}-z\left(e_{2}\right)-n z_{e} e_{R} R_{n}\right]\right\} d n^{r}-C_{\text {noext }}
\end{aligned}
$$


Equation (5.3) shows the expected net gain of a region affected by externality as it considers a unilateral action to ensure this externality is taken into full account in the decision on the level of resource exploitation. Also, equation (5.4) gives the expected net gain of a region that is not affected by externality as it considers a unilateral action to ensure externality on private consumption is not taken into account in resource production. It follows from the two equations that irrespective of the probabilities of victory $\kappa_{1}$ and $\kappa_{2}$, and the probability of destroying the resource in the process, $\sigma$, if all regions suffer the externality and a region pushes for a level of resource exploitation that ignores the externality its expected net gain will be negative. Irrespective of the outcome, this is true with a positive fixed cost of executing such unilateral action. Similarly, if no region suffers the externality and any region executes a unilateral action that implies an externality, the expected net gain for that region may be negative, especially with a fixed cost of implementing such unilateral action. These losses become more imminent with the existence of the probability that the resources may be destroyed in the event of a prolonged conflict. In these circumstances, the expected net gain may be negative and initiating a unilateral action becomes irrational for any region.

When the externality is symmetric, the stability index depends crucially on $\lambda$, the level and clarity of information in the country. Here, information asymmetry becomes the critical reason for the incidence of conflict in such resource producing countries, and

$$
\mathrm{SI}=\mathrm{SI}\left\{\lambda, \mathrm{ENG}_{1}, \mathrm{ENG}_{2}\right\}
$$


Information asymmetry may lead individuals to misrepresent or misperceive the level of welfare across regions, the expected net gains from constitutional change, the incidence of the externality across regions, and the link between the externality (where it affected all individuals) and welfare. This information asymmetry may be aggravated if there is limited mobility across regions for individuals to verify the perceptions they hold, and enrich the information set available to them.

If high mobility arises across regions, individuals are able to independently verify information supplied to them. For instance information on the incidence of externality, and the levels of welfare across regions may be verified relatively easily. Information on the nexus between the private good and the externality, where it exists, may be more difficult to obtain and/or verify. Also the welfare effect of an alternative resource use regime may become clearer after the facts.

For these cases, then, welfare difference across regions arising from the externality and the expected net gain from an alternative political decision making regime may play less of a role, in explaining conflict in resource producing countries, than do information problems. Information asymmetry and the motivation to exploit it may overwhelm both information verification and conflict prevention institutions. The cost to individuals to remove this asymmetry may also be too high in the short run, to police self-aggrandizing political elites. However, information problems may be reduced by the cross-regional mobility. In the long run information may cease to be an issue. 


\subsubsection{The Stability Index when the Externality Affects only Region 1}

\subsubsection{SI when there is no Mobility}

In the event that externality arises from resource production and this externality impacts only region 1, use of a natural resource to fund a national public good will result in welfare differences across regions. Individuals who currently experience lower welfare levels are not indifferent to welfare differences across regions, especially when these differences arise across individuals and groups that were previously equal. Because in our model individuals in region 1 will always have a lower level of welfare than those in region 2, this source of discontent will always be arising from individuals there. Nevertheless the size of this welfare difference will depend on which political system is in effect and will vary in importance in proportion to the percentage of the total population resident in region 1 . Hence even when region 1 has political control over the level of resource exploitation for the purpose of producing the public good and can produce at its preferred optimal level, individuals in region 1 will not be indifferent to their relative welfare position.

The factor $\xi$ incorporates the fact that any increase in resource exploitation will produce more G only at the cost of increasing the negative externality. Hence beyond region 1's optimum, the point where the marginal cost to region 1 just balances the marginal benefit from additional public goods, additional resource production reduces both private consumption and overall utility for individuals in region 1 . The concavity assumption ensures that beyond this point the marginal benefit from more units of the 
public good cannot compensate for the utility loss from further resource exploitation. On the other hand, because private productivity in region 2 is not adversely affected by resource exploitation, the increase in resource exploitation which increases the public good invariably also increases the welfare of region 2 residents. Hence the welfare difference across regions rises as $n^{r}$ moves from $n_{1}^{r^{*}}$ towards $n_{2}^{r}$.

Under federalism, region 1 makes the resource decision. Thus for region 1 any difference between its desired and the actual level of public good can be eliminated at its discretion. Hence despite the absolute difference in utility experienced by region 1 residents relative to region 2 , the marginal external cost of the public good to region 1 is just balanced by the marginal benefit so that region 1 has no reason to wish to go beyond the bargaining possibilities present in the current political equilibrium. Hence potential changes in the constitution do not add considerations that exacerbate the potential for conflict. In region 2, however, the desired level of the public good (and associated resource exploitation) is much higher than the level provided and since region 2 cannot change the level provided under current bargaining rules, region 2 will feel disenfranchised from the current political choice of G. Thus despite realizing a higher level of utility (due to unaffected agricultural productivity), individuals in region 2 feel that utility is lower than it would be if its desired level of $\mathrm{G}$ could be achieved. Implicitly they are comparing the status quo to what they could achieve if they could adopt the counterfactual political structure with its associated equilibrium.

Under unitarism, there is convergence with the federal case discussed above only in the case where the population of region 1 is larger than that in region 2. Here region 1 
will maintain the political majority and hence choose its optimal outcome. However, should the population of region 2 be larger than that of region 1 , the political majority will change regions, changing in turn the SI. With the political majority, region 2 will now set the level of $\mathrm{G}$ (by setting the level of resource exploitation) at its optimal level. While this level of $\mathrm{G}=\mathrm{G}_{2} *>\mathrm{G}_{1} *$ increases welfare for individuals in region 2 , in region 1 the increase in $\mathrm{G}>\mathrm{G}_{1}{ }^{*}$ gives rise to additional pollution and hence a lower level of private consumption in region 1 than would be experienced under federalism. For both these reasons, the welfare difference between the two regions, $\xi$, increases from the level experienced under federalism. In addition, however, region 1 experiences not only a widening gap in income and utility but also a sense of disenfranchisement by its loss of the ability to influence the use of "its" natural resource (to the other more affluent region). It follows that the change in the SI value in (5.1) must include both a measure of the level of discontent with the status quo held by a typical resident of region 1 (relative to potential) and a measure of the change in current welfare the additional externality arising from additional resource use. The latter, when multiplied by the size of the regional population, is our measure of the intensity of current discontent with the outcome of the political system.

Hence, restricting our attention only to the level of discontent arising within the current system, and letting $\psi$ represent

$$
\psi=\left(\mathrm{n}_{1} / \mathrm{N}\right) \xi=\left(\mathrm{n}_{1} / \mathrm{N}\right)\left[\mathrm{U}_{1}-\mathrm{U}_{2}\right]
$$


we can use (2.24) and (2.25), i.e.,

$$
\begin{aligned}
& \mathrm{U}_{1}=\mathrm{U}\left(\mathrm{x}_{1}(\mathrm{e})\right)+\mathrm{U}\left(\mathrm{G}\left(\mathrm{n}^{\mathrm{r}}\right)\right) \\
& \mathrm{U}_{2}=\mathrm{U}\left(\mathrm{x}_{2}\right)+\mathrm{U}\left(\mathrm{G}\left(\mathrm{n}^{\mathrm{r}}\right)\right)
\end{aligned}
$$

To substitute into (4.26), to find,

$$
\begin{gathered}
\Psi=\left(\mathrm{n}_{1} / \mathrm{N}\right)\left\{\left[\mathrm{U}\left(\mathrm{x}_{1}\right)+\mathrm{U}\left(\mathrm{G}\left(\mathrm{n}^{\mathrm{r}}\right)\right)\right]-\left[\mathrm{U}\left(\mathrm{x}_{2}\right)+\mathrm{U}\left(\mathrm{G}\left(\mathrm{n}^{\mathrm{r}}\right)\right)\right]\right\} \\
=\left(\mathrm{n}_{1} / \mathrm{N}\right)\left[\mathrm{U}\left(\mathrm{x}_{1}(\mathrm{e})\right)-\mathrm{U}\left(\mathrm{x}_{2}\right)\right]
\end{gathered}
$$

Substituting (5.6) back into (5.1) we find

$$
\begin{aligned}
& \mathrm{SI}=\mathrm{SI}\left\{\psi, \lambda, \mathrm{ENG}_{1}, \mathrm{ENG}_{2}\right\} \\
& =\operatorname{SI}\left\{\left(\mathrm{n}_{1} / \mathrm{N}\right)\left\{\mathrm{U}\left(\mathrm{x}_{1}(\mathrm{e})\right)-\mathrm{U}\left(\mathrm{x}_{2}\right)\right\}, \lambda, \mathrm{ENG}_{1}, \mathrm{ENG}_{2}\right\}
\end{aligned}
$$

Hence in this model the level of discontent arising from current welfare differences within the current political regime is dependent on how the resource externality affects private consumption across the two regions and on how well individuals are informed of the difference in welfare across regions.

In the absence of parameter changes and mobility, the level of discontent within the country will not change through time. This is because there is no endogenous factor to 
alter welfare differences and the inability to move leaves unchanged the population weight, $\mathrm{n}_{1} / \mathrm{N}$, and thus the political equilibrium. Following parameter changes, such as a change in the resource price, welfare differences will change and the number of individuals who would be willing to relocate will change. Implicitly, the extreme values given to $\beta / \rho$ prevent individuals from doing so.

Under federalism and in the absence of information distortions, the welfare disparity arising across regions due to the externality, i.e., $\psi>0$, is insufficient to lead to regional conflict. This is because region 1 who suffers the lower welfare position also exercises control over the natural resource and so will internalise the externality in deciding on the level of resource to be exploited. Discontent within region 1 may arise among individuals who are willing to relocate to enjoy higher welfare but are unable to relocate to escape the externality because of prohibitively low levels of acceptability or high costs of movement. This grievance of the potential migrants is not associated with the level of public good but with structural impediments within the system. Hence, in the case of federalism and in the case of unitarism when $n_{1}>n_{2}$, the potential threat to stability will come from region 2 which is the only region that believes it could do better under an alternative public choice mechanism. In addition, even though in both these cases region 2 has imposed on it an inferior solution (to the one it would choose if it had unilateral political power), a change in the constitution in the political decision-making regime from federalism to unitarism would still not allow it the means to achieve its optimal solution. Region 2 would still find itself outvoted. Hence it is only when federalism forms the status quo and $\mathrm{n}_{2}>\mathrm{n}_{1}$ that there is the potential for region 2 to 
attempt constitutional change and so provoke regional conflict. This is because region 2 knows that it would improve its welfare if a change in political regime, to unitarism, could be engineered (costlessly). In this case $E N G_{2}>0$ may be the driver of conflict. It is a necessary but not sufficient condition for regional conflict and political violence.

As we have argued above, the stability index includes the net gains, $E N G_{i}$ that one region would expect to gain from initiating unilateral extra-constitutional action to achieve their optimal resource choice/public good outcome and the $E N G_{j}$ that the opposing region would expect to realize by opposing such an action rather than acquiescing. The higher is the value of the $E N G_{i}$, for either region, the higher is the probability of conflict since the expected gain both from victory by the belligerent region and from opposition by the region defending the status quo are higher. Note that even a low probability of success may give sufficient incentive to initiate unilateral action if the gain with success is large enough. Since only a subset of possibilities is needed to represent the cases leading to and standing in the way of potential conflict, we define an effective expected net gain function $\left(E N G_{e f f}\right)$ to capture the discrete changes in the probability function (the step characteristic in the stability index) that arise as the individual ENG values cross between negative and positive values. This is modelled to take into account the various cases discussed in sections (4.1) to (4.3). More formally, let

$$
E N G_{e f f}=\operatorname{STEPFXN}(E N G i, E N G j) .
$$


Where region $i$ is the belligerent region and region $j$ is the defender of the status quo (that favours it). Then $E N G_{\text {eff }}$ can take on three values as a step function that result in the stability index registering a probability of conflict that is

i) LOW, if $E N G i<0$ and region $\mathrm{j}$ has constitutional and political control over resource use.

Here there is no incentive for the disenfranchised region to undertake unilateral action.

ii) MEDIUM, if $E N G i>0$ and $E N G j<0$ and region $\mathrm{j}$ has constitutional and political control of the resources. Here there are potential net gains to negotiating a compromise level of resource use before unilateral action is initiated.

iii) $\mathrm{HIGH}$, if $E N G i>0$ and $E N G_{j}>0$, and region $\mathrm{j}$ has constitutional and political control of the resources. Here there is no intermediate level of resource use that would eliminate the use of unilateral action by $i$.

The probability of belligerence by region 1 is higher if region 1 feels disenfranchised and the probability of victory, $\kappa_{1}$, in the event of a conflict, is higher. Conversely, if $\kappa_{1}$ and $\sigma$ are low, (that is, $\kappa_{2}$ is high and there is a low probability of the destruction of the natural resource) and/or there is a huge gain in the event of victory, then region 2 is more likely to initiate a unilateral, extra-constitutional course of action if its desired level of the public good is denied. Since the group with the highest net gain from unilateral action is the group that is most likely to start an action, the effective $E N G\left(E N G_{e f f}\right)$ that will influence the probability of conflict is the highest $E N G$ in the group. 
With this background, we then complete the Stability Index (SI) begun in (5.1) by substituting in our $E N G_{\text {eff }}$ function for the two individual values of ENG. Hence in the absence of mobility across regions, (5.1) becomes:

$$
\mathrm{SI}=\mathrm{SI}\left\{\psi, \lambda, E N G_{\text {eff }}\right\}
$$

where $\quad \frac{\partial S I}{\partial \psi}>0 ; \quad \frac{\partial S I}{\partial \lambda}>0 ; \quad \frac{\partial S I}{\partial E N G_{\text {eff }}}>0$.

The function SI is then a mapping of the level of discontent, information uncertainty, and regional disenfranchisement onto the domain $[0,1]$. As such, the SI function becomes a probability index with $0 \leq \mathrm{SI} \leq 1$. Under perfect information $(\lambda=0)$ when the externality impacts all individuals in all regions, $\psi=0$ and $\mathrm{ENG}_{\text {eff }}=0$ so that $\mathrm{SI}=0$. Then, as differences in the optimal degree of resource use increase across regions, there arises an increase in the probability of conflict across regions measured as a rise in the SI index above zero. Moreover, holding actual and expected welfare differences constant, the index also captures the feature that the probability of conflict can increase or decrease depending on the information held by individuals and hence on individual beliefs about welfare disparity arising across regions and the link between this disparity and the externality. While we assume that in the long run individual beliefs of differences will converge on actual differences, in the short run misperceptions can arise that may be exploited (or created) for political advantage by risk taking political entrepreneurs.

In the case where $E N G_{i}<0$ and region $\mathrm{j}$ has constitutional control over resources, then $E N G_{\text {eff }}=L O W$ and $\mathrm{SI}=\mathrm{SI}\left(\psi, \lambda, E N G_{\text {eff }}\right)$ will also be low. This is the situation in 
which there exists only normal discontent in the system $(\psi>0)$ arising from welfare differences across regions. Such discontent is unlikely to lead to political instability, either because the region that feels disenfranchised has a low probability of success in an extra-constitutional action or because there is little gain to be made if such action succeeded. Moreover, if region 1 has political control over the resource, then even with $\psi$ $>0$ differences in welfare will not exacerbate the potential for conflict because region 1 already has control over the level of resource use. As mentioned earlier, displeasure may arise among prospective emigrants who are prevented from emigrating, however, such displeasure among this marginal group will be insufficient to cause conflict. On the other hand, if region 2 controls resource use, there remains an uneasy peace. Unless the regions come to see their offsetting positions as a form of a political compromise, instability may reappear as the aggrieved region's probability of victory or potential gain from initiating action increases.

When we turn from federalism to unitarism, it is immediately apparent that if the population of region 1 is large enough that the political majority still resides with region 1 , then the circumstances with respect to the likelihood of conflict will be identical with the federal result discussed immediately above. However, if the population of region 2 is larger than that of region 1, the SI will be impacted differently. Holding the political majority, region 2 will now set its optimal level of $\mathrm{G}$ (by setting the level of resource exploitation). This higher level of $\mathrm{G}=\mathrm{G}_{2}{ }^{*}>\mathrm{G}_{1} *$ gives rise to more of the externality and hence results in a lower level of private consumption in region 1 than would be experienced under federalism. This means $\psi=\left(\mathrm{n}_{1} / \mathrm{N}\right)\left\{\mathrm{U}_{1}\left(\mathrm{G}_{2}{ }^{*}\right)-\mathrm{U}_{2}\left(\mathrm{G}_{2}{ }^{*}\right)\right\}>$ 
$\left(\mathrm{n}_{1} / \mathrm{N}\right)\left\{\mathrm{U}_{1}\left(\mathrm{G}_{1}{ }^{*}\right)-\mathrm{U}_{2}\left(\mathrm{G}_{1}{ }^{*}\right)\right\}>0$. Hence compared to its position under federalism, region 1 experiences not only a decrease in income and a widening of the utility gap with region 2 , but it also experiences political disenfranchisement through the loss of control over the level of its natural resource. The increased externality and its impact on lower private consumption increases the expected net gain $\left(E N G_{I}\right)$ that would be realized from a successful extra-constitutional attempt to (re)claim control of the resource exploitation regime. These effects then compound the increase in the probability of conflict between the regions. This time political turmoil and conflict may originate from region 1 .

Even if $\psi$ does not change over time, changes in $\lambda$ can lead to changes in the SI, as can changes in $\rho$ that change $\kappa_{1}, \kappa_{2}$ and $\sigma$ (which in turn impact $E N G_{e f f}$ and SI). Hence, in the absence of mobility, the probability of political conflict arising from resource exploitation not only depends on how the externality affects relative private consumption across regions and the factors underlying the expected net gains from initiating extraconstitutional change, but also on how accurately individuals are aware (or informed) of differences arising across regions. As we have seen, if the natural resource is evenly distributed across regions and/or the negative externality suffered equally by all individuals across the country, then, as shown in chapter 2 and section 5.1.1, $\psi$ would be zero and there would be no particular gain $\left(E N G_{i}\right)$ in initiating a unilateral action to change the constitution because the federal and unitary resource levels would equalize. However, here individuals need to be aware and informed accurately of the consequences of resource use and its use in the production of the public good to prevent their manipulation by different political elites. Only under both sets of circumstances would 
the SI tend towards zero. On the other hand, to the extent that resource discoveries and their externalities are region specific, $\lambda$ is likely to rise above zero, further increasing the SI index. As long as at least one of the ENG's is negative, political compromise remains feasible, but potentially subject to frustration by the cost of accurate information. Finally when $E N G_{1}>0$ and $E N G_{2}>0$ we expect real difficulties and the $\mathrm{SI} \rightarrow 1$.

Proposition 9: Under the assumptions of our model, the geographic fractionalization of resource revenues and resource externalities create regional tensions and the potential for political instability. Although negotiations to defuse tense political situation are often feasible, such peace negotiations may not take place. In such case, information asymmetry may prevent the realization of mutual gains from cooperation. In certain situations promise will not be feasible. Hence, even a minority region that is highly unlikely to be victorious in a violent conflict may initiate small-scale conflicts to strengthen regional cohesion to win concessions from a stronger majority.

\subsubsection{Mobility Augmented Stability Index}

In this section we add mobility considerations to our analysis of political conflict and social instability and ask whether the increase in individual (and perhaps aggregate) social welfare arising from mobility invariably reduces the probability of conflict. We do this in the context of the comparative static exercise of asking how the probability of conflict responds to a change in acceptance, i.e., $\beta$, when individuals can move across 
regions. The key question of concern is determining the circumstances under which mobility can increase the likelihood of political conflict.

Recall that in the absence of mobility, in section 5.1.2.1 above, the probability of conflict was derived as a function of the difference in the level of welfare of the representative individual in one region and the level in the other region $\psi$; a term representing the degree of information incompleteness or asymmetry in the system, $\lambda$; and a term (a step function) representing the perceived net gain to the regions of taking extra-constitutional action to change the decision making process by which resource use is determined, $\mathrm{ENG}_{\mathrm{eff}}$. This resulted in the Stability Index (SI) given as:

$$
\mathrm{SI}=\mathrm{SI}\left[\psi, \lambda, E N G_{e f f}\right]
$$

where $0 \leq \mathrm{SI} \leq 1$ is a probability index.

When mobility across regions is allowed, as discussed at length in section 3.1 above, the probability of conflict is affected further. Here the extent of population movement will be geared to the individual premium required to leave the region of one's birth, $\rho$, and the obstacle to acceptance in the targeted region of settlement, $\beta$. In combination these considerations form a mobility barrier. To distinguish this version of the Stability Index from the case without mobility, we now call the SI index the Mobility Augmented Stability Index (MASI).

In our earlier discussion in chapter 3 [equation (3.24)], we saw the last migrant to leave region 1 was only marginally better off than those that remained in region 1 . Hence all who remain in region 1 experience roughly the same level of welfare as the marginal 
mover who is just indifferent between moving out or staying. It follows that those who remain in region 1 and continue to suffer the negative externality face a cost in lost utility equal to the utility lost by the marginal migrant who escaped the consequences of the externality only to lose from their loss of attachment to their region and their inability to integrate completely into the life of region 2 . The equality of these returns on the margin implies that when migration is at $\mathrm{k}^{*}$

$$
\mathrm{U}_{1}=\mathrm{U}\left(\mathrm{x}_{1}(\mathrm{e})\right)+\mathrm{U}\left(\mathrm{G}\left(\mathrm{n}^{\mathrm{r}}\right)\right)=\beta / \rho\left(\mathrm{k}^{*}\right)\left[\mathrm{U}\left(\mathrm{x}_{2}\right)+\mathrm{U}\left(\mathrm{G}\left(\mathrm{n}^{\mathrm{r}}\right)\right)\right] .
$$

Then substituting $U_{1}$ from (3.24) into (4.29), we find as our revised stability index that,

$M A S I=\mathrm{SI}\left\{\left(\mathrm{n}_{1} / \mathrm{N}\right)\left|\beta / \rho\left(\mathrm{k}^{*}\right)\left[\mathrm{U}\left(\mathrm{x}_{2}\right)+\mathrm{U}\left(\mathrm{G}\left(\mathrm{n}^{\mathrm{r}}\right)\right)\right]-\left[\mathrm{U}\left(\mathrm{x}_{2}\right)+\mathrm{U}\left(\mathrm{G}\left(\mathrm{n}^{\mathrm{r}}\right)\right)\right]\right|, \lambda, \quad E N G_{e f f}\right\}$,

where migrant and region 2 incumbent utilities differ only by the multiplicative term, $\beta / \rho\left(k^{*}\right)$.

Hence we can simplifying by using

$$
\begin{aligned}
\psi^{m}=\left(\mathrm{n}_{1} / \mathrm{N}\right)\left\{\beta / \rho\left(\mathrm{k}^{*}\right)\left[\mathrm{U}\left(\mathrm{x}_{2}\right)+\mathrm{U}\left(\mathrm{G}\left(\mathrm{n}^{\mathrm{r}}\right)\right)\right]-\left[\mathrm{U}\left(\mathrm{x}_{2}\right)+\mathrm{U}\left(\mathrm{G}\left(\mathrm{n}^{\mathrm{r}}\right)\right)\right\}\right. \\
=\left(\mathrm{n}_{1} / \mathrm{N}\right)\left[\mathrm{U}\left(\mathrm{x}_{2}\right)+\mathrm{U}\left(\mathrm{G}\left(\mathrm{n}^{\mathrm{r}}\right)\right)\right]\left[1-\beta / \rho\left(\mathrm{k}^{*}\right)\right]
\end{aligned}
$$

and write (5.11) as

$$
\text { MASI }=\mathrm{SI}\left[\psi^{\mathrm{m}}, \lambda, E N G_{e f f}\right] .
$$

Next, with migration the expected net effect of changing the resource allocation rules through extra-constitutional action must incorporate the net gains to the migrant group becoming

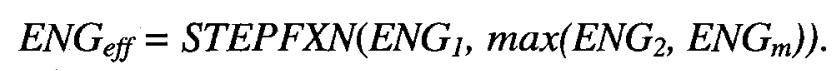

Therefore the overall Mobility Augmented Stability Index becomes 


$$
\begin{aligned}
& M A S I=\operatorname{SI}\left[\lambda, \psi^{\mathrm{m}}, \operatorname{STEPFXN}\left(E N G_{l}, \max \left(E N G_{2}, E N G_{m}\right)\right)\right] \\
& 0 \leq M A S I \leq 1
\end{aligned}
$$

It follows that if there is a change in the degree to which immigrants are accepted in their new region, there will be a compound effect on the stability index. This can be seen by taking the partial derivative of MASI with respect to the parameter $\beta$. Doing so we find,

$$
\frac{\partial M A S I}{\partial \beta}=\frac{\partial S I(.)}{\partial \psi^{m}} \frac{\partial \psi^{m}}{\partial \beta}+\frac{\partial S I(.)}{\partial \lambda} \frac{\partial \lambda}{\partial \beta}+\frac{\partial S I(.)}{\partial E N G_{e f f}} \cdot \frac{\partial E N G_{e f f}}{\partial \beta}
$$

To interpret this compound expression we proceed from term to term. Hence beginning with $\psi^{\mathrm{m}}=\left[1-\beta / \rho\left(\mathrm{k}^{*}\right)\right]\left(\mathrm{n}_{1} / \mathrm{N}\right)\left[\mathrm{U}\left(\mathrm{x}_{2}\right)+\mathrm{U}\left(\mathrm{G}\left(\mathrm{n}^{\mathrm{s}}\right)\right)\right]$, we can see that all else unchanged, the higher is the value of $\beta$, and/or the lower is the value of $\rho$, the lower will be $\psi^{\mathrm{m}}$ and so is the utility difference arising across regions under mobility. This will produce less discontent and less likelihood of instability and violence. It would then appear that greater acceptability and less regional attachment would be stability enhancing. However, the fact that $\beta$ and $\rho$ are related through $k^{*}$ such that higher values of $\beta$ will result in more migration that reduces $\left(n_{1} / N\right)$ and produce higher values of $\rho$ complicates such straightforward comparative statics. That is, an increase in $\beta$ will first decrease MASI by lowering the cost of gaining acceptance in region 2 which increases the opportunity cost of not migrating and so triggers positive migration. It also weakens the political strength of discontent by reducing the relative population size of the disadvantaged region. On the other hand, while migration invariably means a higher 
level of welfare for all who leave, those who are left behind on average and at the margin are those who place a higher (sometimes much higher) value on $\rho$. Thus outward migration separates the original region 1 inhabitants into two groups such that those who remain behind are those for whom the cost of leaving their native region $(\rho)$ is relatively high. Individuals with high values of $\rho$ 's are those with stronger cultural, linguistic, religious roots in their region and, because of this, those who will attach higher priority to regional concerns in common with their neighbors. Hence, as can be seen from equations (5.11) and (5.12), the increase in $\rho$ that increases with migration could mean an overall increase in the probability of conflict, $M A S I$, even if relative welfare across regions did not change.

For a change in $\beta$, then, the impact of mobility on the probability of conflict will depend upon the level of $\rho$, the value of $\psi^{\mathrm{m}}$ and the change in the value of $\rho$ that arises with movement. When $\rho$ is high in the new equilibrium, a high premium was required to induce movement so that the welfare of those individuals remaining in region 1 will be correspondingly low compared to the welfare of the original residents of region 2 . When $\rho$ is low, on the other hand, the ratio $\beta / \rho$ will be close to 1 and mobility will not alter significantly the probability of conflict. In fact when $\rho=1$, moderate mobility reduces the probability of conflict and is welfare improving. This is the situation where attachment to individual's original region is very low, and individuals are willing to relocate with low premium and cost of doing so. Coupled with high acceptability in the other region, high $\beta$, mobility is stability enhancing, and there is negative relationship between mobility and the probability of conflict. 
When movement does not change the political (resource use) equilibrium, we can solve for the effect of a change in $\beta$ on $\psi^{\mathrm{m}}$ (holding nonmigrant income constant) as

$$
\begin{aligned}
& \frac{\partial \psi^{m}}{\partial \beta}=\frac{n_{1}}{N}\left(U\left(x_{2}\right)+U(G)\right) \frac{\partial\left(1-\frac{\beta}{\rho\left(k^{*}\right)}\right)}{\partial \beta}+\frac{n_{1}}{N}\left(1-\frac{\beta}{\rho}\right) \frac{\partial\left[\left(U\left(x_{2}\right)+U(G)\right)\right]}{\partial \beta}+\left(1-\frac{\beta}{\rho}\right) \frac{1}{N}\left(U\left(x_{2}\right)+U(G)\right) \frac{\partial n_{1}}{\partial \beta} \\
& =\frac{n_{1}}{N}\left(U\left(x_{2}\right)+U(G)\right) \frac{1}{\rho}\left[\frac{\beta}{\rho}\left(\frac{\partial \rho}{\partial k^{*}}\right)\left(\frac{\partial k^{*}}{\partial \beta}\right)-1\right]+\left(1-\frac{\beta}{\rho}\right) \frac{1}{N}\left(U\left(x_{2}\right)+U(G)\right) \frac{\partial n_{1}}{\partial \beta} \geq 0, \sin c e\left(\frac{\partial k^{*}}{\partial \beta}\right)=-\left(\frac{\partial n_{1}}{\partial \beta}\right) \\
& \Rightarrow \frac{\partial \psi^{m}}{\partial \beta}=\frac{1}{N}\left(U\left(x_{2}\right)+U(G)\right)\left\{\left[1-n_{1} \frac{\beta}{\rho^{2}}\left(\frac{\partial \rho}{\partial k^{*}}\right)-\frac{\beta}{\rho}\right] \frac{\partial n_{1}}{\partial \beta}-\frac{n_{1}}{\rho}\right\} \geq 0
\end{aligned}
$$

When $\frac{\partial \rho}{\partial k^{*}}<0$ is small, then $\frac{\partial \psi^{m}}{\partial \beta}<0$ and the rise in the subjective cost of leaving the home region will not offset the initial stabilizing effect of greater regional acceptability. If this is the normal case, then under federalism (and under unitarism when $n_{2}>n_{1}$ ) mobility will be stability enhancing. In these cases the region with the politically decisive vote will continue to make the decision on resource use independent of mobility and hence $\left[\mathrm{U}_{1}-\mathrm{U}_{2}\right]$ will not change with mobility. In such cases movement across regions reduces $\psi^{\mathrm{m}}$, because as immigrants move to region 2 , their optimal level coincides with the level chosen by region 2 residents. Hence there remain fewer individuals in region 1 whose optimal level is different from the provided level of the public good.

Under unitarism when mobility leads to a change in the political equilibrium from region 1 having the initial majority (where $\mathrm{G}_{1}{ }^{*}=\mathrm{G}$ ) to region 2 having the majority $\left(\mathrm{G}_{2}{ }^{*}\right.$ $=\mathrm{G}$, and $\mathrm{G}_{2} * \mathrm{G}_{1} *$ ) 
$\frac{\partial \psi}{\partial \beta}<0 ; \quad \frac{\partial^{2} \psi}{\partial \beta^{2}}>0$

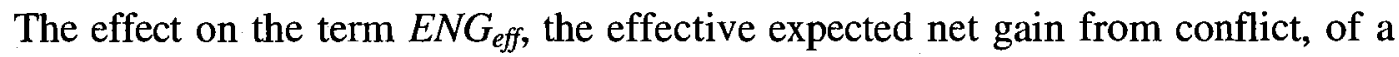
change in $\beta$ is more complex. Here changes in $\beta$ can trigger changes in the step function describing net potential gains and this can transform what is political discontent into the likelihood of conflict. The expected net gain for individuals now differ by their region of origin, their migration status, and the political decision making regime for resource exploitation. For the original residents of both region 1 and 2, the higher is $E N G_{\text {eff, }}$, the higher is the probability of conflict. Here it is the migrants that face the more complicated incentive structure. As shown in section 4.3, migrants are less likely to initiate or support a unilateral course of action by any group of original residents. They fear being expelled to face a negative externality they had moved to escape and experience a discounted net benefit if the proposed conflict succeeds. This makes them less willing to join their new neighbours in using potential conflict for the purpose of increasing the provision of the public good. For this reason, the effective net gain will depend only on $E N G_{I}$ and $E N G_{2}$.

The acceptance term, $\beta$, affects mobility and hence $E N G_{\text {eff }}$ also through its impact on $E N G_{1}$ and $E N G_{2}$. Here an increase in $\beta$ increases the number of immigrants in region 2 and may result in a decrease in the $E N G$ for the aggregate population in region 2 . This is because $E N G$ is bimodal in region 2, with $E N G_{2}$ higher than $E N G_{m}$. This impact of $\beta$ on $E N G_{\text {eff }}$ comes through an indirect channel. That is, even though mobility decreases the absolute population size in region 1, the selective exit of "cosmopolitan" residents increases the regional cohesion within region 1 that increases the probability of victory, 
$\kappa_{1}$, should any political struggle break out with region 2. The arrival of "cosmopolitan" entrants into region 2 reinforces this effect by diminishing the cohesion within region 2 . Moreover, when mobility itself leads to a sufficient population change to trigger a change in the political equilibrium, the change in $\beta$ will also increase the welfare disparity across regions. This in turn increases the potential gain to each region from undertaking unilateral action.

Recall that under federalism where region 1 controls resource use, $E N G_{l}^{f}$ and $E N G_{2}^{f}$ were given in equations (4.13) and (4.14) as

$$
\begin{aligned}
E N G_{1}^{f}=- & -\kappa_{1} \int_{n_{1}^{+}}^{n_{1}^{*}}\left\{U_{G}\left[p R_{n}-z\left(e_{1}\right)-n z_{e} e_{R} R_{n}\right]-U_{x}\left[z_{e} e_{R} R_{n}\right]\right\} d n^{r} \\
& -\sigma \int_{0}^{n_{r}^{+}}\left\{U_{G}\left[p R_{n}-z\left(e_{1}\right)-n z_{e} e_{R} R_{n}\right]-U_{x}\left[z_{e} e_{R} R_{n}\right]\right\} d n^{r}-C_{1}^{f}
\end{aligned}
$$

and

$$
E N G_{2}^{f}=\kappa_{2} \int_{n_{1}^{+}}^{n_{2}^{*}}\left\{U_{G}\left[p R_{n}-z\left(e_{2}\right)-n z_{e} e_{R} R_{n}\right]\right\} d n^{r}-\left(\kappa_{1} \nu+\sigma\right) \int_{0}^{n^{*}}\left\{U_{G}\left[p R_{n}-z\left(e_{2}\right)-n z_{e} e_{R} R_{n}\right]\right\} d n^{r}-C_{2}^{f}
$$

Within the unitary system with $n_{2}>n_{1}$, we have the corresponding measures of (4.23) and (4.24),

$$
\begin{aligned}
E N G_{1}^{u}=- & \kappa_{1} \int_{n_{1}^{*}}^{n_{r}^{*}}\left\{U_{G}\left[p R_{n}-z\left(e_{1}\right)-n z_{e} e_{R} R_{n}\right]-U_{x}\left[z_{e} e_{R} R_{n}\right]\right\} d n^{r} \\
& -\sigma \int_{0}^{n_{r}^{\prime r}}\left\{U_{G}\left[p R_{n}-z\left(e_{1}\right)-n z_{e} e_{R} R_{n}\right]-U_{x}\left[z_{e} e_{R} R_{n}\right]\right\}-C_{1}^{u}
\end{aligned}
$$


and

$$
\begin{aligned}
E N G_{2}^{u}=\kappa_{2} \int_{n_{1}^{* *}}^{n_{2}^{* *}}\left\{U_{G}\left[p R_{n}-z\left(e_{1}\right)-n z_{e} e_{R} R_{n}\right]\right\} d n^{r} \\
\quad-\left(\kappa_{1} V+\sigma\right) \int_{0}^{n_{1}^{r^{*}}}\left\{U_{G}\left[p R_{n}-z\left(e_{1}\right)-n z_{e} e_{R} R_{n}\right]\right\} d n^{r}-C_{2}^{u}
\end{aligned}
$$

Thus

$$
\begin{aligned}
& \frac{\partial E N G_{i}}{\partial \beta}=(\text { potential gain }) *\left[\frac{\partial \kappa_{i}}{\partial n_{i}} \frac{\partial n_{i}}{\partial \beta}+\frac{\partial \kappa_{i}}{\partial \rho} \frac{\partial \rho}{\partial \beta}\right]+\kappa_{i} \frac{\partial(\text { potential gain })}{\partial \beta} \\
&+(\text { potential loss }) * \frac{\partial(\text { probability of loss })}{\partial \beta}+(\text { probability loss }) * \frac{\text { potential loss }}{\partial \beta} .
\end{aligned}
$$

When the change in $\beta$ does not change the political equilibrium, neither the potential gains nor losses themselves change but the probabilities of these gains and losses change with $\beta$. When a change in $\beta$ leads to a change in the political equilibrium, however, the potential gains and losses to all regions also change (along with the associated probabilities). The specific direction and degree of change for the specific equilibra will be examined in section (5.2) that follows. However, here we summarize that outcome by stating that in general we assume that

$$
\frac{\partial \kappa_{i}}{\partial n_{i}}>0 ; \frac{\partial n_{1}}{\partial \beta}<0 ; \frac{\partial \kappa_{1}}{\partial \rho}>0 ; \frac{\partial \rho}{\partial \beta}>0 ; \frac{\partial \kappa_{2}}{\partial \rho}<0
$$

Finally, all else unchanged, the higher the value of $\beta$ the less opposition there will be to individuals who leave the impacted region 1 and arrive in the unaffected region 2 . This encourages migration. However, the effect of greater migration on the information 
available within the system is somewhat ambiguous. On the one hand, a higher level of immigrant acceptability implies a higher degree of cross border movement and this will tend to improve the accuracy of information and decrease information asymmetry by exposing more individuals to the actual situation across regions. On the other hand, those who remain behind in region 1 are those who place a high premium on staying within their home region, $\rho\left(\mathrm{k}^{*}\right)$. Hence those individuals remaining behind in region 1 are those with particularly strong cultural, linguistic, and religious ties to their neighbors and region and with relatively less interest in and sympathy for those outside their region. In this sense, the remaining group may become an easier target for those who have an incentive to misinform and/or play regional biases for political gain. Should there be the political incentive to do so (as there will be in this model), information may become less complete and more biased within the affected region.

Proposition 10: Under certain conditions geographic regional attachments may be stability enhancing in so far as they prevent changes in the political equilibrium as a result of migration. In this sense, regional cohesion can also prevent exacerbation of regional poverty and cross-regional welfare disparities.

Figure 9, below, shows a graph relating the expected net gains and the Stability Index. 
Figure 9: Stability Index and Mobility Augmented Stability Index

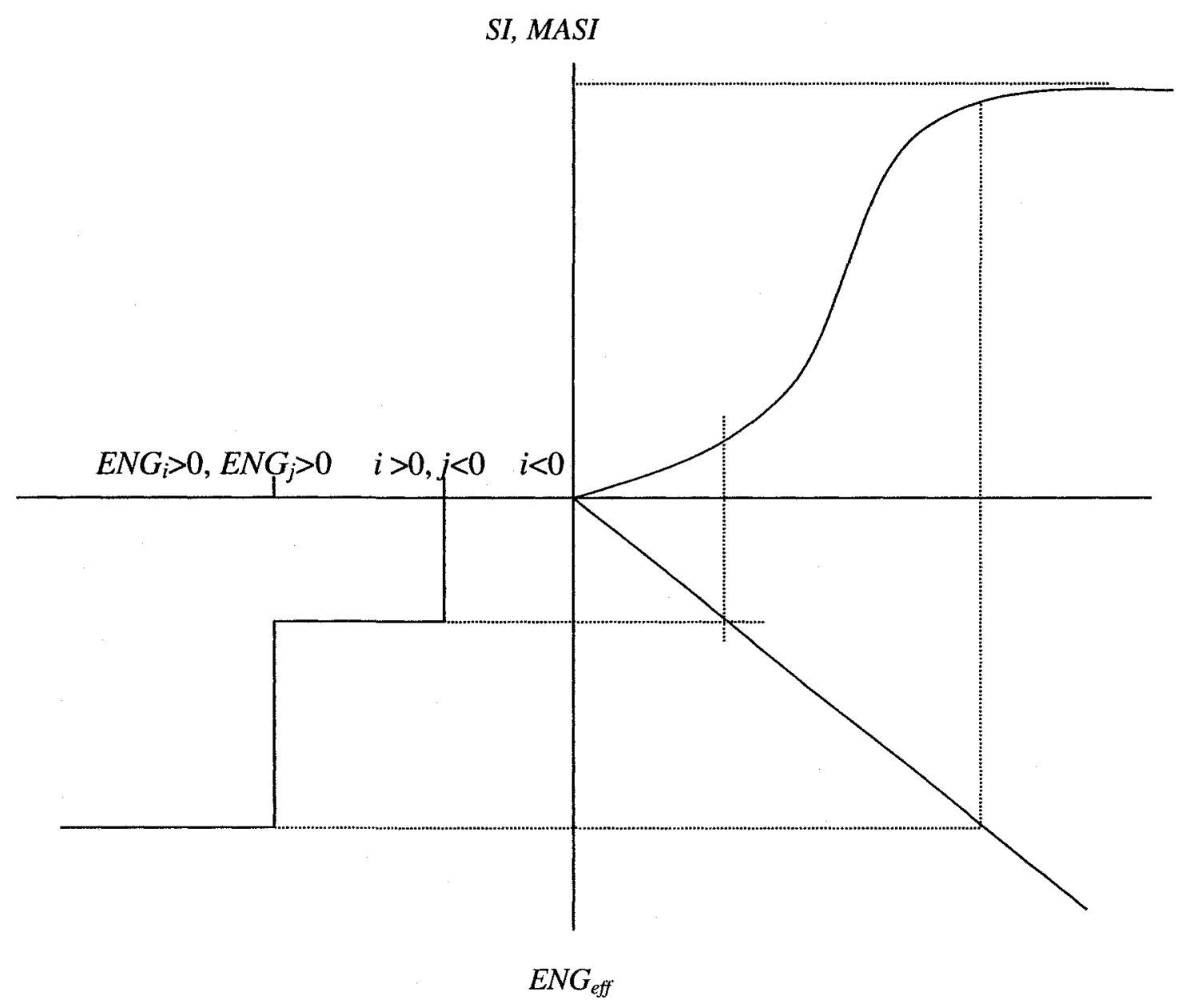

Where region $\mathrm{j}$ has constitutional control over resource use and public good. 


\subsection{Stability, Mobility, the Democratic Process, and Natural Resources}

Thus far we have shown how discord may arise in our model and how this may lead to conflict, both with and without mobility responding to the resource externality. What is left to show is the historical process by which the discovery of natural resources and the political constitutional setting combine to plunge these countries into internal conflict. The starting point is to examine these countries that inherited a set of political institutions when they gained independence from colonial rule prior to the discovery of natural resources. This starting point reflects the fact that many of the natural resource producing (emerging) countries now in conflict were once under colonial rule.

We use our model to guide and explain the pressures leading to the evolution of political institutions and the subsequent incidence of conflict arising within these countries. We use the components of the Stability Index as modified by the role of mobility to analyze the stability of these particular countries as they emerged from colonial rule and as their political institutions evolved with the discovery of natural resources. Our method highlights the position that discontent arises within the polity when there is a disparity in the welfare levels of individuals across regions and when the individuals with lower levels of welfare are politically unable to improve their lot by reducing the externality that causes this disparity. This happens, in part, because there is an inevitable trade-off arising between more of the public good and less pollution and a different preferred rate of trade-off across regions. In addition, discontent may be strengthened by sense of disenfranchisement because the political process and/or current constitution prevents individuals in the lower welfare region from influencing the gap 
between actual and potential welfare. Discontent may also occur if individuals with the lower welfare are prevented from emigrating to escape the externality. The greater the number of individuals who suffer the lower welfare, the greater is the discontent inherent in the system. The nature of that discontent was discussed in sections 4.3 , and 5.1.

\subsubsection{Stability and Political Institutions From Colonialism to Independence}

Unitarism appears to lend itself to colonial rule. This is because the requirement for control from a distance necessitates the concentration of power at and the exertion of control from the center. To the extent the colonial ruler wields the necessary constitutional clout and the extra-constitutional force to keep the various regions of the country in obeisance, the unitary system may be a quite effective model of decision making. However, our interest here is not with the mechanics of colonial rule, but simply to record that whether the current regions were put together by colonial rulers to form a country or conquered as a country already, decision making for the country as a whole was unitary under colonialism—whether or not natural resources existed before the end of colonial rule.

In anticipation of independence, most countries draw up a new constitution and adopt this set of rules at the dawn of independence. Although the central objective of the constitution is to smooth the transition to independence, the type of decision-making adopted at independence is influenced by two salient factors: 
i) the amount of homogeneity in the population - ethnic and geographic, which in turn, determines the level of mobility across regions and the cross regional acceptability of individuals in other than their home region, and

ii) the known distribution of natural resources across the various regions of the country-how their revenues are shared and where the associated externalities fall.

Generally speaking, independence is granted only when the domestic demand for independence has a broad base of support, usually close to unanimity will be required, and the constitution produced results from the same need to produce broad cross-regional support. The exigencies of independence and the requirement for near unanimity tend to guarantee that all regional concerns will be addressed in the independence document. At the stage where the group of regions are agitating for independence, $E N G_{i}<0$ for all regions. It is under such circumstances that even those regions with the smallest population size and the least political clout can sometimes exert as strong an influence on the final form of the constitution as the biggest regions--since it is not in the ultimate interest of any particular region, especially the majority region, to alienate another region at such a critical point in time. Consequently, countries that are highly heterogeneous across their regions, that exhibit limited cross-regional mobility and low levels of acceptability across regions (have values of $\beta / \rho \approx 0$ ), are more likely to adopt constitutional provisions for federal (regional) decision-making than countries whose population exhibits a high degree of homogeneity across regions (where $\beta / \rho \approx 1$ ). In 
strongly heterogeneous countries with limited inter-regional mobility, the fear of being dominated by the majority region may motivate each minority region to demand strong regional autonomy before agreeing to support independence. Hence the majority, in order to assuage the fear of the minority region and not to frustrate the attainment of independence, may acquiesce to a federal constitution with regional autonomy at independence. In such a case $E N G_{1}>0$ while $E N G_{2}<0$, ex ante. This may change upon attainment of independence

On the other hand, for a country where individuals share a common ethnic and religious background and other homogeneities (such as occupational similarities), the fear of being disadvantaged by any other group is minimized $\left(\psi^{\mathrm{m}}=0\right.$ and $\left.\beta / \rho \approx 1\right)$. In such a case, the spirit of oneness will motivate common support for independence and, since learning how to operate under a new type of constitutional decision-making may be costly, it is more likely that the familiar unitary constitution operated by the colonial ruler will be adopted. Since individuals in such a country can and will move to any region to take advantage of better economic opportunities, emerging welfare differences across regions will tend to become equalized.

Secondly, in those countries where natural resources are found only in the smaller sized region, a federal constitution is more likely to be the case than in countries that have no specialized resources or where resources are located only in the larger majority region. This is because any region, irrespective of its size is capable of vetoing the constitution and thus the attainment of independence by the country as a whole during the negotiations for independence. This possibility makes the bigger region, which is usually 
the more vocal in its demand for independence, more willing to acquiesce to the smaller region's demand for more control over its resources, since not granting this demand may jeopardise independence altogether. In this case, the ability to gain control of its own resources, even if that resource produces negative externalities, is a strong motivation for any region to support independence. Under colonial rule the resource is controlled by the colonial ruler and the small region with natural resource will see independence as merely a shift from one colonial ruler to another if it does not control its resource at the onset of independence. This gives it strength in resisting the unitary outcome. On the other hand, if the natural resources are in the majority region, then the region is indifferent between a unitary and federal constitution since the outcome of a political decision making under these systems are not different. The majority region will retain control over the resource in both unitary and federal systems. If $\beta / \rho$ is close to one (1), then the majority region which also has the resource will actually prefer federal system in order to prevent loss of control over the resources due to migration.

It then becomes possible to predict from the analysis above that the early years of independence in countries will likely be relatively peaceful. This is because near unanimity was required to adopt a new constitution for independence and the achievement of independence was secured only because all regions either supported or did not oppose the proposed new constitution. The minority region(s) supported independence because their concerns were taken into account in the constitution, and the majority supported it because either it needed independence more than the minority, or because it would not lose any thing to the minority by supporting it. Hence in the 
absence of some new external shock, the SI and MASI will be expected to be low at the dawn of independence from colonial rule. Whether stability is sustained or not will then depend on the evolution of the natural resource profile of the country and the accompanying changes in the political institutions that do or do not follow the change in profile, and finally, whether the cross-regional mobility discount is changed.

This analysis excludes those countries whose independence was hurriedly put together without pre-independence consultation and negotiation. In these cases the seeds of instability might have been sewn by the process leading to political independence and hence may be unrelated to the issues of natural resources and mobility. Angola is a notable example of such countries. In its case, the colonial rulers simply walked away from the country without pre-independence constitutional negotiation. The result was that Angola, in trying to resolve the mobility-resources dilemma, was plunged into one of the longest civil wars in history.

\subsubsection{Stability and Political Institutions from Independence to the Discovery of Natural Resources}

In the absence of new shocks, the early years of most new, politically independent countries are characterized by consolidation of their independence and sovereignty. This may sometimes lead to the modification of economic and political institutions to better reflect local conditions and aspirations of the regions beyond the exigencies of independence. Consequently the process and the outcomes may depend on 
the level of cross-regional acceptability and differences in welfare and way of life across regions.

ii) the initial distribution of natural resources and externalities, and the region of new discoveries

iii) the level of dependence on these resources for the production of the national public good and the availability of alternative sources of funding for the production of the public good

iv) the political decision-making process provided for by the constitution chosen upon independence.

\section{A Unitary System at Independence}

In the previous section it was seen that under some circumstances preindependence negotiation was likely to produce an independence constitution with unitary decision making. This was likely to arise either when the majority region had the natural resource but, in order to give the minority region a sense of welfare security, proposed a unitary system or, perhaps more likely, when differences across regions were minimal so that adoption of the unitary decision making process used under colonialism proceeds seamlessly. Moreover, the majority region with resources may be indifferent between a unitary and a federal system, as the incidence of control over the resource, in the short to medium run, does not differ. If the resource profile does not change over the years, then further efforts will be made to minimize the relics of the differences existing across the regions of the country to promote further regional welfare equality. 
In a unitary system where strong differences exist across regions so that mobility is limited, efforts to improve mobility may arise strategically on the part of the minority region. This is because that region may see the prospect of becoming a majority sufficient motivation - a motivation anchored in its ability to increase the level of the public good should it achieve majority status and gain control over the resources. Hence individuals will be encouraged to escape the externality to build a more unified prosperous country. To prevent such a prospect, the current majority region, where the resources are, may find it optimal to attempt to block greater homogenization of the country and thus mobility out of its region by keeping $\beta / \rho$ as low as possible. Thus despite having assisted in building the indivisibility of the country into the independence constitution, the current majority region may now proceed to change the decision-making process into a federal one. This can be now done because although the independence constitution required unanimity for legitimacy, post-independence amendments to the constitution typically require ratification only by a subset of the population for legitimacy. When the majority region forms that necessary subset, then a change to federalism after independence becomes a way of ensuring its control over the resource in perpetuity. If the majority region succeeds in changing the political decision making process from a unitary to a federal state, the region itself becomes indifferent to encouraging or discouraging crossregional acceptability and individual mobility. In this case there may be heightened political activities without violent instability.

Suppose, however, the resource profile of the country changes following independence, such that a minority region that did not previously have resources, now 
discovers a valued resource in its region. This may precede or follow a dwindling of the resources in the majority region, or the resources in the majority region may still be at their pre-independence levels. If the new discoveries in the minority region only add to the existing one in the majority region without a dwindling of the resources in the majority region, then there is now a uniform incidence of the resources and associated externalities. As proposed by our model, this incidence of resources and externalities will make all regions to be indifferent to the political decision making process, and the perspective on the public good and externality now converges across regions and it is unanimous. In this case, both regions will maintain the unitary independence constitution, as they seek to avoid the cost of learning the operation of a new constitution. Changes to the independence constitution will be marginal and only involve getting rid of the relics of colonialism and entrenching collective sovereignty. Hence a conflict is unlikely, and stability is strengthened in this case. Efforts to eliminate ethnic and other differences become a preoccupation of policy makers across the regions. Changing to a federal constitution will not be opposed by any region if this helps in increasing national unity and mobility across regions.

Now suppose that the resource profile of the regions changes, such that the resources of the majority region dwindles while there are now discoveries in the minority region. In this case mobility and cross regional mobility now play a central role in the determination of the response to this changing fortune of both regions. If $\beta / \rho$, the mobility is high and there is no pecuniary loss in moving across regions, then the constitutional provision of how the resource is exploited is less relevant. However if 
mobility is very low, such that individuals are not able to move across regions, then the minority region will begin to agitate for change in the constitutional process from a unitary decision-making to a federal decision-making. Suffice to say that the majority whose resources are now dwindling will be opposed to such constitutional changes in order to keep control of the resources. The majority may argue that its resources, when they existed, were used to build the country, therefore, the new resources of the minority must be used to sustain the country. The absence of alternative financing for the public good makes this position of the majority stronger and expressed vocally. Of course, the beginning of exploration and exploitation activities in the minority region means this region, which did not experience the negative impact of the externality on its livelihood, now faces the prospect of dwindling private consumption due to the externality. The limited mobility to escape this experience and the prevailing unitary system, which maintains the control of the resource in the majority region, make their demand for a change of the constitution or a constitutional amendment intense and vocal. A high mobility may encourage individuals to move to the majority region, but in the case of limited mobility this is not feasible. The response of the majority experiencing the dwindling of their resources is to encourage cross regional mobility. However, if the minority perceives this as a ploy, then the minority will resist it. Hence degeneration to ethnic and/or religious rhetoric by politicians in the minority region becomes imminent. This further leads to a widening of the gap between the two regions and stronger attachment to regional course ( $\rho$ increases). Our model proposes that at this stage the minority region will begin to assess the feasibility of a unilateral extra-constitutional 
course of action to either secede or to assert control over its resources $\left(E N G_{I}{ }^{u}\right)$. The majority region at this point also considers its ability and preparedness to defend the unitary independence constitution $\left(E N G_{2}{ }^{u}\right)$. Three cases identifiable are: if region 1 faces a negative expected net gain $\left(E N G_{I}<0\right)$; if region 1 faces a positive expected net gain from unilateral action $\left(E N G_{l}>0\right)$ and region 2 faces a negative expected net gain from unilateral action $\left(E N G_{2}<0\right)$; and if both regions 1 and 2 face positive expected net gain from taking unilateral action to usurp to defend the status quo $\left(E N G_{1}>0\right.$ and $\left.E N G_{2}>0\right)$. In the case that $E N G_{1}<0$, region 1 acquiesces to the status quo. In this case the emerging discontent within the system has no consequences for conflict in the short run.

$M A S I=\operatorname{SI}\left(\psi^{\mathrm{m}}, \lambda, E N G_{\text {eff }}\right)=\mathrm{SI}\left(\psi^{\mathrm{m}}, \lambda, L O W\right)=\mathrm{f}\left(\psi^{\mathrm{m}}, \lambda\right) * L O W=\mathrm{f}\left(\psi^{\mathrm{m}}, \lambda\right)$

If $E N G_{1}>0$ and $E N G_{2}<0$, then region 2, in political majority, may be compelled by the minority in region 1 to concede to a federal constitution, or an amendment that will ensure regional control of the resources in their regions. The negotiation process may also involve a commitment on the part of the minority region to produce a sustainable level of the public good from its new-found resource wealth. If $E N G_{2}$ equals zero while $E N G_{I}$ is still greater than zero, then region 2 stops conceding any more ground. The negotiations may collapse at this stage because the minority now wants more than what the majority is willing to give up.

$M A S I=\operatorname{SI}\left(\psi^{\mathrm{m}}, \lambda, E N G_{e f f}\right)=\mathrm{f}\left(\psi^{\mathrm{m}}, \lambda\right)^{*} M E D I U M$, initially. 
However, this may become

$M A S I=\mathrm{f}\left(\psi^{\mathrm{m}}, \lambda\right)^{*} L O W$, if a concession appeases region 1,

Or

MASI $=\mathrm{f}\left(\psi^{\mathrm{m}}, \lambda\right) * \mathrm{HIGH}$, if negotiations broke down because region 1(the minority) demanded more than region 2 (the majority) could give up.

If $E N G_{1}>0$ and $E N G_{2}>0$, then both regions will maintain a hard-line posture and refuse to shift. Shifting from regional positions to attempt to appease the other region only increases the incentive to go unilateral for any region. In this case, for the minority, even destroying the resources may be a credible strategy, because it may improve welfare in the region if the externality reduces private consumption so adversely that abject poverty is now associated with the discovery of resources, contrary to the expectation of individuals in the region. Individuals had probably thought that the discovery of resources in their region might bring with it increased welfare. A negotiation may not even begin before the onset of conflict under perfect information, especially if negotiations are not costless. This is because negotiations may be seen as a complete waste of time and resources by regional politicians, knowing that the other region may not concede any ground. In this instance internal institutions and arrangements may not be able to broker a peaceful settlement to the impending post-independence conflict. 


\section{A Federal System at Independence}

We posited that a federalist independence constitution was likely if unanimity was required to pass the independence constitutions and any of the following conditions were true:

i) if resources existed in the minority region and the fear of a mere shift from external colonization to internal colonization made the minority region to insist on federalism before ratifying the independence constitution. The minority region knows external colonization is easier to fight than an internal one, and the majority region needed the independence more than it does.

ii) If cross-regional mobility and acceptability was so low that federalism is more workable and is a trust building mechanism, irrespective of natural resource occurrence profile.

iii) Natural resources existed either in all regions or in no region. In the case that no natural resources existed, all regions depended entirely on agriculture.

As previously discussed, the few years immediately after independence are characterized by the adjustment of internal institutions to consolidate political independence and assert sovereignty. Suppose that the resources existed in all regions or in no region, or the profile of regions changed such that all regions now have resources discovered in them or the resource rich region no longer has resource also in the years after independence, then the prospect of post-independence constitutional conflict is reduced. Outcome of the decision on resources is no longer dependent on the political decision-making process. Decisions on resource externality and public good are 
unanimous. In this case, the independence constitution is maintained and strengthened. Regions concentrate on improving cross-regional acceptability and mobility to strengthen national unity.

On the other hand if the resources are found in the minority region, with limited cross-regional mobility and no fundamental change in the years following independence, then the removal of the need to preserve unanimity will see the majority agitating to amend the constitution to provide for unitary control over resources. The minority resource-producing region will resist this. The majority may adopt a strategy of improving cross-regional mobility in order to reduce the opposition and assuage the fear of externality scourging the minority region. If unanimity is not required to proceed with an amendment of the constitution and the majority is sufficient to do so, it will amend the constitution. Should the majority fail to amend the constitution democratically, it might consider a unilateral course of action to change it. In this case, majority region 2 examines its $E N G_{2}^{f}$, and region 1 may decide to defend the current independence federalist constitution upon considering $E N G_{I}^{f}$.

Thus, if $E N G_{1}<0$ and $E N G_{2}>0$ there is potential for negotiation where region 1 concedes some ground to increase the level of the public good as discussed in section (4.3). In this case

$$
E N G_{e f f}=\text { MEDIUM }
$$

In the event that $E N G_{1}$ is negative but close to zero, and $E N G_{2}$ is very large compared to zero $\left(E N G_{2} \gg>0\right)$, then the scope of negotiation is limited for region 1 . Instead of a whole constitutional change to unitary system, an outcome that will increase the public good 
may be feasible while keeping the federalist independence constitution. Conceding to producing a little more of the public good leads to higher level of the externality and an increased level of emigration. Hence, with an independence federalist constitution, postindependence negotiations in the case that $E N G_{I}<0$ and $E N G_{2}>0$, may lead to a peaceful resolution of the impeding conflict on the condition that by producing more of the public good, $E N G_{2}$ is reduced to zero before or when $E N G_{I}=0$.

$M A S I=\operatorname{SI}\left(\psi^{\mathrm{m}}, \lambda E N G_{e f f}\right)=\mathrm{f}\left(\psi^{\mathrm{m}}, \lambda\right) * M E D I U M$, initially.

However, this may become

MASI $=\operatorname{SI}\left(\psi^{\mathrm{m}}, \lambda, L O W\right)=\mathrm{f}\left(\psi^{\mathrm{m}}, \lambda\right) * L O W$, if some concession appeases region 2,

Or

MASI $=\mathrm{f}\left(\psi^{\mathrm{m}}, \lambda\right) * \mathrm{HIGH}$, if negotiations broke down because region 2 demanded more than region 1 could give up.

If $E N G_{2}<0$, region 2 acquiesces to the independence constitution irrespective of its size either because there is no enough incentive to usurp or the probability of victory, if it acts so, is very low. With no information asymmetry $(\lambda=0)$, the perceived disenfranchisement of the majority remains, and while there may not be absolute peace, instability is unlikely. Region 2 may be disgruntled but not belligerent. If there is information asymmetry $(\lambda \neq 0)$ on $E N G_{I}$ and $E N G_{2}$, then political risk takers may choose to manage the information and this may result in instability. In this case that $E N G_{2}<0$,

$M A S I=S I\left(\psi^{\mathrm{m}}, \lambda, L O W\right)=\mathrm{f}\left(\psi^{\mathrm{m}}, \lambda\right) * L O W=\mathrm{f}\left(\psi^{\mathrm{m}}, \lambda\right)$ 
The greatest danger to post independence peace and stability with federalist independence constitution arises when $E N G_{1}>0$ and $E N G_{2}>0$, even if $\lambda=0$. In this case, region 1 is not willing to concede any ground because doing so increases positivity of $E N G_{l}$ since this leads to higher $\rho$ and regional welfare disparities. Therefore $E N G_{\text {eff }}=$ HIGH, and negotiations may yield no positive result. Conflict in such circumstance may be inevitable. Destroying the resources may appear a rational welfare improving strategy for region 1 as an alternative to acquiescing to the demands of region 2 . Tradeoffs in this case may appear irrational as a strategy, hence, internal institutions may prove ineffective in brokering peace.

$$
M A S I=\operatorname{SI}\left(\psi^{\mathrm{m}}, \lambda, E N G_{e f f}\right)=\mathrm{SI}\left(\psi^{\mathrm{m}}, \lambda, H I G H\right)=\mathrm{f}\left(\psi^{\mathrm{m}}, \lambda\right)^{*} \mathrm{HIGH}
$$

The condition may be compounded by information asymmetry.

Proposition 11: Under the assumptions of our model, in certain natural resource producing countries, conflict may be a rational, dominant strategy for all regions, in which case, conflict may be inevitable. In these circumstances, internal may prove ineffective, and external intervention may become expedient in conflict prevention. 


\section{CHAPTER 6}

\section{Evidence from Nigeria and Sudan}

In section 5.2 we discussed the general application of our model to the likely evolution of political institutions and incidence of conflict in primarily agricultural economies that were unified under colonial rule from independence to the years following the discovery of natural resources. We showed how prior conditions with respect to mobility, the prior distribution of natural resources, and the exigency of independence would likely influence the scope and content of the constitution upon independence- and in certain cases undermine the interaction between resource production and local livelihood. We also showed how in the years following independence, any change in the resource profile of regions, the magnitude and incidence of resource externalities, inherent differences across regions and the costs of mobility would impact strongly constitutional and extra-constitutional negotiations over resource utilization. These factors, were they not properly intermediated, might easily evolve to become threats to stability and subsequent conflict in the years following independence and discovery of resources.

We recognize that conflict may be the result of a number of factors acting in concert to overwhelm internal conflict prevention institutions. In this chapter, we 
continue with our focus on resource externality and mobility (or the lack of it) as root causes of conflict in resource producing countries of the south.

Of the fifty-four African countries, all except Ethiopia were once colonies of other countries. Fifteen have had one or more major conflicts since independence, and twenty-three have had some minor conflicts ${ }^{11}$. The table 1 below ${ }^{12}$ shows some characteristic of these countries we consider in this research. A snap shot of this table shows that the regime type - unitary or federal-, and mobility, as used in this study, are very important determinants of conflict in Africa.

\section{Table 1: Taxonomy of African States in Conflict and Political System}

\begin{tabular}{|l|l|l|l|l|l|l|}
\hline & $\begin{array}{l}\text { Number of } \\
\text { Countries }\end{array}$ & Agrarian & $\begin{array}{l}\text { Resource } \\
\text { Prod./ } \\
\text { Dependence }\end{array}$ & Unitary & Federal/ & $\begin{array}{l}\text { High } \\
\text { Mobility }\end{array}$ \\
\hline & 54 & 54 & 46 & 48 & 5 & 23 \\
\hline $\begin{array}{l}\text { Conflict } \\
\text { since } \\
\text { Independence } \\
\text { (min/maj) }\end{array}$ & $15 / 23$ & $15 / 23$ & $12 / 23$ & $14 / 22$ & $0 / 1$ & $13 / 0$ \\
\hline
\end{tabular}

In what follows we analyze how closely our model applies to two cases that seem to fit our initial conditions well, namely Sudan and Nigeria, and how these cases have

\footnotetext{
${ }^{11}$ The definition of what constitutes major and minor conflict is fluid. In our analysis we follow the definition used in the Uppsala Conflict Data Program (UCDP) and maintain that a major conflict is a conflict with more that 1000 deaths while a minor conflict amongst others includes a forced regime change. ${ }^{12}$ All data for this table except for the conflict and mobility were obtained from the CIA world factbook at www.worldfactbook.cia.gov. Conflict data was obtained from UCDP http://www.pcr.uu.se/research/UCDP/our_data1.htm .
} 
motivated our model. We examine the evolution of political institutions from independence to determine how geographic/ethnic difference, mobility costs and the natural resource profile of these countries - and associated negative externalities from these resources- have contributed to the incidence of conflict in these countries. Our argument is that these interactions are more profound causes of conflict in these countries than simply greed, natural disaster, and/or weak government; although conflict may be the result of a more complex nexus connecting all these and many more factors. We proceed by tracing, in the context of our model, the institutional and social changes that took place in these countries from the ebbing days of colonial rule to the discovery of natural resources to the onset of regional conflict. Close attention is paid to constitutional changes, changing resource profiles - new and dwindling resources, across-regional difference and mobility, and the interaction of resource exploitation and local livelihood to the detriment of the local livelihood. The emphasis is on externalities and mobility. Here the phrase "dwindling of resources" is used to capture the phenomenon that the growth rate of the reserves of non-renewable resources, the rise in the market value of those resources, the rate of new discoveries all fall short of the rate of population growth, which in turn, exceeds the reductions in stock or harvest due to natural or man-made disasters.

In analyzing the conflicts in these countries, special attention is paid to role of cross-regional mobility (as defined in our model), natural resources, externalities, the necessity of the public good and the inability (or the dwindling ability) of the government to provide public good through other sources of revenue. 
The conflicts in Sudan and Nigeria are similar in a number of ways, but also different in ways that are relevant to our model. In the terms of our model, the conflict in Sudan can be explained better by the problem of cross regional mobility than externality from resource production. This is because, relative to the size of the country, the resource-producing region acting alone, without the help of the rest of southern Sudan would not have been able to execute a unilateral action at such a large scale. Here, unilateral action was possible only with the support of the rest of the southern Sudan and this was possible because of the high level of mobility and acceptability between the region affected by oil production and the rest of southern Sudan. Such a relation is nonexistent between this oil rich region and northern Sudan. However, the conflict in Nigeria is strongly related to the combination of negative externalities arising from resource production and restricted mobility across regions for those affected by the externality. For this reason our focus in the analysis of the conflict in Sudan is on how limited mobility is aggravated by a changing natural resource profile, while our focus in the analysis of the conflict in Nigeria is on the interaction of natural resource exploitation and local livelihood, and the limited mobility in the context of a changing resource profile of the country.

\subsection{The Conflict in Sudan}

Sudan $^{13}$, Africa's biggest country in area, owes its existence as a single country to its colonial history. Sudan is divided by religion (70 per cent Muslim, 25 per cent animist,

\footnotetext{
${ }^{13}$ See Appendix 6.1 for a regional map of Sudan.
} 
5 per cent Christian), ethnicity (between African and Arab origin Sudanese), tribe and economic activity (between nomadic and sedentary cultures). The country has been in near constant conflict since it became independent in 1956. The most significant form of conflict has been between north and south, with the first civil war lasting from 19561972, and second civil war from $1983-2005^{14}$. Over the last three decades the nature of the war in Sudan has changed, from being an ethno-religious conflict to a conflict over resources, especially with the economic and resource crisis in the north and the discovery of oil in the south (Suliman, 1996).

\subsubsection{SUDAN: Mobility, Stability and Political Institutions from Colonialism to}

\section{Independence}

Because the country of Sudan was under two different colonial rulers, preindependent Sudan had two sets of political and legal institutions. Southern Sudan, making up roughly one-third of the population, was under British rule, governed unitarily by a Westminster-style parliamentary system. It was a secular society and with British rule came western education and Christianity. On the other hand, Northern Sudan, with two-third of the population, was under Egyptian rule with Islam as the source of religion and law, and political institutions that reflected their Egyptian pedigree - strong central government. Although the whole of Sudan was largely agrarian, the Northerners had easier access to the markets of their Arab neighbours and colonial ruler than the

\footnotetext{
${ }^{14}$ See Conflict history - Sudan. International Crisis Group http://www.crisisgroup.org
} 
Southerner had to the markets of their southern neighbours or the British. For this reason, the Northern elites became more affluent and the north quickly established itself as the centre of commerce and wealth. Compounding the differences due to religion and colonial past is the strong ethnic diversity in Sudan - a fact of existence in all African countries.

The pre-independence negotiations between the northern and southern people, and mediated by Egypt and Britain were concluded in 1953, following which the independence constitution (agreement) was drawn and adopted. At the dawn of independence on January 1, 1956, the adopted constitution provided for three salient issues relevant to our analysis.

i) Political institutions were organized as a unitary system with a strong central government and Westminster parliamentary system.

ii) Control over resources remained with regions.

iii) The state was to be secular with legislation forming the source of law. The constitution outlawed discrimination on the basis of ethnicity, religion or sex.

What is interesting about this list is that the constitution exhibits clauses on secularity, control over resources in the regions, and the type of political decision consistent with the predictions of our model. More particularly, the larger more dominant North acquiesced to the demands of the South on at least two of these three important issues. That is, since the North had an overwhelming population majority and was predominantly Islamic, it seemed that the independence constitution would make provision for Islam to be the state religion and source of law. Suffice to say that such position by the Northern majority 
would lead the south either to veto the proposed constitution and/or to seek a separate independent status. Also, because the majority north was under Egyptian rule and hence not conversant with the operation of a British style of governance, it seemed also that the north, being in majority, would naturally adopt the Egyptian style of governance ${ }^{15}$, or elements of it, at independence. Thus consistent with our analysis the exigency of independence and the requirement for a near unanimity -- the possibility of a veto from the minority south -- was sufficient to lead the North to acquiesce to the demands of the minority in the south to gain unanimity. However these same issues of religion, ethnicity, and resources also delineate the degree of difference across regions and serve to limit mobility across regions within Sudan. As we shall also show, they have been at the core of the conflict in Sudan.

On one crucial issue however, the independence negotiation ignored one of the conditions set out by our model for peace in the early years of independence. Our model predicted that for relative peace to prevail, in countries with divergent regional ideals and with low cross-regional mobility due to strong differences across regions, the independence constitution ought to adopt a federal character with regional autonomy. Instead Sudan adopted a unitary decision making a system with strong central government control in spite of the cross-regional differences ${ }^{16}$. Hence, as we would expect, the early years of independence were tumultuous.

\footnotetext{
${ }^{15}$ Egypt at the time of the independence of Sudan operated an authoritarian -bureaucratic one party system with Islamic flavour. For details on Egyptian governance system go to www.countrystudies.us/egypt . Last visisted April 14, 2007

${ }^{16}$ For reasons why a unitary system was adopted see A. M. Abdelmoula, "Religion, Nationalism and Peace in Sudan", paper presented at the US Institute for Peace Conference in September 1997
} 
Whatever the specific reasons for this arrangement, Sudan saw itself at independence, with the south and north now together in a single country, there were strong ethnic, religious, and social ideological differences across the regions of Sudan. The Southern Sudan was relatively more western educated, secular, predominantly Christian, agrarian, and pro-western. On the other hand the north was predominantly Islamic, more conservative in terms of religion, and pro-middle eastern (Arabic), and also wealthier through trade. There are also the numerous ethnic groups across the country. Hence cross-regional mobility was highly limited. Acceptability across regions was very low and attachment to ethnicity and regional ideals very strong.

\subsubsection{SUDAN: Mobility, Stability and Political Institutions from Independence to the Discovery of Natural resources.}

Following independence, and fully aware of the cross regional differences, the political elites set out to unify the Sudan. The early years following independence were characterized by intense political machination in the search for commonalities on which to build a national identity. Since post independence constitutional amendments did not require unanimity, and the population of the north is about two-third of the population of the country, a series of constitutional amendments were effected. Eventually, the northern dominated government adopted a constitutional amendment that made Sharia, a legal system that takes Islam as the source of law, the legal system. It also adopted Arabic as the official state language. This adoption of Sharia and Arabic infuriated the south and 
the secular northern elites. The central government gave harmony and homogeneity as the reasons for such action; however, the south saw it as Islamitization and arabicization of the whole country despising the Christian and English roots of the south. In doing so, the northern dominated government also ignored the ethnic diversity of the country, which added another dimension of resistance. This is because the indigenous people saw the adoption of Sharia as a threat to the survival of local culture. Suffice to say that the government underestimated the opposition to the adoption of the Islamic legal system. An infuriated South was compelled to take the decision to secede from the union.

The first civil war that ensued only entrenched regional differences and reduced further cross regional acceptability and mobility. Since the first civil war was not on control over natural resources, it is relevant to our analysis insofar as we are discussing cross regional mobility and acceptability. The first civil war was the result of a searchfor-national-identity-gone-sour. This tumultuous period of building a homogenous unified country was handled badly by the political elite, hence it ended up entrenching regional differences and further discouraged cross-regional mobility. Suffice to say that the outcome of that war was a stalemate with no side claiming outright victory.

When the first civil war ended, part of the resolution was to remove an anomaly in the independence constitution: the unitary system of government. In its place a federal system with regional autonomy was adopted, reflecting the limited mobility across regions. Islam as a state religion and the source of law for the country, and Arabic as state language were also removed from the constitution. The post civil war constitution 
strongly acknowledged the differences that exist between northern and southern Sudan and made provisions for such differences.

Shortly after the conclusion of the peace agreement following the first civil war, the natural resource profile of the regions changed. The resources of the North dwindled as a result of the combined effect of severe drought that reduced crop yield, and decrease in world commodity prices that decreased value of resources. Economic activities were dominated by the Jellaba (Arab Sudanese, who are the wealthiest group) until the drought, when it became more difficult to farm as the scarcity of water increased, especially in the north, as years of dry spell set in, (Bilsborrow and DeLargy, 1990). Sudan has some 36 million hectares of arable land, of which one third is cultivated, owing to constraints of water availability or the heavy nature of the soil; most farmlands in the north became valueless without water. The drought led to a decrease in the production of farm produce and thus a decrease in food production that led to a famine in Sudan. (Suliman, 1996.)

On the other hand, southern Sudan has more water resources, therefore more valuable land. Oil was also discovered in the 1970 s (Reno, 2002) in the south - in Bentiu region of the south - at the peak of the drought and famine, thus it was perceived as a relief by the government of Sudan, this was seen as the way out of famine and poverty. Subsequently, the Northern dominated government sought to take control of the oil- a strategy that goes contrary to the constitutional provision of regional autonomy and control over resources. The northern dominated government was advised to construct a refinery for oil exploitation and processing. The government wanted this refinery to be 
located in the north, irrespective of the fact that the oil was found in the south. Furthermore, in its desire to assert control over the oil resources, the government decided to redraw the internal boundaries of southern Sudan. The government redrew the map of Sudan, basically dividing the south, taking the Bentiu region ${ }^{17}$ and putting it in the north; so that the northern dominated government could have control of the resources and be able to build the refinery in the north and run the oil pipeline from Bentiu to the north. (Suliman, 1996). This redrawing of land boundaries by the government caused uproar in the south. Southerners felt that they were being robbed of what was rightfully theirs. ${ }^{18}$ The southerners therefore reacted to this act they considered inequitable, provocative and unwarranted; this led to the formation of southern rebel groups to fight the government and its northern supporters. This, thus, fuelled the already existing ethno-religious war between the north and the south. The rebel groups launched several attacks on oil workers and facilities and the construction of the refinery was suspended in 1984.

There was no dispute concerning oil resource until the northern dominated government decided to redraw the south and remove Bentiu from the southern region and relocate it in the north, just to accomplish total control of the oil revenue. The ethnoreligious war and cross regional differences placed sufficient barriers in the way of individuals who desired to move from the north to the southern to take advantage of economic opportunities in the emerging oil industry. Hence the dominant factor driving regional discord, and motivation for unilateral action is more of the lack of cross-regional

\footnotetext{
${ }^{17}$ See Appendix 6.1 - the map of Sudan for the location of the Bentiu region.
} 
mobility than outright negative resource-related externality. The post-war (the first war) constitutional provision of regional autonomy and control over resources prevented the central government from producing the national public good form the new resource in the face of dwindling national revenue from other sources because of the famine. This situation suggested a positive expected net gain for the northern dominated government to initiate a unilateral course of action. Hence the unilateral redrawing of the internal boundaries that placed the region where oil was discovered in northern territory. This solves the problems of access to economic opportunities by the northerners and revenue for the government. It was only after the internal boundary adjustment that the south revolted. These rebels also had a positive expected net gain to defend the borders and the constitution. The second civil war, the war over resources thus erupted.

The Naivasha comprehensive peace accords, bringing peace between North and South Sudan for first time in 20 years was officially signed on 9 January 2005 after over two years of tough negotiations. Under the agreement, the ruling National Congress party and the rebel Sudanese People Liberation Movement (SPLM), with roots in the south, would form a coalition government, decentralize power, share oil revenues and integrate the military. At the end of a six-year interim period, the south may choose vote for secession.

The direct consequence of the drought in Sudan, we posit, is the drastic reduction of the government's ability to produce public good, and a reduction of private

${ }^{18}$ This is analogous to redrawing of the map of Canada by the government (dominated by British Columbians) to relocate Alberta into British Columbia, simply because oil was found in Alberta. 
consumption in the North. Years of ethnic and religious conflict have also reduced cross regional integration and raised ethnic sentiments, which in our model means very low geographic mobility. Prior to the discovery of oil also, there existed sufficient regional control of regional resources, and the country was organized as federalism (soon after the first war) with regional semi-autonomy. Suffice to say that when oil was discovered, the national government, dominated by individuals of northern extraction, saw it as a resource for the production of public good, and generation of employment opportunities following the economic downturn in the north. However, the ability of the northern dominated government to extract the rent from the resources was highly limited since the region in which the oil was discovered was constitutionally in southern jurisdiction and control. Also, mobility across regions was prohibitively low as a result of past conflicts and ethno-religious divisions, hence individuals whose livelihoods had been destroyed by the drought in the north could not migrate to the south to find an alternative source of livelihood, including in the oil sector. The north has political majority in terms of relative population size.

Two options were left for the northern dominated government. First was for it to use its political majority to initiate a change to the constitution from a federal regime to a unitary regime. This would make the production of the national public good easier. Second was to corner the resource for northern use, to provide a source of livelihood for the northerners. The point here is that resource cornering in this case of Sudan was the result of the inability of northerners to move to the south to take advantage of economic opportunities now available in the resource sector in the south - a factor founded in the 
lack of cross-regional mobility and acceptability. The northern dominated government had sufficient incentive in terms of expected gain should it succeed in establishing a unitary control over the resources. The higher population gave the north an impression of a high probability of victory in its unilateral initiative to change the constitution and the resource exploitation regime. The northern dominated government subsequently initiated a constitutional reform, and exerted a unitary regime over the oil. To provide a source of livelihood to the northerners, the government unilaterally redrew the internal boundaries of the country and relocated the region where oil was discovered into northern territory. Hence northerners would now dominate employment in the resource sector, and the rent from the resource would go to the central government dominated by northerners. The low levels of mobility meant that southerners no longer had access to employment in the oil sector, however, those physically living in the area where oil was discovered considered themselves as southerners and ethnically tied to other southerners. Suffice to say that these were the individuals whose agricultural livelihoods would be destroyed as a result of the externality from oil exploration and exploitation. The low level of mobility and high level of attachment to regions of origin meant a high level of cohesion. The high level of cohesion also provided a high probability of successful resistance of the usurpation by the North. This resulted in a high expected net gain from the resistance that would let the south benefit from the resource sector.

The two regions failed to negotiate a superior path of sharing the resources as a solution to this dilemma, and instead descended to decades of civil war. According to our model, the decision to fight by the government was borne out of perceived high 
probability of success coupled with high potential gains in the event of victory. This is a perception borne out of its higher population levels. What the north failed to acknowledge was that its high population was ideologically divided and the level of cohesion was low. The north, following the introduction of Sharia law, had introduced a degree of heterogeneity within the northern region. There existed sufficient opposition to Sharia as the penal code even amongst political and pressure groups based in the north. On this opposition to Sharia law, the views of these northern groups converged with the views of the southerners. Hence, although it was a consensus in the north that the natural resources be controlled by the north, this political vote for a unitary control of the resources did not however mean a support for the government in the event of a violent rebellion by the south. This is primarily because of the inclusion of in the government's war platform. For this reason, the population size of the north did not translate into victory in a violent conflict with the south because of this heterogeneity. Suffice to say that the government's war platform also included imposition of the Sharia legal system. On the other hand, there existed a high level of cohesion in the south due to the common experience of deprivation and high attachment to the southern region. The probability of victory as a signal was blurred by the high but non-cohesive population in the north and the relatively small but more cohesive population in the south. The south, as earlier mentioned, also had a high potential gain in the event of a victory. Moreover, to the south, it also seemed that the destruction of the resources would be a welfare improvement upon the loss of control of the resources and territory. These gave both sides a high probability of victory and a positive expected gain, hence the decision to 
fight. It seemed to be a rational conflict for the two regions. Over two decades of fighting convinced them victory was not as easy as once thought.

In the peace negotiations and agreements signed in January 2005 that followed the decades of sub-optimal fighting, the northern region conceded a lot of grounds to the south, even though the north has a higher population than the south. This has also been explained by our model, which proposed that a minority region that his more cohesive than a majority region may control state instruments as a result of high ability to speak with one voice. The south gained partial control over the resources, and became excluded from the Sharia rule. A referendum is also to hold on the issue of secession in the south six years after the agreement (2011)

A latent issue of the civil war in Sudan was that, had there existed sufficient mobility in the context of our model, individuals from the north could easily move to the south to work in the resource sector and also escape the drought. Also the central government would be able to provide sufficient levels of the public good in these circumstances. The war would probably be averted. Hence, mobility (or lack there of ) and the dwindling ability of the government to produce public good from alternative source provide stronger explanation to the second civil war in Sudan than pure externality from resource production. Although the local population in the Bentiu region may experience negative externality from resource production, this region, in terms of population size, may be too small to cause any national security problem.

The drought was a shock to private and public consumption. Its impact was to increase the intensity of the conflict, but in itself could not cause the conflict. In the 
presence of cross-regional mobility, disasters such as drought would encourage a seemingly costless movement across regions. In 2006, in Louisiana United States, hurricane Katrina destroyed most of the city of New Orleans and other parts of Louisiana. Following the hurricane, individuals impacted by the destruction moved to the State of Texas seamlessly. Some of these have fully integrated since then sharing in the wealth created by the high price of oil. This high ability to absorb the shock was the result of the high degree of mobility across regions in the United States. Had residents of New Orleans been prevented from moving away from the disaster zone, due to low acceptability in other regions of the US, and/or high levels of attachment to regions of origin, then the disaster arising from the hurricane might have led to other negative outcomes. Such level of mobility is lacking in Sudan, other parts of Africa, and in most of the global south. Therefore, disasters may intensify the level of conflict or exacerbate conflict. Nevertheless, natural disasters may never be root causes of conflict.

\subsection{Conflicts in Nigeria}

Its British rulers put the entity Nigeria together in 1914, from a number of British protectorates and colonies that were administered separately before 1914. These protectorates and colonies were in themselves ethnically and culturally very diverse, and by amalgamating them for administrative convenience an even more complex structure was forced together. Suffice to say that, internally, no one was in doubt on the difficulty of the task of sustaining this mosaic of seemingly unrelated parts. This complexity was to 
be increased when in 1961 the outcome of a referendum officially made part of what used to be British administered Trusteeship of Cameroon an integral part of Nigeria.

The task of nation building has been very tumultuous since 1914, especially since independence in 1960. Today, the population of Nigeria stands at over 140 million, a population almost equally divided between those who profess to be Muslims, and those who profess to be Christians. There are about three hundred (300) culturally distinct ethnic nationalities in thirty-six federating states and a capital territory. A north-south political dichotomy, Christian-Muslim bigotry, and ethnic distrusts have all led to violent and non-violent expressions of dissatisfaction with the project of building a prosperous country seen by all as being for all. Two major conflicts, one in the period $1966-1970$, and the other the start date of which is debatable but continues till today have reminded both insiders and outsider of the fragility of this Nigeria's three hundred-by-thirty-six-bytwo matrix ${ }^{19}$. These conflicts have also continued to threaten the viability of this Africa's most populous country, whose oil and gas reserves make it the world's seventh largest exporter of oil.

Here, we analyse the cause, course, and consequences of the resource-related conflict in Nigeria in the context of the model developed thus far. We focus on the role of cross regional mobility and externality from resource production as the root causes of the conflicts.

\footnotetext{
${ }^{19}$ This is a term I have chosen to capture the task facing leaders of this country of 300 ethnic groups in thirty-six federating states divided by two religions.
} 


\subsubsection{NIGERIA: Mobility, Stability and Political Institutions From Colonialism to Independence}

As pointed out above, the British formed Nigeria from obviously unrelated, independent nation states, whose history of coexistence in the region is replete with wars against each other. From this beginning the colonial rulers were able to establish administrative centers in three geographical regions (North, East, and West). Recognizing the limited mobility across these regions, characterized by differences in religion, education, and culture, the colonial rulers allowed for semi regional autonomy with a strong central government- a unitary confederation. These regions, though in the same country, did not talk to each other, but they all talked to the center where the control remained in the colonial ruler. This unitary system, founded on the principle of divideand-rule that kept the governed in perpetual distrust of themselves, was seen as the reason the British were able to rule over a country the size of Nigeria, with some degree of success. The relevant point here is that, while recognizing the limited cross-regional mobility and acceptability as expressed in the regional autonomy granted to the regions, the institution of a unitary system with strong central control was convenient for colonial purposes.

Each region of the colonial country was self-sufficient in its resources, which was chiefly agricultural. Hence, the strong regional autonomy was a natural precipitate of the interaction of limited mobility and self-sufficiency in natural resources.

At the onset of the negotiations for independence, the regional peoples and governments worked together chiefly for the purpose of attaining independence. For this 
reason, and in order not to jeopardize the independence struggle, the independence constitution was a product of wide and far reaching consultations. Even the view of the minorities- educational and ethnic minorities- in the regions that feared being dominated by the majority - essentially a shift from external colonialism to internal colonialismwere taken into account in crafting the independence constitution. To this extent, regional autonomy was granted in the independence constitution, and the status and rights of ethnic minorities also fully accounted for. A strong federalist constitution with provision for a Westminster style of governance was adopted and brought into operation on October 1,1960 . Salient in the independence constitution is the recognition of the limited mobility and acceptability across regions, hence, regional autonomy and control of resources by the regions were pillars of the independence constitution. The fear of any region vetoing the independence struggle ensured this outcome.

At the dawn of independence, the resources of the country seemed evenly distributed across the regions. The country was mostly an agrarian society, with sufficient capacity for each region to earn self-sustaining export income and internal growth. From the very beginning, however, it was clear that putting together over three hundred distinct ethnic groups in three administratively autonomous democratic regions posed enormous challenges. Not least of these challenges was that these three regions were dominated by three of the four major ethnic groups to the disadvantage of the minority ethnic groups that were spread across these three regions. The dominance of the Yoruba in the Western region, the Ibo (Igbo) in the Eastern region, and Hausa-Fulani in the Northern region meant that affairs of the country of 300 ethnic groups, which existed as independent 
nation states before the British conquest of West Africa, was run and executed as the affairs of just these three ethnic groups. Moreover, the fourth largest group, the Ijaw (Ijo) group, because of its geographic spread was divided into two, each part in the Western and Eastern regions, thus making this large ethnic group a minority in the two regions. This group resented this status. At independence in 1960, Nigeria's political governance was a confederation with three regions, West, East, and North. A part of the fourth largest ethnic group - the Ijaw (Ijo) was placed under the Western polispher ${ }^{20}$ dominated by the Yoruba ethnic group, while the other part was placed in the Igbo (Ibo) dominated Eastern polisphere. The Hausa-Fulani group dominated the Northern geopolitical region. Suffice to say that this political arrangement ignored regional heterogeneities, and strong ethnic disposition that prevented the intended population integration within these regions. We submit that cross-regional and ethnic mobility was, therefore, highly limited.

The first few years after independence were relatively peaceful, and the leaders of the country went about nation building - resolving what at that time seemed to be a $300 \times 2 \times 3$ matrix of ethnicity, religion, and semi-autonomous regions. The political interests of individuals only added to the complexity. This is what I shall call a hazy mosaic standing on an uneven tripod held in place by two hands.

\footnotetext{
${ }^{20}$ This is a term I have decided to use to connote sphere of political control.
} 


\subsubsection{Nigeria: Mobility, Stability and Political Institutions from Independence to the Discovery of Natural resources.}

Since independence from British colonial rule in 1960, Nigeria has experienced more constitutional reviews and changes than most other countries in the same period. As Nigeria's leaders engaged in the task of building a unified prosperous country, constitutional amendments became imperative. Some of these constitutions (or the amendments) never got ratified before new ones replaced them. The undertaking to build the "Nigerian identity" from the multiplicity of ethnic identities became tougher than was originally anticipated. Suffice to say that what was to be regional autonomous political governments based on a "Nigerian" concept, quickly degenerated to ethnic governments because of the dominance of one ethnic group in each of these regions. This descent into ethnicity rather than Nigeriana, further eroded cross-regional mobility and acceptability, and increased distrust amongst the ethnic groups, with the most gruesome consequences. Ethnic identity strengthened at the expense of the Nigerian identity. To some, the Nigerian project simply became a "good idea" that was fast becoming unrealizable.

As descent into ethnic enclaves of what were to be autonomous regional building blocks proceeded, two events occurred. Global commodity prices fell, thus reducing the value of the agricultural exports of the regions. Falling with that was the ability of the regional governments to sustain the regional economies and public good systems, which at that point were so decentralized that the central government was almost incapable of providing national public good. Secondly, as the resources of the regions dwindled, oil was increasingly discovered in the ethnic minority sub-region of the Eastern region. The 
discovery of oil in ever increasing reserves in the minority sub-region gave rise to some changes in the polity. The Eastern region dominated by the Igbo group saw the opportunity to be the richest and the most powerful region of Nigeria. The minorities within the Eastern region, in whose territories oil is being produced, were convinced that they could no longer take the perceived marginalization they suffered in the region. These minorities initiated the movement for autonomy within Nigeria. The other two regionsWestern and Northern-, and the central government dominated by the Hausa-Fulani, knew they would be prevented from taking advantage of the economic opportunities in the emerging new economy because of the limited cross regional mobility and constitutional provision of regional autonomy. Moreover, the dwindling agricultural resources from the other regions made it increasingly difficult to produce any form of the public good for an increasing population. Hence, the central government formed a coalition with the Western and Northern regions to form the necessary majority with power to amend the constitution. The constitutional amendment was to move from a regional control to a central control of the oil resources. Suffice to say that while control over the resources was moved from the regions to the centre, the externalities arising from oil exploitation activities were seldom mitigated or remedied. This gave rise to the gradual decay of local livelihood in the oil-producing sub-region. The consequences of such constitutional amendments in a country with limited mobility, are still being felt today - the Nigerian civil war and the ongoing crisis in the River Niger Delta region of the country. 
While some have submitted that Nigeria's civil war, which lasted for four years from 1967 and claimed over 1.5 million lives, was the result of constitutional failure, several scholars, for example Collier (2003), Dudley (1982), Bates (2005, 2006), and others have posited that struggle for control of Nigeria's vast oil wealth was at the core of the civil war in the period 1967-1970, and is the cause of the crisis in the Niger Delta (oil region) since 1999.

An eminent scholar of constitutional law, Prof Itse Sagay, a Senior Advocate of Nigeria (SAN), in his exposition of the numerous constitutional changes in Nigeria, has also located the control of resource at the core of these constitutional reforms. There have been at least seven constitutional reforms since 1951. At least one such constitution, what was to be the 1989 constitution of the country, was never ratified before it was overtaken by events, and a new constitution, which is presently being operated, was adopted in 1999. Different democratic decision making regimes were provided for by the different constitutions since 1951. The 1951 constitution operated by the British monarchy, since Nigeria was still under British rule, understandably allowed for a unitary system of government. On the eve of independence an independence constitution was adopted in 1960, and a republican constitution followed in 1963. Both of these moved away from the unitary system of governance to a federal system while maintaining the Westminster style of governance with regional semi-autonomy. The regional governments were very powerful, exercised full control over resources within these regions, and contributed part of their revenue to a distributable (equalization) pool. By 1965 , oil was beginning to emerge as a strong revenue earner. The first incursion of the 
military into government in 1966 led to a major centralization of control over regions and resources. A discontent Eastern region revolted leading to the civil war in 1967. An extra-constitutional unitary system was instituted during the civil war. The first post war constitution of 1979 further entrenched unitary control over resources, with a constitutional unitarism wresting full control of natural resources from regions and states. In 1999, yet another constitution, which is presently being operated by a federal government, was given effect. This and the 1979 constitutions, besides being called federal constitutions, are unitary constitutions in all aspects of resource governance. The constitutional unitary control of resource has largely being blamed for the crisis in the Niger Delta region of the country, where $99 \%$ of Nigeria's Petroleum is exploited.

In a World Bank report in $1995^{21}$, Ibeanu (2000), Okonta and Douglas (2001) the environmental devastation resulting from uncontrolled oil and gas exploration and exploitation in the resource-producing region of Nigeria were well documented. The World Bank classified the Niger Delta region of Nigeria, which is also the oil and gas producing region of the country as among the most vulnerable and delicate ecosystems in the world, yet unprotected. It was also reported that gas flaring and other effluents from the resource industry have virtually destroyed the ecosystem and associated livelihood in this region of Nigeria. Poverty has increased and other human development indicators have all plummeted as a result of the direct and indirect environmental impact of resource exploitation.

\footnotetext{
${ }^{21}$ For the detail study on the environment impact of oil and gas exploitation, see Worldbank Report (1995) "Defining an Environmental Strategy for the Niger Delta", Vol II, May 15.
} 
The delta of Nigeria's Niger river covers $20,000 \mathrm{~km}^{2}$ within wetlands of $70,000 \mathrm{~km}^{2}$ formed primarily by sediment deposition. Home to 20 million people and over 40 different ethnic groups, this floodplain makes up $7.5 \%$ of Nigeria's total landmass. It is the largest wetland and maintains the third-largest drainage area in Africa. The Delta's environment can be broken down into four ecological zones: coastal barrier islands, mangrove swamp forests, freshwater swamps, and lowland rainforests. This ecosystem contains one of the highest concentrations of biodiversity on the planet, in addition to supporting the abundant flora and fauna, arable terrain that can sustain a wide variety of crops, economic trees, and more species of freshwater fish than any ecosystem in West Africa. The livelihood and occupation of inhabitants of the Delta is closely linked to this ecosystem. Inhabitants are generally fishermen and/or farmers, deriving their livelihood from, and supporting the balance with, the ecosystem. However, this balance has either been destroyed or threatened by resource exploration and exploitation. A report issued by the Nigerian National Petroleum Corporation (NNPC) in 1983, long before the unset of the present armed conflict stated in part:

"We witnessed the slow poisoning of the waters of this country and the destruction of vegetation and agricultural land by oil spills which occur during petroleum operations. But since the inception of the oil industry in Nigeria, more than twenty-five years ago, there has been no concerned and effective effort on the part of the government, let 
alone the oil operators, to control environmental problems associated with the industry" 22

The NNPC places the quantity of oil spilled into the environment yearly at 2,300 cubic meters with an average of 300 individual spills annually. However, because this amount does not take into account spills considered to be minor nature, the World Bank argues that the true quantity of oil spilled into the environment could be as much as ten times the officially claimed amount ${ }^{23}$. According to a 1999 Human Rights Watch report ${ }^{24}$ on Nigeria's Niger river delta, an estimated 5 to $10 \%$ of Nigerian mangrove ecosystems have been wiped out either by settlement or oil. The rainforest, which previously occupied some $7,400 \mathrm{~km}^{2}$ of land, has disappeared as well, going with it is the livelihood of those individuals from the area dependent on it. Spills in populated areas often spread out over a wide area, taking out crops and aquacultures through contamination of the groundwater and soils. In agricultural communities, often a year's supply of food can be destroyed by only a minor leak, debilitating the farmers and their families who depend on the land for their livelihood. Drinking water is also frequently contaminated, and sheen of oil is visible in many localized bodies of water. Offshore spills, which are usually much greater in scale, contaminate coastal environments and cause a decline in local fishing

\footnotetext{
${ }^{22}$ Greenpeace International's (1994) Shell Shocked: Shell-Shocked: The environmental and social costs of living with Shell in Nigeria $\cdot$ http://archive.greenpeace.org/comms/ken/hell.html. Last visited October 28, 2007.

${ }^{23}$ David Moffat et al (1995) Perception and reality: Assessing priorities for sustainable development in the Niger River Delta (.Ambio, v24 n7-8)

${ }^{24}$ Human Rights Watch (1999). The Price of Oil: Corporate Responsibility and Human Rights Violations in Nigeria's Oil Producing Communities. http://www.hrw.org/reports/1999/nigeria/index.htm. Last visited October 28, 2007.
} 
production. Vegetation in the Niger River Delta is comprised of extensive mangrove forests, brackish swamp forests, and rainforests. The large expanses of mangrove forests are estimated to cover approximately 5,000 to $8,580 \mathrm{~km}^{2}$ of $1 \mathrm{land}^{25}$. Mangroves remain very important to the indigenous people of Nigeria as well as the various organisms that inhabit these ecosystems. These systems are highly valued by the indigenous people living in the affected areas. Mangroves forests have been a major source of wood for local individuals. They also are important to a variety of species vital to subsistence practices for local indigenous groups. Since the revenue from resource exploitation accrues to the national government, individuals in this delta whose livelihoods are being destroyed do not derive any private benefit from this exploitation. Nigeria flares more natural gas associated with oil extraction than any other country on the planet, with estimates suggesting that of the 3.5 billion cubic feet $\left(100,000,000 \mathrm{~m}^{3}\right)$ of associated gas (AG) produced annually, 2.5 billion cubic feet $\left(70,000,000 \mathrm{~m}^{3}\right)$, or about $70 \%$ is wasted via flaring. This equals about $25 \%$ of the UK's total natural gas consumption, and is the equivalent to $40 \%$ of the entire African continent's gas consumption in 2001. AG wasted during flaring is estimated to cost Nigeria US $\$ 2.5$ billion on a yearly basis ${ }^{26}$. The health and economic impact of gas flares are well documented and evident. Respiratory problems amongst children in the Delta area have been linked to gas flaring. Even though no rigorous investigation has been conducted to substantiate these claims, inhabitants of

\footnotetext{
${ }^{25}$ Nwilo, P. C., and Badejo, O. T. Impacts And Management of Oil Spill Pollution Along the Nigerian Coastal Areas. http://www.fig.net/pub/figpub/pub36/chapters/chapter_8.pdf. Last visited October 28, 2007.

${ }^{26}$ Friends of the Earth, Media Briefing, October 2004. Available at http://www.remembersarowiwa.com/pdfs/gasflaringinnigeria.pdf . Last visited October 28, 2007.
} 
the delta are especially disenchanted and provoked by the perceived health hazards, and such perception is widespread. Many of these communities claim that nearby flares cause acid rain that corrodes their homes and other local structures.

All these studies also noted that those who suffer these devastating environmental and occupational impacts of resource exploitation also benefit the least from the revenue from the resources. This is because the revenue goes directly to the National government where decision-making is solely mediated by policy makers from the other regions of Nigeria, far removed from the region suffering the impact of resource exploitation. At the same time, those from the resource producing region, who suffer from the externality, have consistently dissented and resented the political decision-making process that has excluded them from having any effective democratic say in the externality that affects their health, their livelihood and environment. Over the years, the resentment and discontent have evolved, and in recent years they have taken militancy dimension.

The contribution of oil and gas revenue to the GDP and National budget has increased progressively from $0 \%$ in 1951 to about $70 \%$ of GDP and $95 \%$ of National budget in 2006. On the contrary the share of resource revenue going to the resource producing (externality suffering) regions (states) over the years is shown in the table below. 
Table 2: Federal - State Percentage Share In Petroleum Proceeds 1960 $1999^{27}$

\begin{tabular}{|l|l|l|l|}
\hline Years & Producing State (\%) & Federal Government (\%) & Distributable \\
\hline $1960-67$ & 50 & Pool (\%) \\
\hline $1967-69$ & 50 & 20 & 30 \\
\hline $1969-71$ & 45 & 50 & - \\
\hline $1971-75$ & 45 less off-shore proceeds & 55 plus off-shore proceeds & \\
\hline $1975-79$ & 20 less off-shore proceeds & 80 plus off-shore proceeds & \\
\hline $1979-81$ & - & 100 & - \\
\hline $1982-92$ & 1.5 less off-shore proceeds & 98.5 plus off-shore proceeds & \\
\hline $1992-99$ & 3 less off shore proceeds & 97 plus off-shore proceeds & - \\
\hline $1999-$ & 13 minus off-shore proceeds & 87 plus off- shore proceeds & \\
\hline
\end{tabular}

There have been two major violent conflicts in Nigeria since 1960 - the civil war from 1967-1970, and the Niger Delta crisis. The start date of the Niger Delta crisis is less obvious to outsiders. It started as a political protest by regional governors in 1981. It became vocal amongst the youth of the region in 1991, anchored mostly by students associations. By 1999, it had assumed the status of a mainstream struggle in the region. In 2003, following the widely discredited national elections it became an arm's struggle precipitated from a conflagration arising from violent political activities within the region. Observers predicted the turning point has not been reached.

\footnotetext{
${ }^{27}$ Table from the presentation by Prof Itse Sagay at the All Niger Delta People Conference, Dallas, 2006.
} 
As noted above, dwindling national revenue from agriculture made oil a vital source of revenue when it was discovered in commercial quantities. Although the interaction of oil exploitation and local livelihood was self-evident, this negative impact was ignored because the oil was discovered in the minority region of the country largely in the former Eastern region. The minority ethnic groups with no effective political representation watched the gradual destruction of their environment. With limited occupational and geographical mobility, this led to the unset of poverty and occupational decay in the minority region of the Eastern region. However, the bigger ethnic groups (Hausa-Fulani, Igbo and Yoruba) dominating the three polispheres quarreled over the control of the oil resources. A military takeover of government led to the implementation of strong unitary control over resources in 1966. These controls instigated the declaration of self-rule by the dominant Igbo group in the Eastern region in Biafra. Following the unilateral usurpation of the national constitution by the Igbo group in the Eastern region, the central government of Nigeria, dominated by the Hausa-Fulani ethnic group of the Northern region, seeing itself as the defender of the constitution, declared a war to prevent the break-up of the country.

Why did Biafra fail? We posit that the Igbo group, which dominated the Eastern region that was to form the Republic of Biafra, ignored the ethnic heterogeneity within the region. Moreover, it ignored the discontent and disenchantment, which was widespread among other ethnic groups within the region, especially within the second largest ethnic group in the region -the Ijaws. The forced silence of these minority groups in the region was mistaken for peaceful and harmonious coexistence within the region. 
According to our model the size of the former Eastern region in terms of total population was thought to translate into support by all the peoples, in the event of a war. The heterogeneity and the low mobility within the region ensured that although the population was large, the region did not form the cohesive whole that was required to successfully execute the secession war against the Federal forces. The Ijaw ethnic group together with other minority groups within the Eastern region actually fought on the side of the federal forces to ensure the secession by the Eastern region failed, because such secession would place them and their resources in Biafra - a prospect these minorities considered worse than the prospect of being part of Nigeria.

Following the war, stronger central control over resources was instituted. Agricultural production fell over the years and with limited ability to raise revenue through taxes, oil emerged as the preeminent source of national revenue. Poverty levels exacerbated in the oil producing minority regions as negative externality increased due to more intense oil exploration and exploitation. Jobs were created outside the oil-producing region; even oil industry opportunities were thought to have been reserved for privileged majority ethnic groups. Limited mobility ensured that occupational mobility was also limited for residents of the resource-rich region. This worsened the discontent within the region. The central government has always been dominated by the majority ethnic groups, thus original residents of the resource-rich region, whose livelihood is being destroyed by the externality from resource exploitation, also feel disenfranchised from the lack of effective political say on resource use. 
Over the years, the worsening poverty levels and the wide scale discontent helped homogenize views among the minority ethnic groups who are in the resource region. Suffice to say that coordinating their efforts for political effectiveness was difficult without a platform for that purpose. The level of ethnic heterogeneity was sufficient to prevent such coordination from taking place. In 1998 a geopolitical reconfiguration was proposed and adopted. This created, for administrative convenience, six geopolitical regions in the country, namely, South-West, South-South, South-East, North-Central, North-East, and North-West. Although these regions were created for administrative convenience, as an unintended consequence, their creation provided a platform for the resource-rich ethnic minorities to coordinate their dilemmas. It also, largely, excluded the Igbo ethnic group from the resource-rich region's affairs, which makes it easier for such coordination. The South-South geopolitical zone has within it over $98 \%$ of the oil and gas resource of Nigeria accounting for about $95 \%$ of the national budget, yet it also accounts for the highest level of poverty due to the interaction of local livelihood and resource exploitation, and limited mobility to other regions. Since the creation of the South-South geopolitical zone, there has been a steady homogenization of views on resource governance within the zone. The common incidence of poverty and resource externality also helps achieve this cohesion. Ethnic bigotry has also intensified, and opportunistic opposition to the resource externality also emerged. Ethnic bigotry has motivated stronger loyalty to regional (ethnic) course within the region.

At a democratic negotiation cum constitutional reform forum instituted to resolve some constitutional dilemmas in 2003, the first signs of the emerging cohesion and 
homogenization amongst the externality impacted minorities of the South-South region were felt by all Nigerians, to the amazement of the majority groups. Issues that were once ignored with ease by the majority regions could not be ignored. These minority groups, on a unified platform, demanded more than the majority was willing to concede, and the negotiations collapsed. In its stead violent expression of the opposition to resource externality and increasing poverty in the externality impacted region arose. Although the ideological opposition is increasingly vocal, the activities of the opportunistic rebels are tending to crowd out the activities of the truthful opposition.

Small-scale conflicts and the government's response to the opposition and conflicts have had the unintended consequence of further homogenizing the opposition. This is because these conflicts have resulted in the movement of residents, who are marginally opposed to the status quo, out of the region, leaving behind an increasingly homogeneous group. Left in the region are individuals with very high attachment to the region, and who share a common experience of aggravated poverty and externality from resource use.

There are those who oppose resource exploitation because the industry does not preferentially source its human resources from the region. In fact this opposition claims that the most preferred economic opportunities in the resource sector have been reserved for individuals from the politically majority regions of the country, namely east, west and north, thus economically marginalizing individuals even more qualified but are from the resource producing region. This opposition may be appeased by expanding economic opportunities to substantially include qualified individuals from the region, and provide 
transferable skill sets to those whose livelihoods have been destroyed by the externality, so they may transfer employment from the agricultural sector to the resource sector. However, this group of opposition may not possess the resolve to carry out an arms struggle. Small scale conflict may push this group out of the region in search of economic opportunities elsewhere, because there attachment to the region ( $\rho$ ) may not be as strong. Secondly, there is the group whose opposition to resource exploitation stems from the perceived neglect of the region in terms of infrastructure development. They claim that even though the region produces the resource which finances the national and regional public goods, this region has been neglecting in the location and development of regional public goods. This, this group believes, is because the region does not have politically effective representation in the national legislature and government to make its demand for regional public goods, such as infrastructure, effective. Again, individuals in this category would be appeased by the equitably allocation of regional public goods, following this, they may support exploitation at current levels and accept the externality. Suffice it to say that small conflict also drives this group out of the region, because even though its attachment to the region is stronger than the previous group, it may not be willing to go into conflict to achieve its demand. A third group is constituted by individuals who demand a local control of the resource becuase they believe local control of resource exploitation in more efficient in its response to the environmental impact of resource exploitation and in dealing with the impact on local livelihood. Some individuals from this group, though not all, are genuinely concerned about the environmental effect and will want to see efficient environmental policy within the 
resource exploitation policy. The demand here is both economic and ideological, hence it is potent compared to the two previous groups. A fourth group is solely concerned with the environmental impact of resource exploitation and it is purely ideological in its demands. A fifth group demands secession of the region from Nigeria, because it believes the resolution of the conflict is only possible in a separate country with only the region impacted by resource exploitation. Individuals in the third, fourth and fifth groups have strong attachment to the region, however those of the fifth and third groups are more vulnerable to information management and manipulation by political entrepreneurs. Individuals from the third and fifth groups are those who are likely to be left behind in the region in the event of a small arm conflict. Their attachment to the region is high enough to make them the least mobile of all the groups. Leaving behind this group in the region will make resolution of the conflict harder than it would if individuals of groups one, two and four did not leave the region. Individuals of groups one, two and four provide the heterogeneity required to prevent unanimity in taking the decision for civil war or large-scale conflict.

Since the opposition to the control of the resources started in the 1981, the revenue from the resources that is returned to the region from the national account has progressively increased from $0 \%$ in 1980 to $13 \%$ in 1999 . The region that produces the resources has however maintained a demand for control of the resources within the region. The majority groups have resisted this demand since this will lead to a collapse of the social infrastructure in the country, except in the resource-rich region. Presently, the majority and minority regions seem to have positive expected net gain from conflict. As 
posited in our model, the resolution of the conflict is not feasible within the current constitutional framework. Moreover, it is highly unlikely that any internal institution is capable of resolving the impending conflict because of the positive expected net gain facing the two sides of the conflict.

Although there is a consensus on the course of these conflicts, there has been no consensus on root causes. Bates (2005), Bates et al (2006), Collier (2003), Collier et al (2004), and others posit that natural resources (petroleum) is at the center of both the civil war and the Niger Delta crisis. The poverty, and rebels wishing to control the resources, Collier (2003), and the government desire for control, Bates (2005) have been taken to explain these conflicts. Here we posit that- deviating from the literature- the Niger Delta crisis in Nigeria is not due to weak government or greedy rebels. It is the result of a combination of poverty-aggravating resource-related externality, lack of effective political voice by those impacted by the negative externality, limited mobility due to ethnic and religious differences across geographic regions, and homogenization of the opposition over the years. Our model has also explained why the majority over the years has progressively increased the share of the revenue going to the externality-impacted region, and why the opposition has been increasingly vocal over the years.

We submit that efforts at resolving the Niger Delta crises must take into account the entire root causes outlined above. Even though mobility determined the outcome of the civil war, environmental and occupational impact of resource exploitation, mobility and the lack of effective political say by the affected individuals are at the core of the 
conflict in the Niger Delta of Nigeria. These must also form the core of any resolution to the conflict. 


\section{Appendix 6.1 Regional Map of Sudan ${ }^{28}$}

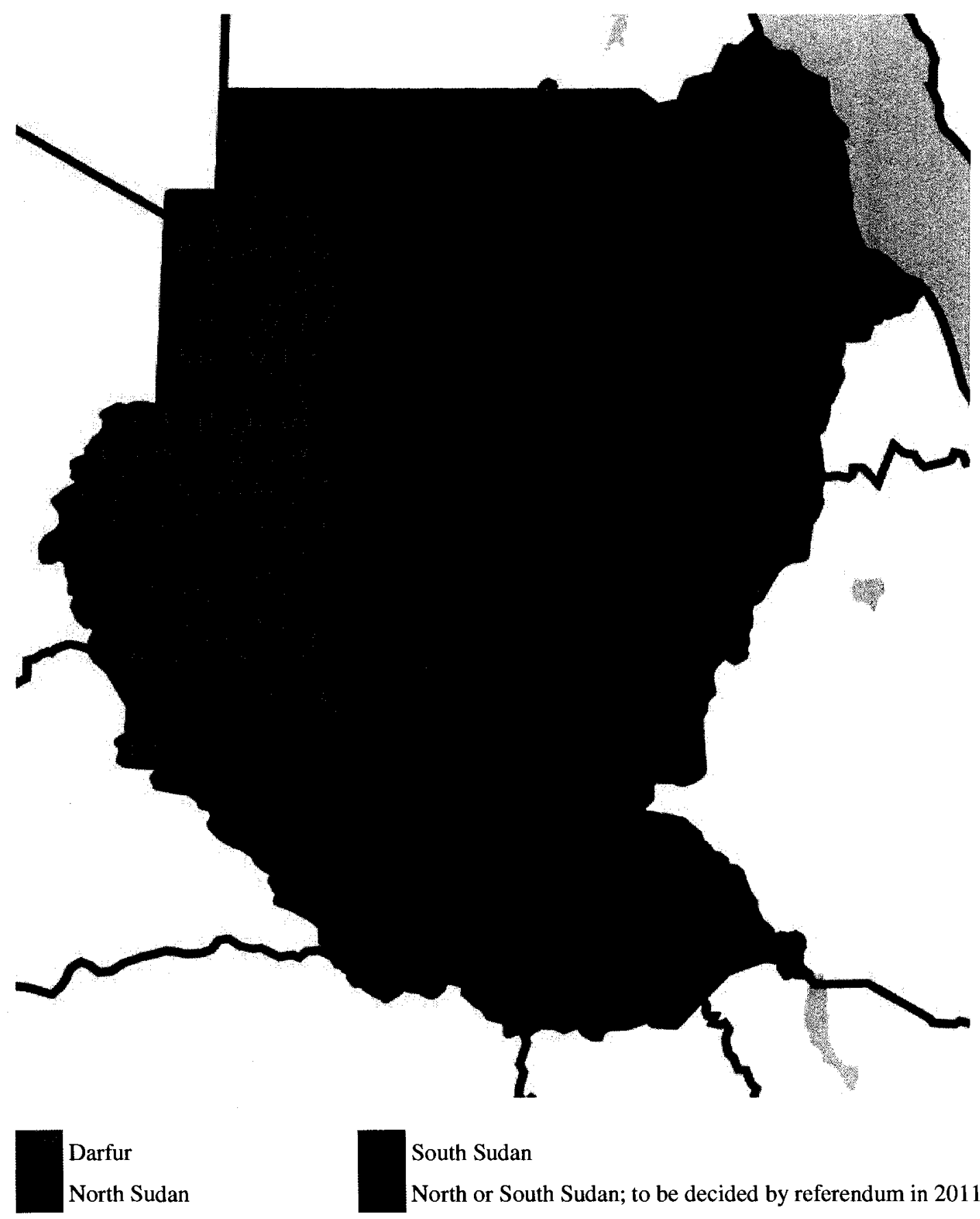

\footnotetext{
${ }^{28}$ Source: Wikipedia free source. http://commons.wikimedia.org/wiki/Image:Regions_of_Sudan.png . Last visited October 8, 2007.
} 


\section{Appendix 6.2 Linguistic and Vegetation Map of Nigeria ${ }^{29}$}

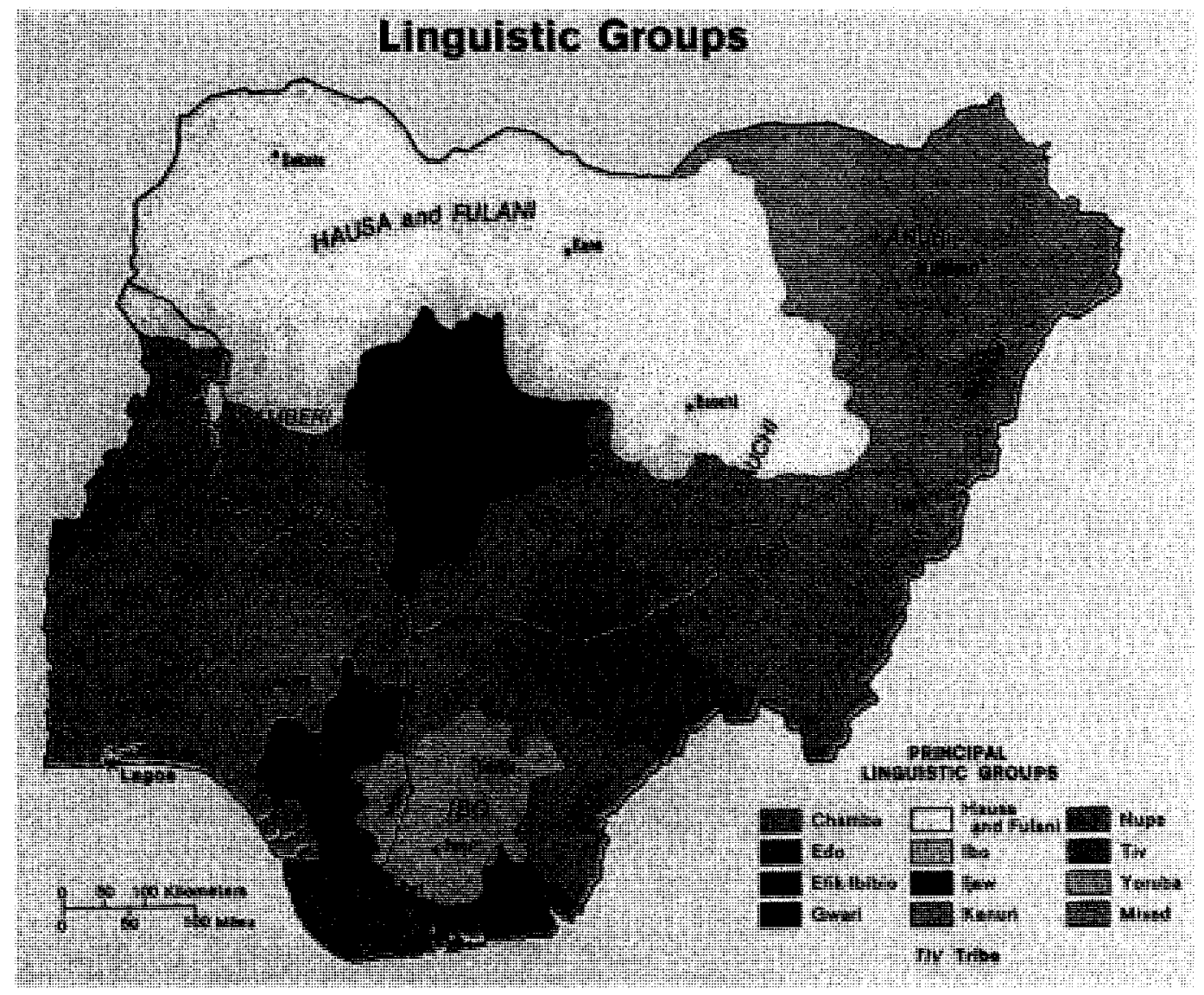

${ }^{29}$ Source: Wikipedia free source. http://commons.wikimedia.org/wiki/Image:Regions_of_Sudan.png . Last 


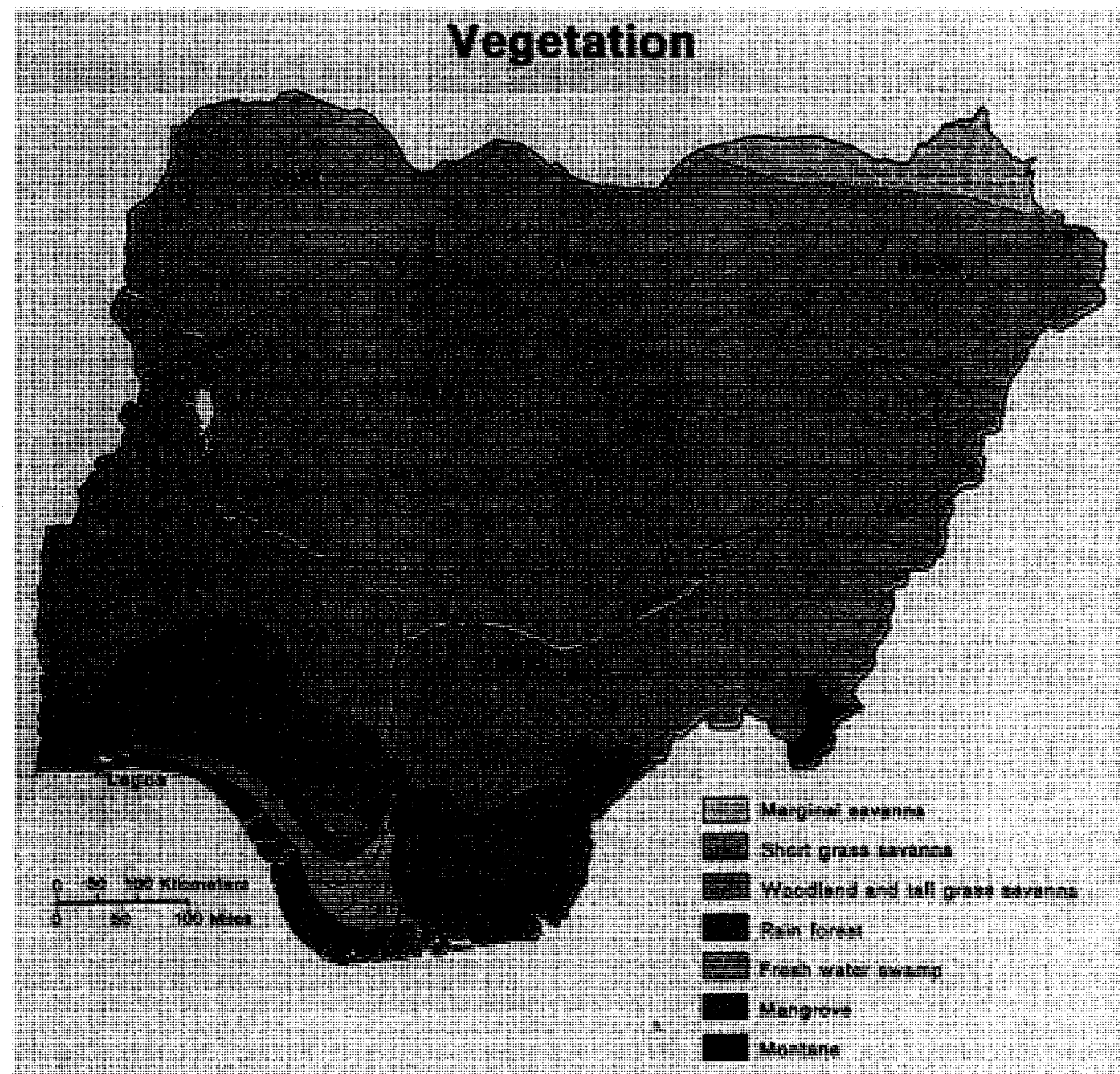

visited October 8, 2007. 


\section{CHAPTER 7}

\section{Policy Implications, and Policy Prescription}

In what follows, we shall examine the policy implications and prescriptions for mobility and externality driven resource conflicts in heterogeneous societies.

On efficiency, the separation of the incidence of externality and political control may result in either production or consumption inefficiency. The outcome of a democratic decision, without mobility as described, may be most efficient when the resources are produced from the political majority region in a unitary system. Consumption inefficiency may be the outcome in a strict federal system with the minority control of the level of the public good and resource exploitation without mobility. Production inefficiency may arise under strict unitarism with the minority region suffering the externality from resource use. Inefficiency in these circumstances is both technological and political. The political decision to produce a higher level of the public must be constrained by the technological problem of minimizing externalities from resource production. Reducing the externality, arising from resource production, while producing an appropriate level of the public good, will entail either the political will to develop other sources of government revenue, such as tax reforms, or investment in, and deployment of, technology that minimizes externality from resource production. The issue of tax reforms will be discussed later. It suffices to say that technological efficiency does not resolve the issue of ownership and control. The achievement of the simultaneous 
production and consumption efficiency - social efficiency- may require a deviation from strict constitutional definitions and provisions of unitarism and/or federalism. Extraconstitutional institutions may be required to balance the requirement for public good (consumption efficiency) with the negative externality (production efficiency). From the standpoint of federalism, where the minority region produces the resource, this will ensure increasing the level of resources marginally, while maintaining the total net benefit to the externality-suffering region at positive levels. In a unitary system with the minority region suffering the externality, such extra-constitutional institutions will ensure the minimization of externalities -maintaining total benefit to externality-impacted region at positive level- while maintaining the higher production of the public good. Suffice to mention that such marginal considerations are internally feasible if at least one of the total considerations of $E N G_{i}(\mathrm{i}=1,2)$ is negative. The policy implications for $E N G_{i}$ will be discussed later. Also, occupational and geographic mobility may be encouraged to reduce the number of impacted individuals. This may reduce the inefficiency in terms of the impact of resource externality on human livelihood. It places a wedge between resource use and poverty.

The separation of production and consumption efficiencies gives rise to the possible increase in welfare disparity across regions when the objective of policy makers is solely to increase aggregate welfare. This becomes more problematic when the region in political majority also controls resource use, while the region in political minority suffers the externality, and limited mobility across regions prevents those impacted by the externality from escaping it. Creating two separate institutions, one for externalities and 
the other for production, with equal precedence will enable negotiations by the two institutions. When the control of externalities rests with the externality-impacted region, such separation of instruments will encourage inter-institutional (regional) negotiations.

The adverse effect of the externality is on local livelihood. This is made worse by the limited occupational and geographic mobility. Attachment to regions of origin often impedes occupational mobility. It has been noted that because of the fact that certain occupations are specific to certain environments individuals usually grow into occupations specific to their environment. For instance, individuals in the Delta region of Nigeria are usually into fishing. Such skills are not readily transferable to the occupations prevalent in the hinterlands, namely land farming and animal husbandry. Hence geographical mobility is also limited by occupational immobility. For this reason, when resource production negatively impacts local livelihood, in addition to destruction of the livelihood in the locality, individuals are not able to change occupations because of the non-transferable skill set. To resolve the problem of local livelihood and resource externality, policies must seek to place a wedge between livelihood of individuals not in the resource industry and the externality from resource production. Such a wedge may mean deliberate policy to diversify the skill set of individuals in occupations vulnerable to the impact of resource production. This is to make them occupationally mobile. As simple as it may sound, in countries with so much diversity and cross regional distrust like Sudan, Nigeria and most democracies of the south, this may be understood as government spending more in certain regions than others, and thus may be subject to ethnic opposition. It is in assuaging the opposition to such policies from other regions not 
impacted by the externality that policy makers will require negotiating skills and political will.

Population homogeneity and opportunism provide regions the ability to either effectively oppose policies or exacerbate conflict. These also make individuals vulnerable to the rhetoric of political entrepreneurs and bigotry. Population homogeneity also inhibits flow of information from one region to the other and prevents individuals in one region from being truthfully informed of the reality in other regions. Movement out of the region affected by negative externality increases the homogeneity of population in this region. And as shown, this remaining population is more prone to violent conflict that a highly heterogeneous population. Hence, policy makers, in order to reduce the likelihood of conflict, must limit the homogeneity (ethnic, religious, etc) of population in any given region. Cross regional contact and population mixing must be encouraged. In alleviating the impact of the negative externality on local livelihood, policy makers must be cautious in making sure such policies do not lead to movement of individuals out of the affected region, since this may lead to population homogeneity. In countries such as Nigeria, Sudan, and most other countries of the global south, this will also mean citizenship reforms. It is appallingly astonishing that in a country such as Nigeria, living in a region for even ten generations or more does not make one a citizen of that region. That, except one's ethnicity could be traced to a given region, it does not matter how long one has lived in a region, or how much contribution one as made to a region, an individual is not considered a citizen of that region. Citizenship reform is therefore necessary in order to create a national identity. If economic opportunities and alternative occupations are 
provided, such opportunities should be created within the impacted region. By creating alternative economic opportunities within the affected regions, individuals who are marginally opposed to resource production are encouraged to remain within the region. Individuals from other regions are also encouraged to seek economic opportunities in the affected region. A heterogeneous population that might be opposed to conflict would thus be created in the affected region. Individuals from other regions moving into the affected region to take advantage of economic opportunities created in the affected region will also have first hand information on the negative impact of resource exploitation. A higher population in the impacted region may also be more committed to democratic decisionmaking process than a lower but homogeneous population that is alienated by the majoritarian democratic decision-making process. Moreover, a heterogeneous population iss less likely to speak with one voice on issues of extra-constitutional unilateral action. A heterogeneous population is also less vulnerable to bigotry. Economic development of affected regions and citizenship reforms are therefore essential in creating this form of stability enhancing heterogeneity. Creating economic opportunities outside the region for affected individuals, will only encourage emigration of those individuals whose attachment to the affected region is relatively weak, thus, leaving behind a populace with strong attachment to the region - those most prone to bigotry, and vulnerable to recruitment by opportunistic rebels. Mobility, when it does not lead to changes in political equilibrium, is welfare improving and stability enhancing. Where mobility leads to changes in political equilibrium, then its impact on social welfare is ambiguous, and it may lead to greater instability. Mobility and the willingness to take advantage of 
economic opportunities across regions seem to have an inverted-U effect on political and social stability. At low levels of mobility efficiency improves, as total number of impacted individuals decreases, and welfare also improves. However, high levels of mobility, and actual movement of impacted individuals willing to take advantage of economic opportunities across regions, increase the concentration of individuals with stronger attachment to regional specific ethnic, cultural and/or language differences in the impacted region. This manifests in high cost of movement, and high premium on movement. The same population flow also increases diversity and non-cohesiveness in the majority region. A change in political equilibrium arising from this may lead to lower social welfare.

Information (level and quality) is critical to how individuals perceive the povertyexternality-public good nexus. In countries, such as Nigeria, Sudan, and others experiencing resource-related conflicts, with incredibly low levels of education and information levels and flow, it seems plausible to conclude that individuals may not be properly informed of the nexus connecting the public good, resource exploitation and poverty. Truthfully informing individuals in all regions of the impact of resource exploitation on local livelihood, and the importance of the resources in the provision of the public good may influence voting decisions of individuals in all regions. This may also encourage individuals to take interest in other regions. If the information space is competitive and complete, then political entrepreneurship and opportunism may have little or nothing to exploit as a result of information asymmetry. As shown, information management may lead to political and social instability as the level and clarity of 
information affects individual perception of the externality, the public good, and the expected net gain in taking unilateral extra-constitutional actions. Therefore, in eliminating such asymmetry policy makers may be resolving some dilemma, which political entrepreneurs and opportunists may exploit. Also, when information asymmetry exists on regional welfare disparity, acceptability and cohesion within regions, then politicians and regional leaders may manage information in pursuit of regional interest. This may lead also to instability as information is updated over time.

In deciding to take a unilateral, extra-constitutional action to usurp the status quo by any region, the most potent determinant is the expected net gain from such action. We have shown, even under complete information, how this expected net gain might be simultaneously positive for both regions. Of all the cases of the expected net gain examined, this case of simultaneous positive is very critical to the incidence of violent conflict in resource producing countries with differences across regions. It suggests that internal institutions may be incapable of resolving potential conflict situations, since both sides of the divide may be unwilling to negotiate for lack of incentive to do so. The implication is that conflict may be a conscious rational decision ex ante. In this circumstance only external institutions such as the intervention of multilateral institutions seen to be neutral to both sides may be able to resolve such conflicts. The United Nations, and/or regional organizations such as the African Union in Africa, of all such multilateral institutions may be the best placed to prevent conflicts in such cases. Internal mechanisms may simply fail, or fail to yield lasting resolutions. Knowing when potentially volatile situations call for such external intervention will require proactive 
actions and engaged monitoring of such situations, in addition to understanding the peculiarities of resource related conflicts across the world, especially in the heterogeneous resource-rich countries of the global south. 


\section{CHAPTER 8}

\section{Concluding Remarks}

Conflict is the outcome of a complex array of causes, some of which are commingled, therefore a simple model may not be capable of explaining all the manifestations of conflict. Nevertheless, we have studied the role played by two critical factors that have not been given adequate attention in the literature, namely externality and mobility. We have done so under perfect and imperfect information in different democratic decision-making systems. A general model was developed and then specialised in order to do so.

The most important determinants of resource related conflict in this study are cross-regional and occupational mobility within a country, and the impact of resource exploitation on local livelihood. In the case that occupational and cross regional mobility is highly limited, then it becomes equally important where the political decision on resource exploitation is taken - that is, centrally or regionally -, if resource exploitation impacts negatively on local livelihood. Constitutional provisions that alienate those who suffer negative externalities from resource exploitation are potential grounds for conflict. Where the individuals impacted by the externality are not able to escape the externality through emigration, these constitutional provisions, guided by strict majoritarian democracy, more than anything else become the source of resource related conflict. 
Other causes of resource related conflict, shown here, are government dependence on revenue from natural resources and opportunism - recurrent themes in the literature. Information, the degree to which individuals in the country are aware of the importance and impact of resource exploitation and the accuracy of the information, is critical to the type of decisions that are made by policy makers on resources.

In order for any, or a combination, of these factors to crystallize a violent conflict the expected net gain from such conflict by the belligerents plays a central role. The expected net gain from unilateral usurpation of constitutional provisions is critically dependent on the probability of victory, information level (and accuracy) in the society, and the gains from victory. In these, the level of cohesion in the belligerent region together with information plays a yet unmatched role.

It suffices to say that resource related conflicts involve a complex system of factors working together, and so policies to prevent or resolve these conflicts must also not be simplistic. This is in agreement with the current body of literature that conflict underscores a complex system of factors working together in a complex relationship. Here, we have studied the role of mobility and externality in the context of democratic decision making regimes.

The literature on rational conflict has been very strict and narrow, relying on information and transfer mechanisms to generate rational conflict. Here, by combining mobility with inability to carry out transfers, resource-dependence, and externality rational conflict was generated even in the presence of perfect information. 
This study has explained why there has been no consensus on the cause of conflicts in a number of the natural resource producing countries, especially those in Africa and Latin America. It has also explained why proposed resolutions to such conflicts have failed. For instance, the Kimberly process ${ }^{30}$ advocates the elimination of market for looted resources seen to be fueling conflict. This process was specially designed for Sierra Leone. It was founded on the greed and grievance theory due Collier and Hoeffler (2000), that by eliminating the market for the looted resources, the rebellion would be choked, and the incentive for war removed. This has failed to solve the Sierra Leone conflict, because, according to our model, fundamental issues of mobility, citizenship, and livelihood remained unresolved. Especially that the large scale mining for diamond which takes away the livelihood of individual miners and local farmers in the locality of the mines, who are now left to face the environmental damage were unresolved. These individuals are also not able to relocate occupationally and geographically. Moreover, they have constitutionally and politically ineffective say on issues relating to resource exploitation.

The conclusions of this analysis and the proposition that rational conflict is possible derive from the following critical assumptions. First, the public good produced from resource revenues is not a substitute for a private good. Second, resource revenues must be used to produce a public good. Third, other forms of transfer are blocked. Thus while all regions enjoy the benefits from any increase in the public good, the externality from resource production is strictly local. Furthermore, the fact that revenues from the

\footnotetext{
${ }^{30}$ See http://www.kimberleyprocess.com.
} 
resource do not go to providing a private good for any region makes it infeasible for the unaffected region to use some of the revenue to pay for the externality. It follows that paying the impacted region with part of the proceeds of resource exploitation does not make any one better off. This is because it reduces the public good to all with no benefit to the region not impacted by the externality. Also, because of the convexity of the cost function both sides are necessarily worse off than they would be were the extra unit of the resources that generated the revenue not produced. Furthermore, by limiting mobility across regions, a traditional means of equalizing welfare is blocked. That is, mobility has the effect of enabling those affected by the externality to escape by emigrating to the other region, since the marginal productivity of land in this region is unaffected by the resource externality.

The present body of literature is fragmented, calling for a complex model capable of integrating the different and sometimes opposing paradigms. The model developed in this study responds to this call. It is a broad model, with general applicability. It integrates the state-centred approach and the paradigm based on methodological individualism with instrumental rationality. Such a model is rich enough as a foundation for a robust empirical study on the causes of conflict. It is capable of explaining conflict in the general case of differences in preferences over policy alternatives across individuals, regions or countries with limited ability to transfer resources while operating within a common governance system. Yet, we have specialized it in order to be able to explain conflict in democratic, developing, and resource-dependent countries with limited transfer and cross-regional migration mechanisms. International and trans-national 
institutions dealing with global issues with limited ability to make transfers, raise taxes, and hindered by limited global migration readily come to mind in applying the model developed in this study. What is left to do is to extend the model to include more of the causes of conflict, and also to specialise it in order explain conflict in some other situations and regions. A new generation of empirical work on the resource-conflict nexus is suggested based on the findings of this study.

\section{Nomenclature}

d Value of productivity of agricultural land.

e level of externality produced by unit of resource produced.

G Level of public good provided.

$\mathrm{G}_{\mathrm{i}}{ }^{*} \quad$ Optimal level of public good chosen by residents of region $\mathrm{i}(\mathrm{i}=1,2)$.

$\mathrm{k}^{*} \quad$ Population of region 1, the impacted region, at the equilibrium of emigration.

$n_{i} \quad$ Original population of region $i(i=1,2)$.

$n_{i}^{r} \quad$ Level of employment in the resource sector proposed by original residents of region $i(i=1,2)$.

$\mathrm{n}_{1}^{\mathrm{r}^{*}} \quad$ Optimal level of employment in the resource sector chosen by original residents of region 1 (the impacted region).

$\mathbf{n}_{2}^{\mathbf{r}^{*}} \quad$ Optimal level of employment in the resource sector chosen by original residents of region 2 (the unimpacted region).

$\mathrm{n}_{\mathrm{m}}{ }^{{ }^{*}}$ Optimal level of employment in the resource sector chosen by immigrants to region 2 (the unimpacted region). 
$\mathrm{n}_{b}{ }^{\mathrm{r}} \quad$ Level of employment in the resource sector proposed by a negotiated bargain.

$\mathrm{n}_{\mathrm{s}}^{\mathrm{r} *} \quad$ Social Optimum level of employment in the resource sector using a Utilitarian welfare function.

$\mathrm{n}_{\mathrm{A}}^{\mathrm{T}} \quad$ Level employment in the resource sector in case A.

N Total population of the country.

p market price of the natural resource.

$\mathrm{R} \quad$ Stock of extractive natural resource.

$\mathrm{U}_{\mathrm{i}}^{\mathrm{j}} \quad$ Utility of an individual in region $\mathrm{i}(\mathrm{i}=1,2)$ under $\mathrm{j}[\mathrm{j}=\mathrm{f}$ (federalism), $u$ (unitarism)].

$U_{i} \quad$ Utility of an individual in region $\mathrm{i}(\mathrm{i}=1,2)$.

$x_{i} \quad$ private consumption of an individual in region $i(i=1,2)$.

z(e) productivity of agricultural land impacted by externality.

$\mathrm{z}_{0} \quad$ productivity of land without the externality.

$C_{i}^{j} \quad$ The fixed cost of unilaterally usurping or defending regime $\mathrm{j}(\mathrm{j}=$ federalism, unitarism) by region $\mathrm{i}(\mathrm{i}=1,2)$.

$C P A_{i}$ The fixed cost of peaceful political activism to uphold or change the status quo regime by region $\mathrm{I}(\mathrm{i}=1,2)$.

$E G_{i}^{j}$ Expected (potential) gain to region (group) $\mathrm{i}$ if it succeeds in changing or defending regime $\mathrm{j}$ (federalism, unitarism).

$E N G_{i}^{j}$ Expected net gain to region (group) $\mathrm{i}(\mathrm{I}=1,2, \mathrm{~m})$ if it succeeds in changing or defending regime $\mathrm{j}$ (federalism, unitarism). Where $\mathrm{m}$ connotes the migrant group. 
$E N G_{\text {eff }}$ The effective expected net gain prevailing in the country for all groups considering unilateral course of action to either defend or usurp the status quo regime.

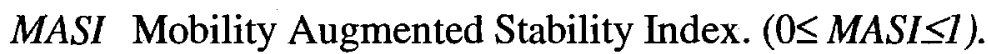

SI Stability Index. $(0 \leq S I \leq 1)$.

$\alpha_{i j}=\alpha$ Marginal impact on the utility of a typical individual in jurisdiction $i$, due to a unit private consumption by an individual in jurisdiction $\mathrm{j}(0 \leq \alpha \leq 1)$.

$\beta_{i j}=\beta$ The degree of acceptability in region $j$ of an individual originally from region $i$, $(0 \leq \beta \leq 1)$.

$\kappa_{i} \quad$ The probability that in any unilateral action or conflict region $\mathrm{i}$ will be victorious.

$\lambda \quad$ The level of information asymmetry in the country $\left(0 \leq \kappa_{i} \leq 1\right)$.

$\theta \quad$ A binary indicator, zero (0) if voter is uninformed and one (1) if voter is informed.

$v \quad$ The probability that the country will break up into separate countries of the regions in the event of conflict $(0 \leq v \leq 1)$.

$\rho$ The degree of individual attachment to their regions, and a measure of reluctance to emigrate from it $(p \geq 1)$.

$\sigma \quad$ The probability that in the resource may be destroyed in the event of prolonged conflict. $(0 \leq \sigma \leq 1)$.

$\tau \quad$ The proportion of informed voters in the country $(0 \leq \tau \leq 1)$. 
$\omega$ The probability a peaceful political action to change a regime may be successful, $(0 \leq \omega \leq 1)$.

$\xi \quad$ The welfare gap $\left(\mathrm{U}_{1}-\mathrm{U}_{2}\right)$ between individuals in the two regions. A measure of discontent with the status quo.

$\psi \quad$ A measure of the level discontent within the country, $\left(n_{1} / N\right)\left[U_{1}-U_{2}\right]$, due to the externality when movement across regions is prohibitive.

$\psi^{m} \quad$ A measure of the level discontent within the country due to the externality, when movement across region occurs.

$\beta / \rho \quad$ Mobility factor. The ease with which cross regional migration and integration occur. $(0 \leq \beta / \rho \leq 1)$. 


\section{LITERATURE CITED}

Aginam O, (1998). Exploring the multiple Dimensions of compensation for Oil Pollution in Nigeria: The Uncertain Promise of the Law. Unpublished Masters Thesis, Queen's University, Kingston, 1998.

Arrow, K. J. (1963) Social Choice and Individual Values, New Haven CT: Yale University Press, 1963 (1st ed. 1951).

Assetto, VJ, Hajba, E. Mumme SP. (2003) Democratization, decentralization, and local environmental policy capacity: Hungary and Mexico, The Social Science Journal, $40,249-68$

Baber, W (2004) Ecology and Democratic Governance: Towards a Deliberative Model of Environmental Politics. Social Science Journal 41, 331-46

Baker, M. J. (2003). An Equilibrium Conflict Model of Land Tenure in Hunter-Gatherer Societies. Journal of Political Economy, 111(1): 124-73

Ballentine, K., and Sherman, J. eds. (2003). The political economy of armed conflict: Beyond greed and grievance. Lynne Rienner, Boulder and London.

Berdal, M. and Malone, D. M. (Eds.) (2000). Greed and Grievance. Lynne Rienner, Boulder and London.

Bilsborrow, E. R., and DeLargy F. P., (1990). "Land Use, Migration, and Natural Resource Deterioration: The Experience of Guatemala and the Sudan." Population and Development Review, 16, Supplement: Resources, Environment, and Population: Present Knowledge, Future Options. 125-47. 
Black, D. (1948). "Decisions of a Committee Using a Special Majority." Econometrica. $16,245-61$.

Black, D. (1958). The Theory of Committees and Elections. Cambridge: Cambridge University Press.

Collier, P. and Hoeffler, A. (1998). On economic causes of civil war. Oxford Economic Papers 50, $563-73$.

Collier, P. (2000). Rebellion as a quasi-criminal activity. Journal of Conflict Resolution, 44(6): 839-53.

Collier, P. and Hoeffler, A. (2000). Greed and grievance in civil war. World Bank Policy Research Paper 2355.

Collier, P. and Sambanis, N. (2002). "Understanding Civil War: A New Agenda [Introduction to special issue on Understanding Civil War]." Journal of Conflict Resolution 46(1):3-12.

Collier, P., and Hoeffler, A. (2002). On the incidence of civil war in Africa. Journal of Conflict Resolution 46 (1): 13-28.

Collier, P. (2003). “The market for civil war". Foreign Policy, May/June, pp. 38-45.

Collier, P., Elliott, V.L., Hegre, H., Hoeffler, A., Reynal-Querol, M., and Sambanis, N. (2003). Breaking the conflict trap: Civil war and development policy. Washington, DC: World Bank and Oxford University Press

Collier, P., and Hoeffler, A. (2005). "Resource rents, governance, and Conflict". Journal of Conflict Resolution 49 (4): 625-33. 
Collier, P., and Sambanis, N. (2005). Understanding Civil War: Evidence and Analysis. Vol 1. Washington DC. World Bank.

David, S. R. (1997). "Internal war: causes and cures". World Politics, 49, 552-76.

Davis, O. A.; Hinich, M. J. and Ordeshook, P C. (1970) "An Expository Development of a Mathematical Model of the Electoral Process," Amer. Political. Science. Review. 64(2): $426-48$

Downs, A. (1957) "An Economic Theory of Political Action in a Democracy". Journal of Political Economy. 65(2): 135-150

Dunning, T. (2005). "Resource dependence, economic performance, and political stability". Journal of Conflict Resolution 49 (4): 451-482.

Elbadawi, I. and Sambanis, N. (2000). "Why are there so many civil wars in Africa? Understanding and preventing violent conflict". Journal of African Economies, 9(3): 244-269.

Ellner, S. and Hellinger, D. (2003) Venezuelan politics in the Chávez era: Class Polarization, and Conflict. Rienner Publishing, Boulder, Co.

Enelow, J., and Hinich, M. (1984) The Spatial Theory of Voting. Cambridge University Press: Cambridge.

Enelow, J. M., Lin, T., and Dorussen, H., (1999). "Equilibrium in Multi-candidate Probabilistic Spatial Voting" Public Choice 98, 59-82

Englebert, P., and Ron, J. (2004). "Primary commodities and war: Congo-Brazzaville's ambivalent resource curse". Comparative Politics 37 (1): 61-81. 
Fearon, J. (2005). "Primary commodities exports and civil war". Journal of Conflict Resolution 49 (4): 483-507.

Fearon, J. and Laitin, D. (2003). "Ethnicity, insurgency, and civil war". American Political Science Review 97 (1): 75-90.

Fearon, J. (1995) "Rationalist Explanations for War”. International Organization. 49 (3): 379 - 414.

Freedom House, Freedom in the World 2004: The Annual Survey of Political Rights and Civil Liberties. Rowman \& Littlefield Publishers, Inc Lanham MD.

Geldermann, J., Rentz, O., (2003) “Environmental decisions and electronic democracy” Journal of Multi-Criteria Decision Analysis 12 (2-3): 77 - 92.

Goldstone, J. A. (1980). “Theories of revolution: The third generation”. World Politics 32 (3): $425-53$.

Goodwin, J. (2001). No other way out: States and revolutionary movements, 1945-1991. New York: Cambridge University Press.

Goulder LH, (1998) "Environmental Policy Making in a Second-Best Setting”. Journal of Applied Economics, 1(2): 279-328.

Gurr, T. R. (2000). Peoples Versus States: Minorities at Risk in the New Century. US Institute of Peace, Washington, DC. 
Hegre, H., Ellingsen T., Gates, S. and Gleditsch, N. P. (2001). "Toward a democratic civil peace? Democracy, political change, and civil war, 1816-1992". American Political Science Review 95 (1): 33-48.

Hero, R. E. and Tolbert, C. J. (2004). "Minority Voices and Citizen Attitudes about Government Responsiveness in the American States: Do Social and Institutional Context Matter?" British Journal of Political Science 34 (1): 109-21.

Humphreys, M. (2005). "Natural resources, conflict, and conflict resolution: Uncovering the mechanisms". Journal of Conflict Resolution 49 (4): 508-37.

Ibeanu, O. (2000) "Oiling the Friction: Environmental Conflict Management in the Niger Delta, Nigeria". Environmental Change and Security Project Report (Woodrow Wilson Center)

Karl, T. (1997). The paradox of plenty: Oil booms and petro states. Berkeley: University of California Press.

Khan, A. S., Nigeria: The Political Economy of Oil. Oxford University Press, 1994.

Kraft, M. E. (1998) "Clean Air and the Adirondacks: Science, Politics, and Policy Choice". Environmental Science and Policy. 1, 167-73.

Kirchgassner G. and Schneider, F. (2003). "On the Political Economy of Environmental Policy". Public Choice 115, 329-96. 
Levine, D. (1973). Conflict and Political Change in Venezuela. Princeton: Princeton University Press.

Licklider, R. (1995). "The consequences of negotiated settlements in civil wars, 19451993". American Political Science Review, 89(3): 681-90.

Lujala, P., Gleditsch, N.P. and Gilmore, E. (2005). "A diamonds curse: Civil war and a lootable resource". Journal of Conflict Resolution 49 (4): 538-62.

Mansfield, E. D. and Snyder, J. (1995). "Democratization and the danger of war". International Security, 20(1): 5-38.

Moser, P. (1999). "The Impact of Legislative Institutions on Public Policy: A Survey". European Journal of Political Economy. 15, 1-33.

Mueller, D.C. (2003). Public Choice III, Cambridge University Press, Cambridge.

Obi, C. (1999). "The Crisis of Environmental Governance in the Niger Delta 19851996". African Political Science Association, Harare-Zimbabwe, Occasional Paper Series 3(3): 1-35.

Okonta I and Douglas, O. (2001) Where Vultures Feast: Shell, Human Rights and Oil in the Niger Delta Sierra Club Books, New York.

Omeje, K. (2005). "Oil Conflict in Nigeria: Contending Issues and Perspectives of the Local Niger Delta People", New Political Economy 10(3): 321-34. 
Profeta, P. (2002) "Retirement and Social Security in a Probabilistic Voting Model". International Tax and Public Finance, 9, 331-48.

Pumpim de Oliveira, J. A. (2002). "Implementing environmental policies in developing countries through decentralization: The case of protected areas in Bahia, Brazil". World Development, 30(10): 1713-36.

Reno, William. (2002). "Economies of War and Their Transformation: Sudan and the Variable Impact of Natural Resources on Conflict", conference paper presented at Money Makes the War Go Round: Transforming the Economy of War in Sudan, Brussels, June 12-13.

Reynal-Querrol, M. (2001). Ethnicity, political systems and civil wars. Institut d'Analisis Economic, Campus de la UAB: Bellatera-Barcelona"

Ross, M. (1999). "The political economy of the resource curse". World Politics 51 (2): 297-322.

Ross, M. (2004). "What do we know about natural resources and civil war?" Journal of Peace Research 41 (3): 337-56.

Rothschild, D. (1986). "Interethnic conflict and policy analysis in Africa". Ethnic and Racial Studies, 9(1): 66-86.

Sambanis, N. (2000). "Partition as a solution to ethnic war: an empirical critique of the theoretical literature”. World Politics, 52(4): 437-83. 
Sambanis, N. (2001). "Do ethnic and non-ethnic civil wars have the same causes? A theoretical and empirical inquiry (part 1)". Journal of Conflict Resolution, 45(3): $259-82$.

Sambanis, N. (2002) "A Review of Recent Advances and Future Directions in the Quantitative Literature On Civil War". Defence and Peace Economics. 13(3): 21543.

Sambanis, N. (2004). "Using case studies to expand economic models of civil war". Perspectives on Politics 2 (2): 259-79.

Sanchez-Jankowski, M. (1992). Islands in the street: Gangs and American urban society. Berkeley: University of California Press.

Sandler, T. (2000). "Economic analysis of conflict". Journal of Conflict Resolution, 44(6): 723-29.

Schneider, F. and Volkert, J. (1999). "No Chance for Incentive-Oriented Environmental Policies in Representative Democracies? A Public Choice Analysis." Ecological Economics. 31, 123-38.

Schofield, Norman (2003) "Valence Competition in the Spatial Stochastic Model", Journal of Theoretical Politics 15(4): 371-83

Silva, E. (1997). "The Politics of Sustainable Development: Native Forest Policy in Chile, Venezuela, Costa Rica and Mexico.” Journal of Latin American Studies, 29, $457-93$. 
Skocpol, T. (1979). States and social revolutions: A comparative analysis of France, Russia and China. New York: Cambridge University Press.

Snyder, J. (2000). From Voting to Violence: Democratization and Nationalist Conflict. Norton Publishers, New York.

Steel, B. and Weber, E. (2001). "Ecosystem Management, Decentralization, and Public Opinion." Global Environnemental Change. 11, 119-31.

Suliman, M. "Civil War in Sudan - The Impact of ecological degradation", in: Bächler and Spillmann (1996). 109-44.

Tiebout, C. (1956). "A Pure Theory of Local Expenditures". Journal of Political Economy 64(5): 416-24.

Tran, T.C., Euan, J., Isla ML (2002) "Public Perception of Development Issues: Impact of Water Pollution on a Small Coastal Community". Ocean \& Coastal Management, 45, 405-20.

Tugwell, F. (1969) Petroleum and public policy in Venezuela, 1959-1966: a study of conflict and interdependence. Columbia University.

Ward, M. D. and Gleditsch, K. S. (1998). "Democratizing for peace". American Political Science Review, 92(1): 51-61. 
Weingast B. R., and Marshall W.J. (1988) "Industrial Organization of Congress; or, Why Legislatures, Like Firms, Are Not Organized as Markets". Journal of Political Economy, 96(1): 132-63.

Weinstein, J. (2005). "Resources and the information problem in rebel recruitment". Journal of Conflict Resolution 49 (4): 598-624.

Wickham-Crowley, T. P. (1993). Guerrillas and revolution in Latin America. Princeton, NJ: Princeton University Press.

Worldbank Report (1995) Defining an Environmental Strategy for the Niger Delta, Vol II,.

WorldBank, World Development Report (2003) http://econ.worldbank.org/wdr/wdr2003/. Last visited November 20, 2004.

Young, H.P.,(1997). “Group Choice and Individual Judgments”, in: D.C. Mueller (Ed.), Perspectives on Public Choice, Cambridge University Press, Cambridge, 181-200. 